\title{
Nutrient-mucosal interactions in the human small intestine : the role of iron and lactoferrin
}

Citation for published version (APA):

Troost, F. J. (2003). Nutrient-mucosal interactions in the human small intestine : the role of iron and lactoferrin. [Doctoral Thesis, Maastricht University]. Universitaire Pers Maastricht. https://doi.org/10.26481/dis.20031210ft

Document status and date:

Published: 01/01/2003

DOI:

10.26481/dis.20031210ft

Document Version:

Publisher's PDF, also known as Version of record

\section{Please check the document version of this publication:}

- A submitted manuscript is the version of the article upon submission and before peer-review. There can be important differences between the submitted version and the official published version of record.

People interested in the research are advised to contact the author for the final version of the publication, or visit the DOI to the publisher's website.

- The final author version and the galley proof are versions of the publication after peer review.

- The final published version features the final layout of the paper including the volume, issue and page numbers.

Link to publication

\footnotetext{
General rights rights.

- You may freely distribute the URL identifying the publication in the public portal. please follow below link for the End User Agreement:

www.umlib.nl/taverne-license

Take down policy

If you believe that this document breaches copyright please contact us at:

repository@maastrichtuniversity.nl

providing details and we will investigate your claim.
}

Copyright and moral rights for the publications made accessible in the public portal are retained by the authors and/or other copyright owners and it is a condition of accessing publications that users recognise and abide by the legal requirements associated with these

- Users may download and print one copy of any publication from the public portal for the purpose of private study or research.

- You may not further distribute the material or use it for any profit-making activity or commercial gain

If the publication is distributed under the terms of Article $25 \mathrm{fa}$ of the Dutch Copyright Act, indicated by the "Taverne" license above, 


\title{
Nutrient-mucosal interactions in the human small intestine
}

\author{
the role of iron and lactoferrin
}




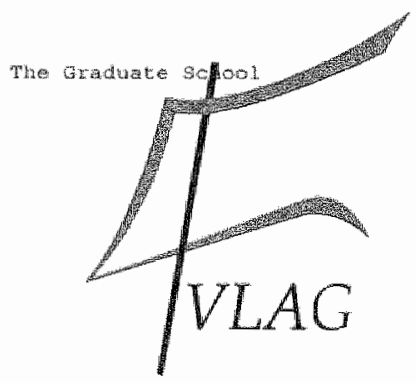

The studies presented in this thesis were pertormed at the Nutrition and Toxicology Research Institute Maastricht (NUTRIM), which participates in the graduate school VLAC Food Technology, Agrobiotechnology, Nutrition and Health Sciences), accredited by the Royal Netherlands Academy of Arts and Sciences.

Cover design: Ellen Oostew wijk

Printed by: Datawyse, Universitaire Pers Maastricht

(0) Freddy Troost, Mastricht 2003

ISBN $90-5278-398-5$ 


\title{
Nutrient-mucosal interactions in the human small intestine
}

\author{
the role of iron and lactoferrin
}

\section{Proefschrift}

Ter verkrijging van de graad van doctor aan de Universiteit Maastricht, op gezag van de Rector Magnificus,

Prof. Dr. A.C. Nieuwenhuijzen Kruseman, volgens het besluit van het College van Decanen in het openbaar te verdedigen op woensdag 10 december 2003 on 14.00 uur

door

Frederik lan Troost

Geboren te Twello op 20 juni 1973

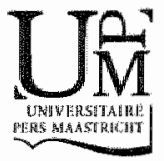




\section{Promotores}

Profidrir. WHM Saris

Prof.dr. R-JM Brummer

\section{Beoordelingscommissie}

Prot. dr. F. Van Schooten (voorzitter)

Prof. dr. ir. RP Mensink

Dir. NEP Deutz

Prof. J-R Malagelada, MD, Autonomous University, Barcelona, Spain

Dr. JD Söderholm, MD, University Hospital, L.inköping, Sweden

The studies described in this thesis were financially supported by DMV international (Veghel, The Netherlands), Agennix Inc. (Houston, TX, USA), and the European Union Key Action $\|$ : QLK -CT-1999-00337. FeMMES project. 


\section{CONTENTS}

Chapter 1

General introduction

Chapter 2

Mucosal integrity of the small intestine in women using iron supplements

Chapter 3

A new method to study oxidative damage and antioxidants in the human small bowel: effects of iron application

\section{Chapter 4}

In vivo regulation of gene expression in the small intestinal mucosa by iron-induced oxidative stress

\section{Chapter 5}

Iron supplements inhibit zinc but not copper absorption in vivo in ileostomy subjects

\section{Chapter 6}

Gastric digestion of bovine lactoferrin in adults.

\section{Chapter 7}

Survival of orally ingested lactoferin and endogenous lactoferrin secretion in the stomach and small intestine in vivo in women. A study using the ileostomy model

Chapter 8

Recombinant human lactoferrin ingestion attenuates indomethacin-induced enteropathy in wivo in healthy volunteers

Chapter 9

General discuission

\section{Summary}

Samenvatting

\section{Dankwoord}

List of publications 

CHAPTER 1

GENERAL INTRODUCTION 
Introduction

Iron and lactolerrin as model ingredients to study small intestinal functions

Structure and function of the small intestine

Small intestinal permeability

Intestinal oxidatuve stress

Iron-mediated gene expression

Iron, zinc and copper absorption routes

Lactoferin

Aims of this thesis

Outhe of the thesis 


\section{Introduction}

The gastrointestinal (G) tract is an important organ for many homeostatic processes in the body. It contains numerous pathogenic compounds from exogenous, dietary sources as well as those from endogenous origin, such as the intestinal microflora, which are potentially dangerous to the host. A healthy gut protects against detrimental effects of pathogenic compounds present in the intestinal lumen, and ill allows digestion and absorption of micro- and macronutrients, which are essential for proper functioning and development of the host. The Gl tract is composed of several functionally and anatomically distinctive sections. The mouth, oesophagus and stomach are important for food grinding and digestion. Furthermore, the low gastric pH provides a defence mechanism against (microlorganisms, and can stimulate or inhibit several pH-dependent processes. In addition to the upper Gil tract, food digestion contimues in the small intestine. Most energy, water and mutrient absorption takes place in this part of the Gl tract. The colon is responsible for additional water absorption. Moreover, it contains large bacterial colonies, the intestinal microflora, which contribute to final food digestion.

Although the role of the small intestine in the pathogenesis of gastrointestinal diseases has drawn much attention over the years, the exact mechanism of action of many of the ongoing processes in the small intestine and their functional role in the aetiology of diseases remain to be elucidated. The literature provides surprisingly little informa. tion about physiological processes in the human in vivo situation. The vast majority of studies of small intestinal processes has been performed in cell lines, developed and cultured as a model for the human epithelial barrier. Despite the obvious advantage of convenient accessibility of cell lines to study processes, the in vitro situation often does not accurately resemble the human in vivo situation. The same problem arises when studying different animal species as a model for the human in vivo situation. The development of validated methodologies to study small intestinal physiology and biochemistry has been hampered by its anatomical postion in the body. This often requires invasive techniques to study site-specific processes. The need to develop human models to study nutrient-mucosal interactions in the small intestine has initiated the variety of studies described in this thesis.

\section{Iron and lactoferrin as model ingredients to study small intestinal functions}

The study of the in vivo consequences of iron administration to humans is a central theme in this thesis. Iron is an essential micronutrient for many processes. Iron deficiency is one of the most abundant nutrient deficiencies, affecting approximately 30 $\%$ of all people worldwide (WHO, 1999). It can result from any condition in which dietary iron does not meet the body's demand. This is often observed in children and adolescents, and in people with increased iron losses, such as people suffering from warious gastrointestinal diseases, wound bleeding or menstruating women (Andrews, 1999). Inadequate absorption of iron may result in iron deficiency. This is the case in people consuming iron deficient diets or diets with a low uron bioavailability. Also, 
absorption interactions with other micronutrients of gastrointestinal disorders may inhibit iron bioavailability. Iron deficiency is the principal cause of iron deficiency anaemia. This disorder is associated with a decreased maximal workload, a decreased immune function and cognitive and physical impairment. It is commonly treated with oral ferrous iron containing supplements, generally prescribed because of their higher bioavailability compared to ferric iron supplements (Frewin, Henson \& Provan, 1997). High intra-luminal amounts of ferrous iron may, however, induce damage to the intestinal wall, owing to its high toxicity. Hence, enough iron needs to be consumed to maintain or restore sufficient iron levels, but the potential iron toxicity limits the prescription of high dosages of iron.

In the studies described in this thesis, iron was administered to study small intestinal processes, function, stress and defence mechanisms in vivo, applying recently developed and novel models. Furthermore, the application of the milk protein lactoferrin to prevent damage to the small intestinal mucosa was investigated. Lactoferrin has been proposed as a functional food ingredient due to its antioxidative, antiviral, antimicrobial and anti-inflammatory properties.

\section{Structure and function of the small intestine}

The small intestine has an important function in many processes. It provides a physical barrier against luminal pathogens, mediates immune and endocrine processes, and is essential for proper food digestion and energy, water and nutrient absorption. Furthermore, several nutrients are transformed into biologically active or -inactive forms during small intestinal transit.

The small intestine comprises different compartments. The lumen, the mucosa including the brush border, the submucosa and a muscle layer, surrounded by the serosa, can be distinguished (Figure 1A). The lumen of the small intestine contains intestinal fluid. This intestinal fluid is a mixture of, among other things, electrolytes, mucins, enzymes, (bile) acids, glycoproteins, microorganisms and immunoglobulins (Lentner, 1981). The small intestinal mucosa comprises the brush border, covered with intestimal lining fluid, the epithelium and the lamina propria. The intestinal lining fluid is an unstirred layer of fluid. The brush border contains a number of digestive enzymes located on microvilli. These microvilli increase the luminal surface or absorptive area of the small intestine by a factor of about 20 , and hence serve to optimize small intestinal absorption (Figure 1B). The epithelium is a single cell layer, linked together through tight junctions. It functions as a selectively permeable barrier capable of both secretion and absorption as required for absorption (Figure 2). The epithelium rests upon the lamina propria. This is a compact stroma, composed mainly of reticular- and elastin fibres, and provides support to the structure of the intestinal wall.

The undlerlying submucosa comprises a matrix of collagenous and elastic fibres in which larger blood vessels, lymph vessels and nerves ramify. The muscle layer, which covers the submucosa, contains a circular and a longitudinal muscle layer. Its combined actions are responsible for the propulsion of luminal contents (peristalsis). It is surrounded by the serosa, which permits the intestine to slide over adjacent organs during peristaltic movements (Magee \& Dalley, 1986). 


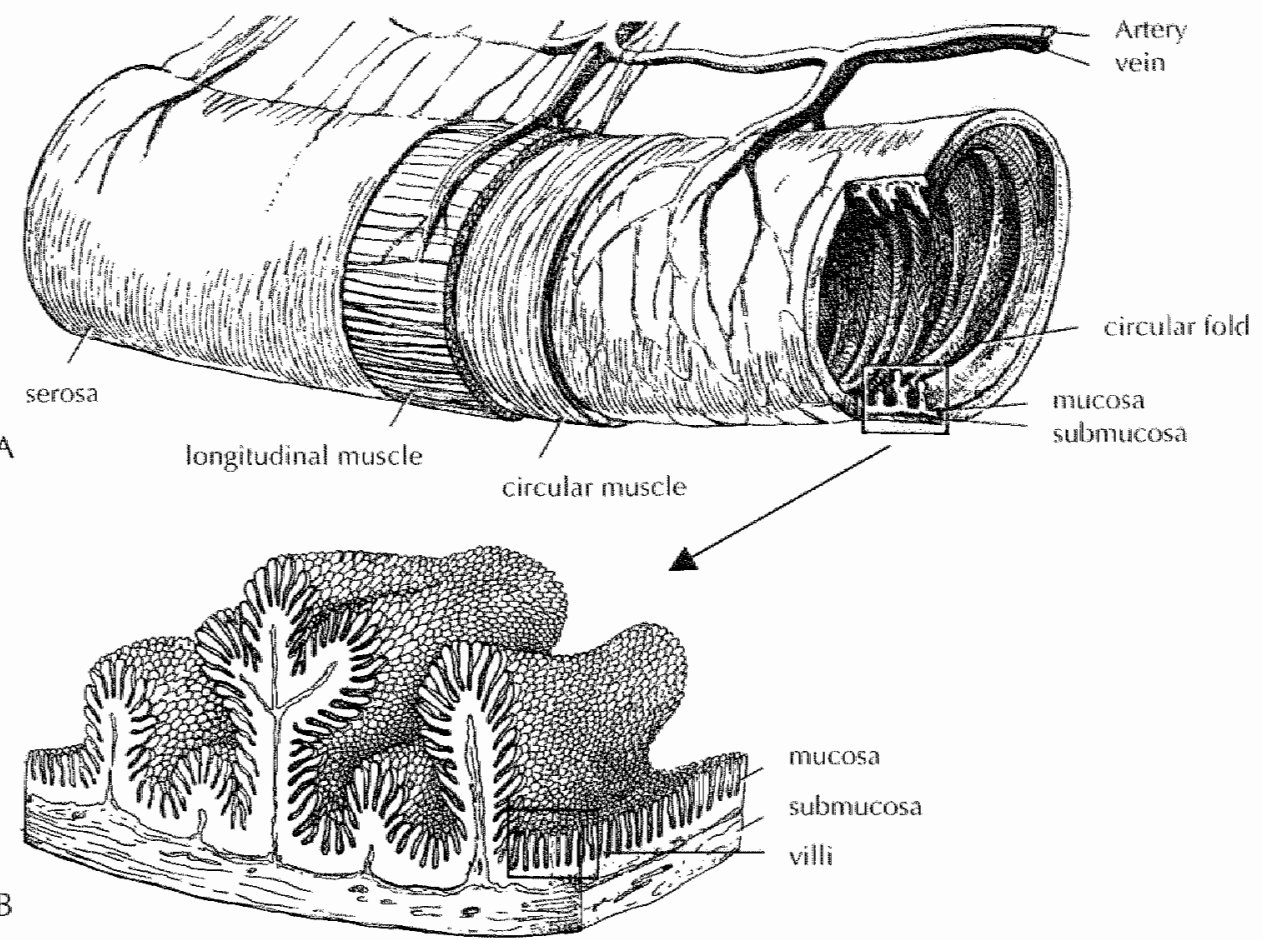

Figure 1 . Anatony of the small intestine A Morphology of the intestinal wall. B htestimal mucosa and subnucosa. Adapted from Moog (1981).

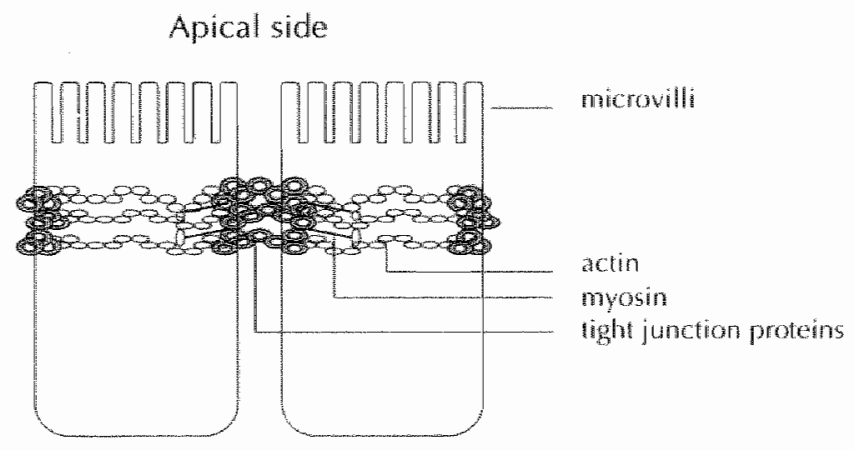

\section{Basolateral side}

Figure 2. Schematic represendition of thigh junctons, connecting two adjactent enterocytros. The mo

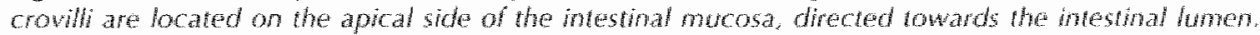
Actin haments are represented as the small circles, myosin by the thes and stucturat wht junction protems by the darge bold cirches. 
The intestine is innervated by the extrinsic and the intrinsic or enteric nervous system (ENS). Nerves from the extrinsic nervous system synapse with so-called ENS cells. The ENS has a complex structure and organization. The most prominent anatomically distinct networks are situated in the myenteric and submucosal plexuses. These plexuses consist of nerve cell bodies, axons, dendrites, and nerve endings, and can function autonomously to regulate a wide variety of intestinal processes (Johnson, 1991).

Luminal contents are potentially harmful to the intestinal mucosa. Damage to the small intestinal mucosa will impair the mucosal barrier, and may initiate considerable health problems, such as local intestinal inflammation, but also in systemic activation of inflammation or sepsis. The integrity of the mucosal barrier is reflected by small intestinal permeability. Since the intestinal integrity is an important end -point in intestinal stress studies, the mechanisms responsible for an impaired mucosal barrier function, with special emphasis on the detrimental effects of intestinal oxidative stress, will be explained in more detail in the next paragraph.

\section{Small intestinal permeability}

The physical construction of small intestinal mucosa creates the first line of defence against luminal pathogens. The epithelial layer of the small intestine mediates nutrient absorption, whereas it only allows passage of minute amounts of pathogenic and toxic molecules. Pathogens that do permeate the intestinal epithelium are potentially dangerous to the host. They may initiate immune activation, which aims to attack and eliminate the toxic compound. In healthy individuals, a low rate of intrusion of pathogens into the epithelium and a subsequent initiation of an immune response is a continuous process and does not harm the epithelial barrier. Damage to the intestinal mucosa however may disrupt the integrity of tight junctions. Tight junctions connect adjacent enterocytes, and normally allow permeation of molecules in a charge and size dependent manner (Figure 2). These tight junctions are formed by a multiprotein complex including occludin, claudin, several zona occludens proteins (ZO1, ZO2 and ZO3), actin, myosin, cingulin and 7 H6 (Mitic \& Anderson, 1998; Mitic, Van Itallie \& Anderson, 2000; Nusrat, Turner \& Madara, 2000). The transmembrane proteins occludin and claudin form fibrils that interact with fibrils from an adjacent cell to close the paracellular space between two enterocyles. These fibrils are linked to an intracellular cytoskeleton in the enterocytes. Tight junctions can be affected by several mechanisms. Structural tight junction proteins can be cleaved, the actin cytoskeleton or the peri-junctional actomyosin ring can be modified or even disrupted, and pathogen intrusion cam trigger transmigration of polymorphonuclear leukocytes (PMNs) that may directly affect tight junctions. Furthermore, synthesis of tight junction-associated proteins may be modified, resulting in deformation of the tight junctions or the intracellular cytoskeleton (Berkes et al., 2003; Nusrat et al., 2001; Sears, 2000), and intracellular myosin light chain kinase (MLCK) may be phosphorylated by luminal contents. This stimulates cytoskeletal contraction of the actin cytoskeleton as well as of the peri-junctional actomyosin ring, and result in tension on the tight junctions and, therefore, increased permeability (Atisook, Carlson \& Madara, 1990; Turner et al., 1997), and is an important feature of the 'compromised gut'. 
Invasion of pathogens triggers a complex activation of the immune system that is not yel fully elucidated. Initially, proinflammatory interleukins trigger interleukin-8 sectetion on the basolateral membrane. This attracts circulating neutrophils to the apical surface of epithelial cells. Other specific signals are responsible for further neutrophil migration towards the pathogens, such as Pathogen Elicited Epithelial derived Chemoattractant (PEEC) (Berkes et al., 2003; McCormick et al, 1998). The resulting inflammatory response may cause disruption of the tight junctions and, consequently, induce an increase in intestinal permeability. This may result in further intrusion of enteric pathogens, such as lipopolysaccharide (LPS) and microbes, which initiates an additional response of the local intestinal immune system. This response involves PMNs translocation, activation of intraepithelial lymphocytes (IELs), which release, among others, the cytokines interleukin 4 and $10(\mathrm{~L}-4$ and $1 \mathrm{~L}-10)$ and interferon-g (IFN-g), which were shown to be the major barrier-disruptive cytokines (Nusrat et al, 2000). Synchronously, nuclear factor kB (NFkB) is released. NFkB mediates most proinflammatory cytokines, chemokines, immune receptors, and cell surface adhesion molecules, and is considered to be a major regullator of intestinal inflammation (Berkes et al, 2003). Although such inflammatory responses are necessary for a proper immune function, it also induces additional damage to the mucosal barrier. The cytom kines may alter tight junctions through modulating the cytoskeleton activity (Perez, Barber \& Ponz, 1997), which will aggravate the mucosal damage and progressively increase permeability. Progressive damage to the mucosa of the small intestine may result in bacterial translocation. This passage of gastrointestinal microflora across the lamina propria to local mesenteric nodes, and then to extranodal sites, initiates an additional cytokine response, a further invasion of pathogens and may eventually initiate a systemic inflammatory response or sepsis (Thomson et al, 2000 ).

Damage to tight junctions in the small intestinal epithelium causes disruption of the integrity of the intestinal mucosa. This causes an increase in small intestinal permeability, which can be determined non-invasively by urinary sugar recovery tests. These tests are based on the comparison of intestinal permeation of molecules with different sizes. A typical measurement of small intestinal permeability comprises administration of inert sugar probes, such as the monosaccharide L-thamnose and the disaccharide lactulose, and subsequent determination of the 5-h urinary lactulose/rhamnose excretion. This method has been validated previously (van Nieuwenhoven et al, 1999) and is commonly applied in healthy wolunteers, as well as in patients. It is regarded as a reliable parameter of the integrity of the small intestinal mucosa.

Increased permeability has been associated with several gastrointestinal disorders, such as Crohn's disease (Meddings, 1997), coeliac disease (Smecuol et al., 1997), viral gastroenteritis (15olauri et al., 1989) and food allergy (Crowe \& Perdue, 1992). The maintenance of the intestinal barrier function is of pivotal importance for a proper gut function and to avoid health problems.

\section{Intestinal oxidative stress}

Nutrients, drugs and other intra-luminal contents can induce several adverse effects in the small intestine. Dietary oxidants or substrates that cause production of reactive oxygen species (ROS) may induce oxidative damage to any component of the small 
intestine, such as to the brush border, epithelial cells, enzymes or tight junctions. This implies a serious health threat, because intestinal oxidative stress is associated with the development of impaired barrier function, intestinal inflammation and even carcinogenesis. However, despite the common concern about possible detrimental effects of oxidative stress to the human small intestine, its causes and consequences remain to be elucidated.

A potential promoxidant is iron, which if ingested in large amounts, as occurs during iron supplementation, may result in oxidative stress in the small intestine. Iron supplements are commonly prescribed to treat iron deficiency anaemia. Typicall oral iron repleition therapies consist of three daily dosages of iron supplements containing 65 mg iron each. In healthy people, approximately $15 \%$ of all dietary iron is absorbed in the gastrointestinal tract, whereas about $1 \%$ of the unabsorbed iron fraction remains in the intestine as free iron ions (Lund et al, 1999). Free ferrous iron ions readily react with hydrogen peroxide, which is formed as a result of superoxide radical $\left(\mathrm{O}_{2}\right)$ production, a by-product of normal metabolism, to form ferric iron and highly reactive hydroxyl radicals (equation 1), a process denoted as Fenton chemistry. In the presence of $\mathrm{O}_{2}$, ferric iron ions are reduced to ferrous iron with concomitant production of molecular oxygen (equation 2). The resultant of these reactions (equation 3 ) is known as the Haber-Weiss reaction (adapted from (Crichton, 2001)).

$$
\begin{aligned}
& \mathrm{Fe}^{2 *}+\mathrm{H}_{2} \mathrm{O}_{2} \rightarrow \mathrm{Fe}^{3+}+\mathrm{OH}+\mathrm{OH}^{-} \text {(equation 1) } \\
& \mathrm{Fe}^{3+}+\mathrm{O}_{2} \rightarrow \mathrm{Fe}^{2+}+\mathrm{O}_{2} \quad \text { (equation 2) } \\
& \mathrm{O}_{2}+\mathrm{H}_{2} \mathrm{O}_{2} \rightarrow \mathrm{O}_{2}+\cdot \mathrm{OH}+\mathrm{OH}^{*} \text { (equation 3) }
\end{aligned}
$$

Fenton-mediated production of thydroxyl radicals is a continuous process in most living organisms. Hydroxyl radicals are extremely reactive, as is indicated by their very short half life (10 ${ }^{-9}$ sec) (Sies, 1991), and can inflict damage to any biological molecule in its direct environment. The free electron is able to transfer from one molecule to another, thereby initiating a cascade of damaging reactions. ROS, such as superoxide anon radicals, hydrogen peroxide and hydroxyl radicals, may inflict damage to lipids, proteins, carbohydrates and DNA, and hence may initiate or propagate carcinogenesis (Blakeborough, Owen \& Biton, 1989; Ray et al., 2000; Simic, 1994). In homeostasis, continuous ROS production participates in several metabolic processes, such as apoptosis and immune responses. They do not induce damage to healthy tissue because ROS production is ballanced by the antioxidant network. Antioxidants are able to scavenge or sequester free radicals, thereby inhibiting their harmful effects.

Excessive ROS production induces a disturbance in the pro- and antioxidant balance, and results in oxidative damage. This may occur in the presence of large amounts of free iron, which is the case during iron supplementation. Oral iron treatment is associated with considerable gastrointestinal side effects, such as nausea, vomiting, heart burn, abdominal pain and constipation, whereas intravenous iron treatment does not induce Gi discomtort (al-Momen at al, 1996). Furthermore, previous investigations showed that oral iron supplements induced intestinal oxidative stress in rats (Srigiridhar \& Nair, 1998; Srigiridhar et al, 2001), aggravated lactic acid-induced damage to the barrier function of the small intestine epithelium (Gonzalez et al, 1997), promoted colon carcinogenesis in mice (Siegers et al., 1992) and induced inflammatory proc- 
esses in rats with colitis (Aghdassi et al, 2001; Reifen et al, 2000). Epidemiological studies showed a role of dietary iron in the development of colon cancer (Wurzelmann et al, 1996). Iron-induced oxidative stress in the intestine after oral ingestion of iron supplements may in part be responsible for these adverse effects.

\section{Iron-mediated gene expression}

As discussed above, iron administration has several functional consequences in the human small intestine. Iron-induced oxidative stress and its metabolic consequences mediate gene expression in epithelial cells. Recent studies showed that gene expression could be modified by dietary interventions (Davis \& Jolnnson, 2001; Massimino er al., 1998). Prior to the development of CDNA microarrays, gene expressions were determined by direct quantification of the amount of mRNA representing a specific gene in a sample. The application of genome-wide CDNA microarrays, developed in 1995 (Schena et at. 1995), enables simultaneous monitoring of the expression of thousands of genes. This technique, commonly referred to as transcriptomics, provides unique insights into the many processes that, in a continuous interplay and under control of local gene expression, result in homeostasis or in a response to disturbances in the homeostatic equilibrium. Its greatest merit lies in explorative studies with no obvious empirical based hypothesis. In such studies, cDNA microarrays may be applied to obtain information about many processes and to design more specific studies. However, the large number of genes studied using genome wide microarrays is also the most critical drawback of the technique. The likellhood of false-positive results increases with the number of genes studied. This problem can partially be overcome by mathematical calculations, thereby limiting the sensitivity but increasing the specificity of the assays.

In combination with human intervention techniques, the application of genome wide CDNA microarrays in gastrointestimal research will help to unravel the complex and largely unidentified processes and mechanisms, which are involved in proper functioning of the gut. This information will also be useful in the design of studies to the pathogenesis, prevention and treatment of gastrointestinal diseases.

\section{Iron, zinc and copper absorption routes}

In addition to the capacity to catalyze ROS production, iron supplementation may exert other adverse effects in the small intestine. Iron administration is associated with a decreased absorption of other divalent melals, such as zinc and copper. After oral administration, intestinal iron is reduced by a ferric reductase and transported across the apical membrane of the small intestine by divalent metal transporter 1 (DMT1), a protein that also transports zinc and copper (Gunshin et al., 1997). Competive bind ing to DMTT in the presence of iron may decrease zinc and copper absorption. Furthemore, dietary iron mediates DMT1 expression (Yeh et al, 2000) through signalling iron levels in enterocytes (Frazer et al, 2003). Hence, iron repletion may reduce zinc and copper transier by down-regulating DCT1.

Studies to date are not conclusive about iron-zinc and iron-copper interactions. Some investigators showed competitive absorption beween iron and zinc (Dawson. Albers \& McGanity, 1989; Simmer \& Thompson, 1985) and iron and copper (Burns \& 
Paterson, 1993; Yu et at., 1995) respectively, whereas others did not observe such interactions (Davidsson et al., 1995; Donangelo et al, 2002; Sheldon et al. 1985). Zinc deficiency is associated with impaired immune function, growth, appetite and wound healing and with mucosal dystrophy, whereas copper deficiency may cause microcytic hypochromic anaemia, neutropenia, impaired growth of neonates, arthritis, myocardial disease, low serum ceruloplasmin, low red blood cell superoxide dismutase and platelet cytochrome-c oxidase (Bonham et al., 2002; Castillo-Duran \& Uauy, 1988; Danks, 1988; Williams, 1983). For a wellmbalanced prescription of micronutrient supplements, it is important to fully elucidate the interactions between them.

\section{Lactoferrin}

Lactoferrin is a glycoprotein of the transferrin family. It is present in milk, salliva, tears, bile, blood plasma, mucosal and genital secretions (Britigan, Serody \& Cohen, 1994; Levay \& Viljoen, 1995) and released by neutrophil specific granules (Davidson \& Lonnerdal, 1989). It was suggested that lactoferrin increases iron absorption (Rosa \& Trugo, 1994; Sanchez et al., 1996), because it binds iron with high affinity (Anderson et al., 1989, Lönnerdal \& lyer, 1995), and specific lactoferrin receptors are present in the intestinal brush border (Davidson \& Lönnerdal, 1988; Kawakami \& Lönnerdal, 1991). However, others were not able to confirm this hypothesis (Davidsson et al, 1994; Fairweather-Tait et al., 1987). Severall other biological effects, such as bactericidal (Bellamy et al., 1992; Zagulski et al., 1998), anti-inflammatory (Nuijens, van Berkel \& Schanbacher, 1996), antiviral (Harmsen et al., 1995; keda et al., 2000) and antioxidative (Baldwin, Jenny \& Aisen, 1984; Britigan et al, 1994) activities, have been attributed to lactoferrin. Its mechanisms of action are largely unknown, despite extensive research in this field. Human lactoferrin is slightly different from that of other species, especially with regard to the composition of the glycans. Bovine lactoferrin does not bind to the human lactoferrin receptor (Davidson \& Lönnerdal, 1986; Davidson \& Lönnerdal, 1988). The observation that lactoterrin is present in large quantities in colostrum and in smaller concentrations in normal milk suggests an imporlant function in newborns. Furthermore, it was shown that oral lactoferrin administration suppresses the release of the pro-inflammatory cytokines interleukin-1, interleukin-6 and TNFa by activated monocytes and macrophages (Crouch, slater \& Fletcher, 1992: Matsby-Baltzer et al, 1996; Zimecki et al., 1999; Zimecki et al., 1998). Hence, lactoterrin is able to mediate imnunological responses. Lactoferrin is a well-recognized antioxidant, owing to its strong iron chelating capacity. The iron ions bound to lactoterrin are not able to participate in Fenton chemistry. This diminishes the production of hydroxyl radicals and consequently attenuates oxidative stress (Britigan et al. 1994). The capacity of lactoferrin to participate as an antioxidant in the presence of iron may provide a functional application of lactoferrin. It may prevent iron-induced oxidative damage in the small intestine, especially if large amounts of iron are present, as occurs during iron repletion therapies.

\section{Aims of this thesis}

This thesis presents and discusses seven studies related to the interactions between iron, as a specific micronutrient, in relation to the small intestinal mucosa in vivo in 
humans as well as in relation to other micronutrients or bioactive compounds. The specific aims of these studies were:

- To investigate the effects of iron application on

- small intestinal oxidative stress and mucosal integrity

- bioavallability of the micronutrients zinc and copper

- To investigate whether synchronous lactoferrin administration as a bioactive compound attenuates acute gastroenteropathy, induced by indomethacin.

\section{Outline of the thesis}

Iron administration may cause intestinal oxidative damage. This may in turn increase smal intestinal permeability. Chapter 2 describes the effects of a one-month iron supplementation study on small intestinal permeability in iron-deficient premenopausal women. In this study, after the four weeks of iron supplementation, indomethacin was administered to investigate the effects of iron supplementation in a situation of acute intestinal damage.

Due to the unavailability of a model to directly investigate oxidative stress in the human small intestine, an intestinal perfusion model was developed for this purpose. Chapter 3 describes the first study applying this newly developed model to quantify intestimal oxidative stress. In this experiment, the effects of intraduodenal iron administration on lipid peroxidation and on the antioxidant network were investigated. The results from this study were used to expand the model and design the study described in chapter 4 . An intervention study in healthy volunteers was performed, applying the perfusion model in combination with flexible duodenoscopy to obtain mucosal samples. In this study, iron-induced oxidative stress by different dosages of iron was investigated. Furthermore, the chapter describes the effects of these iron interventions on the expression of all functionally mapped genes. Gene expression was measured with genome-wide CDNA microarrays.

In addition to affecting ROS production, iron may have other adverse effects in the small intestine. It may affect the bioavailability of other micronutrients. Chapter 5 describes a study of the interactions between iron, zinc and copper absorption in the human small intestine. Znc absorption was calculated from urinary excretion of orally administered stable zinc isotopes in ileostomy patients. Copper absorption was determined by calculating the ballance of stable copper isotopes administered orally and their excretion in ileostomy effluent.

Lactoferrin, alycoprotein with strong iron-binding properties, may be applied as a functional ingredient of food supplements. Before studying its biological effects after oral administration, its metabolic fate needs 10 be investigated to obtain detailed information about its bioavailability. Chapter 6 describes a study to investigate lactoferpin digestion in the stomach in thealthy volunteers. The data from this study justified the design of a sudy to the survival of lactoferrin after passage of the stomach and small intestine, which is described in chapter 7. This information about the bioawailability of orally administered lactoferrin in the colon is pivotal for the design of future studies to investigate the role of lactoferrin in that tissue.

The non-steroidal anti-inflammatory drug indomethacin causes a reproducible, acute enteropathy and a subsequent increase in intestinal permeability in the small intestine in healthy subjects, corresponding to that observed in gastrointestinal mucosal disw 
eases. The effects of lactofertim administration in the stomach and small intestine after indomethacin administration were investigated applying the lactulose/rtamnose/sucrose gut permeability test. This method provides a commonly accepted model to determine integrity of the gastric and small intestinal mucosa. This study is described in chapter 8 .

All studies are discussed separately and in relation to each other in chapter 9 . The consequences of the findings of the different studies in relation to small intestinal healtit and future research are discussed. 


\section{References}

Aghdassi, E., Carrier, J., Cullen, J., Tischler, M. \& Allard, 1.P. (2001): Effect of iron supplementation on oxidative stress and intestinal inflammation in rats with acule colitis Dig Dis 50 46(5): 1088-94.

al-Momen, A.K., al-Meshari, A., al-Nuaim, L., Saddique, A., Aboralib, Z, Khashogi, T. A Abbats, M. (1996): Intravenous iron sucrose complex in the treament of iron deficiency andemiat during preg. nancy Eur I Obstet Gynecol Reprod Brol 6922: 1214.

Anderson, B.E., Baker, H., Norris. G.E., Rice, D.W. B Baker, E. . (1989): Structure of Human Lactoterrin: crystallographic structure analysis and refinement at $2.8 \mathrm{~A}$ resolution 1. Aol. Biol. $209: 711-34$.

Andrews, N.C. (1999); Disorders of iron metabollism N Engl / Med 34126): 1986.95.

Atsook, K. Carlson, 5. \& Madara, 1.L. (1990): Effects of phlorizin and sodiun on glucosemelicited alterations of cell functions in intestinal epithelia Am / Physiol 2584 ( Pt 1): C77-85.

Baldwin, D, Jenny, E. \& Aisen, P. (1984): The effect of human serum transtern and milk lachoferrin on hydroxyl fadical formation from superoxide and hydrogen peroxide / Brol Chem 25921): 13391-4.

Beattie, I.H., Reid, M.D., Harvey, LI., Dainty, IR., Majsak-Newman, G. \& Faimweather-Tan, S.J. (2001): Selective extraction of blood plasma exchangeable copper for isotope studies of dietary copper absorption Analyst 126(12): 2225-9.

Bellamy, W., Takase, M., Yamauchi, K., Wakabayashi, H., Kawase, K. \& Tomita, M. (1992): Identification of the bactericidal domain of lactoferrin Biochim Biophys Acta 1121(1-2): 130-6.

Berkes, In, Viswanathan, V., Savkovic, S. \& Hecht, C. (2003): Intestinal epithelial responses to enteric pathogens: effects on the tight junction bartier, ion transpont and inflammation Gut 52(3): 439-51.

Blakeborough, M.H., Owen, R.W. \& Bilton, R.F. (1989): Free radicall generating mechanisms in the colon: their role in the induction and promotion of colorectal cancer? Free Radic Res Commun $6(6): 359-67$.

Bonham, M. O'Connor, J.M., Hannigan, B.M. \& Strain, 1.J. (2002): The immune system as a physiological indicator of marginal copper status? Br / Nutr 87(5): 393-403.

Britigan, B.E., Serody, IS. \& Cohen, M.S. (1994): The role of lactoferen as an anu-inflammitory molerule Adv Exp Med Biol 357; $143-56$.

Burns, J. Baterson, C.R. (1993): Effect of hron-folate supplementation on serum copper concentration in late pregnancy Acta Obstel Cynecol Scand 72(8); 6\#6-8.

Castillo-Duran, C. \& Uau, R. (1988): Copper deficiency impairs growh of infants recowering from malnutrition Am / Clin Nutr a 744 : 71044

Crichton, R. (2001): Inorganic Biochernistry of Iron Metabolism. John Wiley \& Sons, LId, Chichester.

Crouch, S.P., Slater, K.J. \& Fletcher, J. (1992): Regulation of cytokine release from mononuclear cells by the iron-binding protein lactoferrin Bhood $80011 \%: 235 \sim 40$.

Crowe, S.E. \& Perdue, M.H. (1992): Gasirointestinal food hypersensitivity: basic mecharisms of pathophysiology Gastroenterology 103(3): 1075-95.

Danks, D.M. 11988: Copper deficiency in humans Annu Rev Nut 8: 235-57.

Dawidson, L.A. \& Lonnerdal, B. (1986): Isolation and characterization of thesus monkey milk lactofer. rin Pediatr Res 2012): 197-201.

Davidson, L.A. \& Lönerdal, B. (1988): Specific binding of lactoferin la brush-border membrane: onlogeny and effect of glycam chain Am / Physiof 254 (4 Pt 1): C580.5. 
Davidson, L.A. \& Ionnendal, B. (1989): Fe-saturation and proteolysis of human lactofertin: effect on brush-border receptor-mediated wptake of Fe and Mn Am / Physiol 2576 P: 1): $0930-4$.

Davidsson, L., Amgren, A., Sandström, B. \& Hurrell, R.F. (1995): Zinc absorption in adult humans: the effect of iron fortification $B r / N u t r 74(3): 417-25$

Davidsson, L., Kastenmayer, P., Yuen, M, Lönnetdal, B. \& Hurrell, R.F. 1994): Influence of lactoferrin on tron absorption from human millk in infants Pediatr Res 35(1): 117-24.

Davis, C.D. \& Johnson, W.T. (2001): Dietary copper and dimethylhydrazine affect protein kinase C isozyme protein and mRNA expression and the formation of aberant crypts in colon of rats Biofactors $15(1): 11-26$.

Dawson, E.B. Abers, 1. \& McCanity, W.J. (1999): Sam zinc changes due to iron supplementation in reen-age pregmancy Am / Clin Nut $50(4): 848-52$.

Donangelo, C.M. Woodhouse, L.R., King, S.M., Viteri, F.E. \& King, I.C. 2002): Supplemental zinc lowers measures of iron status in young women with low iron reserves/Nuti 132(7): 1860-4.

Fainweather-Tait, S.1. Balmer, S.E., Scott, P.H. \& Minski, M.). (1987): Lactoferrin and iron absorption in newborm indants pediatr Res 22(6): 659 -4.

Frazer, D.M. Wilkins, S., Becker, E.M., Murply, T.L., Vulpe, C.D. Mckie, A.T. \& Anderson, G.J. 2003: A rapid decrease in the expression of DMT1 and Dcyb but not Ireg1 or hephaestin explains the mucosal block phenomenon of iron absoption Cut 52(3): 340-6.

Frewin, R, Henson, A. \& Provan, D. (1997): ABC of clinical haematology. iron deficiency anazmia 8 $M / 314\{7077): 360-3$.

Gonzalez, P.K., Doctrow, S.R., Malfroy, B. \& Fink, M.P. (1997): Role of oxidant stress and iron delocalization in acidosis-induced intestinal epithelial hyperpermeability Shock 8(2): 108-14.

Gunshin, H., Mackenzie, B., Berger, U.V., Gunshin, Y., Romero, M.F., Boron, W.F., Nussberger, S., Gollan, J.L. \& Hediger, M.A. (1997): Cloning and characterization of a mammalian protoncoupled metal-ion transporter Nature $388(6641): 482 \ldots$.

Harmsen, M.C., Swart, P.J., de Bethune, M.P. Pauwels, R., De Clercq, E., The, T.H. \& Meijer, D.K. 11995): Antivinal effects of plasma and milk proteins: lactoferin shows potent activity against both human immunodeficiency virus and human cytomegalovirus replication in vitro / hafect Dis $1722): 380-8$

lkeda, M. Nozaki, A., Sugiyama, K, Tanaka, T., Naganuma, A, Tanzka, K., Sekihara, H., shimotohno, K. Saito. M. Kanto, N. (2000): Characterization of antiviral activity of lactorerrin against hepatitis C virus infection in human cultured cells Virus Res $66(1): 51-63$.

Lolaun, E. Jumtunen, M. Wiren, S., Vuorinen, P. \& Koivula, T. 1989$)$ Intestinal permeability changes in acute gastroenteritis: effects of clinical factors and nutritional management / Pediat Castroenixarol Nut 844: $466-73$.

fohnson, L. 1991): Gastrointestinal Physiology edited, Mosby-Year Book, Inc, Missouri.

Kawakami. H. \& Lonnerdal, B. (1991): Isolation and function of a receptor for human lachoferrin in human fetal intestinal brush-border membranes Am / Physiol 267 (5 Pt 1): GB41-6.

Lentmer, C. (1981): Units of measurement, body fluids, composition of the body, nutrition. In Ceigy Sctentific Tables, vol. 1 edined, pp. 147-150, Ciba-Geigy, Basle.

Levay, P.F. \& Vifjen, M. (1995): Lactoferrin: a general review Haemotologica 80: 252-267.

Lönnerdal. B. \& 1yer, \$. (1995): Lactoterrin: molecular structure and biological function Anou Rev Nutr 15893: $93-110$. 
Lund, E.K., Whari, S.G., Fairweather-Tait, S.I. \& Johnson, A.T. (1999y: Oral letrous sulfate stpplements increase the free radical-generating capacity of faeces from healthy wolunteers American foumal Of Clinical Nutrition $6921: 250-5$.

Magee, D. \& Dalley, A.F. (1986): Digestion and the structure and function of the gut. Karger, Basel.

Massimino, S.P., McBurney, M.I. Field, C.J., Thomson, A.B. Keelan, M. Hayek, M.G. \& Sumold, G.D. (1998): Fermentable dietary fiber increases GL.P. secretion and improves glucose homeostasis despite increased intestinal glucose transport capacily in healthy dogs / Nutr 128010): 1736-93.

Mattsby-Balizer, I., Roseanu, A., Motas, C., Everfors, I., Engherg, I , Hanson, L.A. (1996): Lactoferrin or a fragment thereof inhibits the endotoxin-induced interleukin-6 response in thuman monocytic cells Pediatr Res 40021: 257-62.

McComick, B.A., Parkos, C.A. Colgan, S.P. Cames, D.K. Madara, J.L. (1998): Apical secretion of a pathogen-elicited epithelial chemoattractant activity in response to surface colonization of intestinal epithelia by Samonella typhimurium / Immunol $160(1): 455466$.

Meddings, I.B. (1997): Rewiew article: Intestinal permeability in Crohn's disease Aliment Pharmacol Ther 11 Suppl 3: 47-53; discussion 53-6.

Mitic, L. \& Anderson, J. (1998): Molecular architecture of tight junctions Annu Rev Physiol 60: 121-42.

Mitic, L., Van Itallie, C.M. \& Anderson, I.M. (2000): Molecular physiology and pathophysiology of right junctions :. Tight junction structure and function: lessons from mutant animals and proteins Am J Physiol Gastrointest Liver Ploysiol 27921: G250-4.

Moog. F (1981): The lining of the small intestine. Scient Am 245: 154-179.

Nuijens, J.H, van Berkel, P.H. \& Schanbacher, F.L. (1996) Structure and biological actions of lactorerrin J Manmary Gland Biol Neoplasia 1 13): 285-95.

Nesstat, A., Turner, J.R. \& Madara, J.L. (2000): Molecular ploysiology and pathophysiology of tight junctions. IV. Regulation of thight junctions by extracellular stimuli: nutrients, cytokines, and immune cells Am / Physiol Gastrontest Liver Physiol 279(5): G851-7.

Nusrat, A, von Eichel-Streiber, C., Turner, J.R., Verkade, P., Madara, J.L. \& Parkos, C.A. (2001): Clostridium difficite toxins disrupt epithelial barrier function by altering membrane microdomain localization of tight junction proteins infect $\mathrm{mmm}$ 6993): 1329.36 .

Perez, M., Barber, A. \& Ponz, F. (1997): Modulation of intestinal paraceltular permeability by intraw cellular mediators and cyloskeleton Can J Physiol Pharmacol 75(4):287-92.

Ray, G., Batra, S., Shukla, N.K., Deo, S., Raina, V., Ashok, S. Husain, S.A. (2000): Lipid peroxidat thon, free adical production and antioxidant status in breast cancer Breast Cancer Res Treat 59(2): $163-70$.

Reffen, R., Matas, Z. Zeidel, L., Berkovitch, Z. \& Bujanower, Y. (2000): Iron supplementation may aggravate inflammatory status of colitis in a rat model Dig Dis SCi 452 ): $394-7$.

Rosa, G. \& Trugo, N.M. \{1994): Iron uptake from lactoferrin by inlestinal brush-border membrane vesiches of human neonates Braz M Med Biol Res 27(7): 1527 31 .

Sanchez, L. Ismail, M., Liew, F.Y. \& Brock, IH. (1996): Iron transport across Caco-2 cell monolayers. Effect of transferris, lactoferin and nitric oxide Biochim Bophys Acta 1289(2): $291-7$.

Schena, M. Shaton, D. Davis, R.W. \& Brown, P.O. (1995): Quantiative monitoring of gene expression pattens with a complementafy DNA microarray Science 27065235$)$ : 467.70 .

Sears, C.L. (2000): Molecular physiology and pathophysiology of tight junctions V. assaull of the tight junction by enteric pathogens Am I Physio/ Gastrointest Lver Physiol 279(6): $01129-34$. 
Sheldon, W. A. Apillaga, M.O., Smith, P.A. \& Lind, T. 1985). The effects of orat iron supplementation on zinc and niagnesium levels during pregnancy ar l Obstet Gynaecol 92(9): 892-8.

Siegers, C.P., Bumann, D., Treptad, H.D. Schadwinkel, B. \& Baretton, G. (1992): Influence of dietary iron overtoad on cell proliferation and intestinal tumorgenesis in mice Cancer Lett $65(3): 245-9$.

Sies, H. (1991): Oxidative stress: from basic research fo clinical application Am / Med 91(3C):31-385

Simic, M.G. (1994): DNA markers of oxidative processes in wivo relevance to carcinogenesis and anticarinogenesis Cancer Rey 5417 Suppl $1918 \mathrm{~s}-1923 \mathrm{~s}$.

Simmer, K. Thompson, R.P. (1985): Maternal zinc and intratuerine growth retardation Clin Sci 6844) $395-9$.

Smecuol, E., Bai, J.C., Vazquez, H., Kogan, Z., Cabanne, A. Niveloni, S, Pedreira, S., Boerr, L., Maurino, E. Meddings, J.B. (1997): Gastrointestinal permeabihty in celiac disease Castroenterology $11244: 1129-36$.

Srigiridhar, K. \& Nair, K.M. 1990 : Iron-deficient intestine is more susceptible to peroxidative damage during iron supplementation in rats Free Radic. Biol Med 25(6): 660-5.

Srigiridhar, K. Nair, K.M., Subramanian, R. \& Singotamu, L. 2001): Oral repletion of iron induces free radical mediated alterations in the gastrointestinal tract of rat Mol Cell Biochern 219(1-2): 91-8.

Thomson, A.B., Keelan, M. Thiesen, A, Clandinin, M.T., Ropeleski, M.J. \& Wild, G. (2000): 5mall bowel review: part I Can / Gastroenterol 1499:791-816.

Turner, J.R., Rill, B.K., Carlson, S.L., Cames, D., Kerner, R., Mrsny, R.1. \& Madara, I.L. (1997): Physiological regulation of epithelial light junctions is associated with myosin light-chain phosphorylation Am / Physiol 27344 Pt 11: C1378-85.

vari Nieuwemoven, M.A., Geerling, B.J., Deutz, N.E., Brouns, F. \& Brummer, R.J. (1999): The sensitivity of the lactulose/rhamnose gut permeability test Eur / Clin lnvest $29(2): 160-5$.

WHO 1999: Prevention and Control of Iron Deficiency Araemia in Women and Children. In Report of the UNICEFANHO Regional Consultation edited, Geneva, Switzerland.

Willams, D.M. (1983): Copper deficiency in humans Semn Henatol 20(2): 118-28.

Wurzelmann, J.I, Silver, A., Schreinemachers, D.M., Sandler, R.S. \& Everson, R.B. 1996): fron intake and the risk of colurectal cancer Cancer Epidemiof Biomarkers Prev 5(7): 503-7.

Yeh, K.Y., Yeh, M., Wakims, 1.A., Rodriguez-Paris, 1. \& Glass, 1. 2000): Dietary iron induces rapid changes in matt intestinal divalent metal transporter expression Am / Physiol Gastrointest Lwer Physiol 27985): G1070-9.

YH. S., Beems, R.B., Joles, I.A., Kaysen, G.A. \& Beynen, A.C. (1995): Iron and copper metabolism in analbuminamic rals fed a high-iron diet Comp Biochen Physiol A Physiol 1102): 131-8.

Zagulski, T., larzabek, Z., Zagulska, A. \& Zinecki, M. (1998): The main systemic, highly effective, and quickly acting antimicrobial mechanisms generaled by factoferin in mamuals in wivo. Activity in thealth and disease Adv Exp Med Brol 443:24750

Zimecki, M. Spiegel, K. Whasczyk, A., Kubler, A \& Kruzel, M.L. (1999): Lactoferrin increases the output of neutrophil precursors and attenuates the spontaneous production of TNF-alpha and IL.6 by periphenal blood cells Arch immunol ther Exp 472): 113-8.

Zimecki, M., Waszczyk, A. Cheneau, P., Brunel, A.S., Mazurier, 1., Spils, G. \& Kubler, A. (1998): Immunoregulatory effects of a nutritional preparation conlaining bovine lactoferin taken orally by healthy individuats Arch Immunol ther Exp 46(4): $231-40$. 
CHAPTER 2

\section{MUCOSAL INTEGRITY OF THE SMALL INTESTINE IN WOMEN USING IRON SUPPLEMENTS}

Freddy J Troost, Wim HM Saris, Robert-Jan M Brummer

Submitted 


\begin{abstract}
Background Iron supplementation causes Fenton driven free radical production in the intestine. This may induce oxidative damage to the mucosa and consequently impair the integrity of the intestinal wall. This study aimed to investigate the effects of iron supplementation on the integrity of the small intestine in iron deficient women.

Design Thirty-one iron deficient but otherwise healthy women were randomly allocaled to receive placebo $(n=16)$ or $300 \mathrm{mg}$ iron/d as ferrous fumarate $(n=15)$ for 1 month. A baseline and after 28 days of supplementation, small intestinal permeability was determined applying the lactulose/hamnose (L/R) gut permeability test. After 31 days of supplementation, $75 \mathrm{mg}$ and $50 \mathrm{mg}$ of indomethacin was administered 9 and $1 \mathrm{~h}$ prior to a third permeability experiment to investigate the effects of acute intestinal stress on small intestinal permeability after one month iron application.

Results Serum ferrition was significantly increased after 4 weeks of iron supplementafion $(24 \pm 12 \mu \mathrm{g} / \mathrm{L})$ compared to placebo $(10 \pm 7 \mu \mathrm{g} / \mathrm{L})$. Urinary $L / R$ ratios, as parameter of small intestinal permeability, did not differ between the groups receiving placebo or iron supplements in any of the experiments.

Conclusion Iron supplementation in iron deficient but otherwise healthy women does not impair the mucosal integrity of the small intestine, which suggests that the human small intestine has a powerful antioxidant defence mechanism against luminal oxidative stress.
\end{abstract}




\section{Introduction}

Iron deficiency is one of the most abundant nutrient deficiencies worldwide. As many as $14 \%$ of all adult females suffer from iron deficiency in Europe and North America, and approximately $30 \%$ of all people worldwide (DeMaeyer \& Adiels-Tegman, 1985). It causes iron deficiency anaemia owing to decreased erythropoiesis and microcytosis. Symptoms of iron deficiency anaemia are pallor, fatigue, poor exercise tolerance, and decreased exercise tolerance (Andrews, 1999). It is commonly treated with prescribed or over-the-counter oral iron supplements, which often contain divalent ferrous salts because of their higher bioavailability compared to the trivalent ferric salts. Iron supplementation may comprise up to $195 \mathrm{mg}$ of elemental irond divided over three single dosages as ferrous sulfate, fumarate or gluconate respectively (Frewin. Henson \& Provan, 1997). However, free ferrous iron participates in Fenton chemistry, which results in instantaneous production of highly reactive hydroxyl radicals (Fodor \& Marx, 1988; Srigirichar \& Nair, 1998). These hydroxyl radicals can induce damage to biological molecules, such as lipids, proteins, carbohydrates and DNA. In normal homeostasis, hydroxyl radicals and other reactive oxygen species (ROS) are balanced by the antioxidant network. Increased ROS production may, however, exceed the capacity of the antioxidant network to trap or neutralize $R O S$ and, hence, result in oxidative damage. Previous studies showed that increased ROS production, caused by iron repletion in iron deficient rats, promoted oxidative stress at the site of iron absorption (Srigirichar \& Nair, 1998). Iron repletion with synchronous supplementation of ant:oxidants, however, protected the gastrointestinal tract of iron deficient rats to oxidative stress during oral iron repletion (Srigiridhar \& Nair, 2000). This supports the hypothesis that oxidative damage mainly occurs when the maximal capacily of the antioxidant network is exceeded.

The clinical observation that oral iron therapy regularly induces gastrointestinal (Gl) side effects, such as nausea, vomiting, heartburn, abdominal pain and constipation in some patients, in contrast to intravenous iron treatment (al-Momen et al, 1996), may well be associated with iron-induced oxidative stress in the gastroimtestinal tract. Especially in patients with an already compromised gut or an impairment of the mucosal or systemic antioxidant capacity, such as in Inflanmatory Bowel Disease or celiac disease (Geerling et al., 1998; Lih-Brody et al., 1996; Marx \& van Asbeck, 1996; Odetti et al., 1998; Yamada \& Grisham, 1991), oral iron therapy may induce intestinal oxidative stress and aggravate gastroenteropathy in these patients.

This study aimed to investigate the effects of onemonth oral iron supplementation on the integrity of the small intestinal mucosa in iron deficient but otherwise healthy premenopausal women, reflected by small intestinal permeability. Secondly, this study aimed to investigate the detrimental effects of oral iron therapy on small intestinal permeability in subjects with acute mucosal damage, applying administration of the nonmsteroidal anfi-inflammatory drug indomethacin as a model for gastrointestinal disorders-associated enteropathy. 


\section{Methods}

\section{Subjects}

Thirty-one iron deficient, premenopausal women (age $21 \pm 2$ y) were recruited. All subjects received detailed information and gave their written informed consent before participation. Volunteers with a history of gastrointestinal complaints and those who had used oral iron-containing supplements at any time during the 6 months prior to testing were excluded from participation. The study design was approved by the Ethics Committee of the University Hospital Maastricht, Maastricht, The Netherlands.

\section{Study design}

Iron deficiency criteria for inclusion in this study were determined by assessing blood parameters (serum ferritin $<15 \mu \mathrm{g} / \mathrm{L}$, blood haemoglobin $<7.5 \mathrm{mmol} / \mathrm{L}$, blood haematocrit $<0.36 \mathrm{~L} / \mathrm{L})$ in a screening blood sample drawn from an antecubital vein in the forearm. After inclusion, subjects were randomly allocated to either the iron- or the placebo group.

On the day prior to the first experiment, a venous blood sample was obtained to assess baseline iron status. The next morning, after an overnight fast and after voiding, small intestinal permeability was measured using the lactulose/rhamnose gut permeability test as described below. For the 31 days following the baseline measurement, subjects ingested a masked $d_{f}$ sealed gelatine capsule containing $100 \mathrm{mg}$ iron as ferrous. fumarate or placebo three times a day. Subjects were instructed to take the supplement one hour before breakfast, one hour before lunch and one hour before dinner to ensure maximal bioavailability of the iron.

Twenty-eight days after the start of supplementation, iron status and small intestinal permeability was assessed using the lactulose/rhamnose gut permeability test. Thirty days after the start of the supplementation, $75 \mathrm{mg}$ indomethacin (Genfarma BV., Maarsen, The Netherlands) was administered at 1100 PM. Subsequently, after an overnight fast, $50 \mathrm{mg}$ indomethacin was administered at $0700 \mathrm{AM}$, and a third small intestinal permeability test was performed one hour later.

\section{Small intestinal permeability}

Small intestinal permeability was assessed using the lactulose/rhamnose gut permeability test. This test is based on the comparison of intestinal permeation of molecules of different sizes. After voiding, a hyperosmolar drink containing $20 \mathrm{~g}$ sucrose, $5 \mathrm{~g}$ lactulose (Genfarma bw. Maarssen, The Netherlands) and $0.5 \mathrm{~g}$ L-rhamnose (ICN Biomedicals Inc., Aurora, OH, USA) in $100 \mathrm{~mL}$ water was administered. Subsequently, urine was collected for five hours. Subjects refrained from eating during the time of urine collection. Consumption of water was allowed ad libitum during the last two hours of urine collection. The urine volume was determined, and urine aliquots were taken and stored at $-80^{\circ} \mathrm{C}$ until analysis. 
The fractional 5-h urinary recovery of the sugar probes was determined. The urinary lactulose/rhamnose excretion ratio provides an accurate parameter of small intestinal permeability (van Nieuwenhoven et al., 1999). Sucrose was added to obtain a byperosmolar solution, which improves the sensitivity of the test compared to isoosmolar solutions (Sigthorsson et al., 1998). Lactulose and rhamnose were determined by fluorescent detection high-pressure liquid chromatography (HPLC). All samples were spiked with lactose as an external standard that does not interfere with determination of lactulose and rhamnose. Samples were incubated overnight with derivatization reagent (9-fluorenylmethyl chloroformate hydrazine) at $65^{\circ} \mathrm{C}$. After cooling to room temperature, the reaction mixture was injected into a dedicated HPLC-system. The fluorescence was detected with a fluorescence detector (B\&L systems, Zoetermeer, The Netherlands). The protocol for lactulose and rhamnose analysis was well validated and described in detail previously (Rooyakkers, van Eijk \& Deutz, 1996).

\section{Statistics}

Lactulose/rhamnose ratios of the placebo- and the iron group at baseline, after 4 weeks of iron supplementation and after the indomethacin challenge were compared applying ANOVA, entering placebo and iron as factors. Haematological parameters of the placebo- and the iron group at baseline and after 4 weeks of iron supplementation were compared with paired Students t-tests. Differences were regarded as significantly different at a significance level of $P<0.05$. All statistical comparisons were performed using the Statview 5.0 software package for the Macintosh.

\section{Results}

None of the subjects suffered from adverse effects of the iron supplements, besides occasional black colorization of the stool, which is a common phenomenon during ingestion of supplemental iron.

Baseline serum ferritin did not significantly differ between the group receiving placebo $(11 \pm 6 \mu \mathrm{g} / \mathrm{L})$ or iron supplements $(9 \pm 7 \mu \mathrm{g} / \mathrm{L})$. After 4 weeks serum ferritin was signifi-

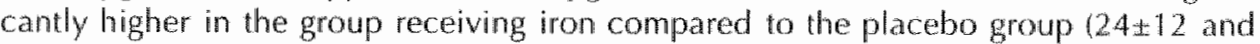
$10 \pm 7 \mu \mathrm{g} / \mathrm{L}$, respectively; $\mathrm{P}<0.05$ ). None of the other haematological parameters differed between the two groups at baseline or after 4 weeks of supplementation (Table 1).

Urinary lactulose/rhamnose ratios were $0.013 \pm 0.009$ and $0.016 \pm 0.007$ at baseline, $0.016 \pm 0.006$ and $0.017 \pm 0.009$ after four weeks of iron administration, and $0.031 \pm 0.020$ and $0.032 \pm 0.013$ after the indomethacin challenges in the groups receiving placebo or iron supplements, respectively, and did not differ at any time (Figure 1). Urinary lactulose- and rhamnose recoveries did not significantly differ between the groups receiving placebo or iron supplements either at baseline, after four weeks of iron supplementation or after the indomethacin challenges (Table 2). 
Table 1 . Haematological parameters at baseline and after 4 weeks of supplementation with either placebo or $300 \mathrm{mg}$ iron/day

\begin{tabular}{|c|c|c|c|}
\hline & & baselline & 4 weeks \\
\hline \multirow[t]{2}{*}{ Ferritin (ugl } & placebo & $11=6$ & $10 \pm 7$ \\
\hline & iron & $9 \pm 7$ & $24 \pm 12 *$ \\
\hline \multirow[t]{2}{*}{ Haemoglobin (mumol/L) } & placebo & $8.2 \pm 0.5$ & $8.1 \pm 0.5$ \\
\hline & iron & $7.8 \pm 0.5$ & $8.7 \pm 0.6$ \\
\hline \multirow[t]{2}{*}{ Matmatocrit (\%) } & placebo & $38.9+25$ & $36.9 \pm 2.60$ \\
\hline & iron & $37.5 \pm 2.6$ & $37.1=2.7$ \\
\hline
\end{tabular}

Data are expressed as mean $\pm 5 d$. Statistically different from placebo, P<0.05

Figure 1. Urinary lactuloseformonose ratios

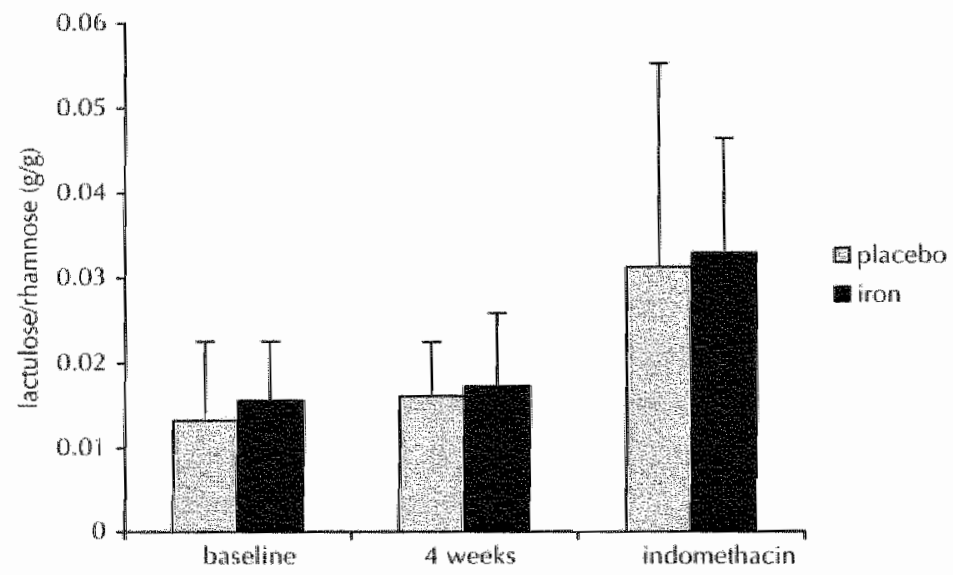

Five-to urhary lactulose hammese ratio after ingestion of at hyperosmolar lest drink containing 5 g lactuhlose $0.5 \mathrm{~g}$ hamnose and 20 gg sucrose at baseline, after 4 weeks of placebo or iron supplementation $1306 \mathrm{mg}$ irom/d as forrous gluconate; black bars) and swbsequenty, atter ingestion of 75 and 50 mg. indomethatcin at 9 and $1 \mathrm{~h}$ betore ingestion of the lactulosethamnose test drink (average+sol). No shgrificant differences beween the treatments were observed at any time; $P<0.05$. 
Table 2. Urimary lachlose-and rhamnose recoweries

\begin{tabular}{|c|c|c|c|c|c|c|}
\hline & \multicolumn{2}{|c|}{ basehine } & \multicolumn{2}{|c|}{ 4 weets } & \multicolumn{2}{|c|}{ indomethatin } \\
\hline & placelbo & iron & placelo & inon & Dlucebo & iron \\
\hline We lab recovery & $0.13 \pm 0.08$ & $0.18 \pm 0.09$ & $0.2 \pm 0.1$ & $0.19 \pm 0.09$ & $0.3 \pm 0.18$ & $0.39 \pm 0.27$ \\
\hline forlian recovery & $11.7 \pm 605$ & $13.2 \pm 6.2$ & $14.4 \pm 18$ & $13 \pm 72$ & $113 * 61$ & $12 \pm 54$ \\
\hline
\end{tabular}

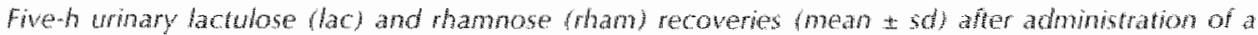
Jactulose/thamnose/sucrose solution at baseline, after 4 weeks of supplementation with ehther placebo $(\mathrm{n}=16)$ or $300 \mathrm{mg}$ iron as ferrous gluconate $(\mathrm{n}=15)$ ard, subsequenty, after administration of $75 \mathrm{mg}$ and $50 \mathrm{mg}$ of indomethacin at 9 and $1 \mathrm{~h}$ before ingestion of the sugar drink, respectiven.

\section{Discussion}

The present study shows that iron supplementation with large daily dosages of ferrous iron supplements does not increase small intestinal permeability in premenopausal healthy women, despite the previous observation that iron administration causes free radical production in the intestine (Srigiridhar et al, 2001) (Lund et al, 1999). Also, iron supplementation did not cause an increased susceptibility of the small intestine to acute enteropathy, obtained by an indomethacin challenge. However, small intestinal permeability data should be interpreted with caution. Epithellial cells, tight junctions, intracellular cytoskeletons, intestinal microvasculature and other components that are involved in the control and maintenance of mucosal integrity were not damaged by the iron intervention to such an extent that permeability of the small intestine increased. This does not exclude oxidative damage to other intestinal compounds, such as brush border microvilli, enzymes etc, which may induce adwerse effects in vivo in humans. Although not the scope of this study, supplementation with $300 \mathrm{mg}$ iron/d for $28 \mathrm{~d}$ increased serum ferritin levels in these subjects. After the supplementation period, 12 out of 15 subjects were no longer considered as iron deficient according to the criteria, whereas in the group receiving placebo, 4 out of 16 subjects still were iron deficient after the supplementation period.

The mucosa of the small intestine provides a tightly controlled barrier against exogenous, orally ingested pathogens. Oxidative damage in the intestine may disrupt the integrity of tight junctions, decrease villus heights and induce apoptosis (Baker, Baker \& LaRosa, 1995; Madesh et al., 1999; Srigiridhar et al., 2001). This disrupted integrity is reflected by an increased intestinal permeability (Baker et al., 1995). An increase in permeability may result in intrusion of enteric pathogens, such as lipopolysaccharide (LPS) and microbes, which initiates a response of the local intestinal immune system. This response involves polymorphonuclear leukocytes (PMNs) translocation, a cylokine response and activation of intraepithelial lymphocytes (IEL.s), all of which induce further damage to the mucosal wall (Nusrat, Turner \& Madara, 2000; Perez, Barber \& Ponz, 1997). Progressing damage to the mucosa of the small intestine may result in bacterial translocation and, owing to an additional cytokine response, a further invasion of pathogens and may eventually initiate a systemic inflammatory response or sepsis (Thomson et al, 2000). Furthermore, increased intestinal permeability is associated with a large array of gastrointestinal diseases, such as Crohn's disease (Andre et 
al. 1988; Meddings, 1997), celiac disease (Smecuol et al, 1997), viral gastroenteritis (Isolauri et al, 1989 ) and food allergy (Crowe \& Perdue, 1992). It is, therefore, important to maintain the integrity of the intestinal wall and to limit any changes in permeability.

During iron therapy, relatively large amounts of iron remain in the intestine in a form that is likely to participate in Fenton reactions. During Fenton chemistry, free ferrous. iron ions catalyze the formation of hydroxyl radicals in the presence of superoxide anion radicals and hydrogen peroxide, both produced as a result of normal metabolism. Hydroxyl radicals are highly reactive and can inflict chemical or structural damage to any biologic molecule in its direct environment. The radical can instantaneously transfer to another molecule and thus initiate a cascade of reactions. The catalyzing role of iron in the production of ROS in vivo has been established previously in animal studies. Micromolar concentrations of ferrous and ferric iron were shown to induce lipid peroxidation to microvillus membranes of rabbits (Fodor \& Marx, 1988). Additionally, oral iron supplements aggravated lactic acid-induced damage to the barrier function of the small intestine epithelium (Gonzalez et al., 1997), promoted colon tumorigenesis in mice (Siegers et al., 1992) and inflammatory processes in rats with colitis (Aghdassi et al., 2001; Reifen et al., 2000). EPR spectroscopy in rats in vivo showed that oral iron therapy with ferrous sulfate resulted in iron mediated oxidative stress through hydroxyl radicals in the small intestine. This stress resulted in a decrease in cell turnover, shortening of micro-villus height and partial or complete erosion of the microvilli in the duodenum (Srigiridhar et al., 2001). The free radical generating capacity from faeces in healthy volunteers was markedly increased after moderate iron supplementation (Lund et al., 1999). However, this was determined ex vivo. The true radical production and its consequences in the intestine in vivo remain to be elucidated.

The findings of the present study do not confirm the data from animal studies. Iron ingestion did not induce oxidative damage to the permeation routes in the healthy human small intestine. Considering the well-established capacity of iron to catalyze free radical formation in the intestine, the human small intestine must have a powerful defence system against oxidative challenges. This supports the findings of a recent study from our group. Ingestion of a single, acute dosage of $80 \mathrm{mg}$ iron as ferrous sulfate directly into the human duodenum in wo induced significant lipid peroxidation in the lumen of the small intestine. This lipid peroxidation was accompanied by an instantaneous, massive increase in the total antioxidant capacity of the intestinal secretions (Troost et al, 2003). From a physiological point of view, there is an obwious need for a powerful defence network against dietary oxidants in the small intestine, considering the high amount of oxidants and other potentially hazardous compounds

Furthermore, iron supplementation did not cause the small intestine to be more susceptible to indomethacin administration. The indomethacin challenge, which was shown previously to induce enteropathy and consequently a rise in small intestinal permeability by a factor 2-3 (Bjarnason et al. 1993; Bjarnason et al. 1989; Bjarnason et al. 1986), did not cause a larger increase in small intestimal permeability in the 
group receiving iron supplements compared to placebo. This supports the conclusion that iron supplementation does not induce extensive oxidative damage in the small intestine in these healthy subjects. However, the observation that the small intestinal permeability did not differ between the groups receiving placebo or iron may also be explained by the damage induced by indomethacin itself. Theoretically, the observed rise in permeability following indomethacin administration, which was approximately 2-fold, may reflect the maximal extent of enteropathy that can be detected by the lactulose/rhamnose gut permeability test and, hence, additional damage cannot be detected. Although this sugar recovery test is well walidated and wildely used, no data are available regarding the maximal permeability changes that can be detected. Previous studies applying the sugar test however do show permeability changes up to approximately 3-fold (Daenen et al, 1991, Lambert et al, 2001), which implies that any synergistic damage of indomethacin administration and iron supplementation would have been detected in the present study.

It was previously shown that IBD patients have an imbalance between ROS production and antioxidant status (Geerling et al, 1998; Lih-Brody et al, 1996), which puts them at higher risk for developing oxidative stress-associated enteropathy than the iron-replete, healthy subjects tested in the present study. Hence, the results of the present study cannot directly be extrapolated to pathological situations, in which iron supplementation may aggravate enteropathy.

The findings of the present study show that one month of high-dose iron supplementation does not impair the mucosal integrity of the small intestine in healthy females, either in the presence or absence of an indomethacin challenge as a model to stress the intestinal mucosa, compared to placebo. This may be explained by the presence of a powerful antioxidant network in the human small intestine in vivo. Future re search will have to elucidate the capacity and mechanism of action of the antioxidant network in the human small intestine, both in the healthy and in the compromised gut: 


\section{References}

Aghdassi, E., Carrier, 1., Cullen, J., Tischler, M. \& Allard, J.P. (2001) Effect of iron supplementation on oxidatwe stress and intestinal inflammation in rats with acute colitis Dig Dis Sci 46(5): 1088-94.

al-Momen, A.K., al-Meshari, A., al-Nuaim, L., Saddique, A., Abotalib, Z, Khashogi, T. \& Abbas, M. (1996): Intravenous iron sucrose complex in the treatment of iron deficiency anaemia during pregrincy Eur IObstet Cynecol Reprod Biol 69(2): 121-4.

Andre, F., Andre, C., Enery, Y., Fonchon, J., Descos, L. \& Minaire, Y. 19988: Assessment of the lactulose-mannitol lest in Crohn's disease Gut 29(4): $511-5$.

Andrews, N.C. (1999): Disorders of iron metabolism N Engl/ Med 34126): 1986-95.

Baker, R.D., Baker, S.S. \& LaRosa, K. (1995): Polarized Caco-2 cells. Effect of reartive oxygen metabothes on enterocyte barrier function Dig Dis Sci 40(3): 510-8.

Bjarnason, I., Hayllar, J. Macpherson. A.J. \& Russell, A.S. (1993): Side effects of nonsteroidal antiinflammatory drugs on the small and large intestine in humans Castroenterology 104(6): 1832-47.

Bjannason, 1., Smethurst, P., Fenn, C.G., Lee, C.E, Menzies, 1.5. \& Levi, A.J. (1989): Misoprostol reduces indomethacin-induced changes in human small intestinal permeability Digestive Direases And sciences $34(3): 407-11$.

Bjarnason, I. Williams, P., Smethurst, P., Peters, T.J. \& Levi, A.J. (1986) Effect of non-steroidal antiinflammatory drugs and prostaglandins on the permeability of the human small intestine Gut 27(11): $1292-7$.

Crowe, S.E. \& Perdue, M.H. (1992): Gastrointestinal food hypersensitivity: basic mechanisms of pathophysiclogy Gasiroenterology 103(3): 1075-95.

Daencn, S., Muskiet, F.A., Marrink, J. \& Halie, M.R. (1991): Aggressive chemotherapy for acute leukaemia frequently causes intestinal protein leakage Eur/Cancer 27(5): 552-6.

DeMacyer, E. \& Adiels-Tegman, M. (1985): The prevalence of anaemia in the world World Heath Stat Q 3803: $302-16$.

Fodor, I. \& Marx, 1.J. (1988): Lipid peroxidation of rabbit small intestinal microvillus membrane vesides by iron complexes Biochim Biophys Acta 96101 : 96-102. Frewin, R., Henson, A. \& Prowan, D. (1997): ABC of clinical hatematology. Iron deficiency anaemia $B$
M A 314(7077):360-3.

Geerling, B... Badart-Smook, A., Stockbrügger, R.W. \& Brummer, R.j. (1998): Comprehensive nutri. lional status in patients with long-standing Crohn's disease currently in remission Am / Clin Nutr
$67(5): 979-26$.

Gonzalez, P.K., Doctrow, S.R. Malíry, B. E Fink, M.P. (1997): Role of oxidant stress and iron deloCalization in acidosis-induced intestinal epithelial hyperpermeability shock $8(2)$ : $108-14$

Isolauri, E, Juntunen, M. Wiren, S., Vuorinen, P. \& Koivula, T. (1989). Intestinat permeability changes

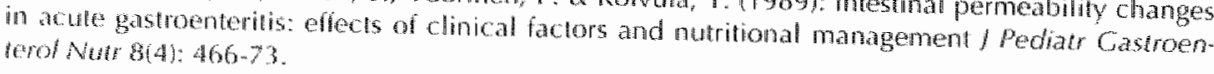

Lambert, G.P., Broussard, L.., Mason, B.L., Mauermann, W.I. \& Gisolfi, CV. (2001): Gastrointestinal permeability during exercise effects of aspirin and energy-containing beverages / Appl physiol
gof(6): 2075-30.

Lilh-Brody, L., Powell, S.R., Collier, K.P., Reddy, G.M., Cerchia, R., Kahn, E, Weilssman, G.S., Katz, S. Floyd, R.A. Mckinley, M.I. Fisher, S.E. \& Mullin, G.E. (1996): increased oxidative stress and de- 
weased antioxidan detenses in mucosa of inflammatory bowel disease Dig Dis $5 c$ 4 11101: 2078. 86.

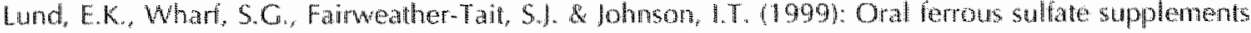
increase the free radical-generaling capacily of feces from healthy wolunees Anerican fouma of Chical Nutrition $69(2): 250-5$.

Madesh, M., Anup, R., Benard, O. \& Balasubramanian, K.A. (1999): Apoptosis in the monkey small intestinal epthetium: structural and functionall alterations in the mitochondria Free Radic Buol MAd $26(7-8): 836-43$

Marx, J.J. \& wan Asbeck, B.S. (1996): Use of iron chelators in preventing hydroxy radicall damge: adult mespiratory distress symono as an experimental model for the pathophysiology and theatment of oxygen-radicalmediated fissue damage Acta Haemato 9511 h: 49-62.

Meddings, 1.B. (1997): Review article: Intestinal permeability in Crolun's disease Ahmen Pharmacol Ther 11 Suppl $3: 47-53$; discussion $53-6$.

Nusrat, A., Tumer, J.R. \& Madara, J.L. (2000): Moleculat physiology and palnophysiology of tight junctions. IV. Regulation of tight junctions by extracellular stimuli: nutrients, cytokines, and imenune cells Am ) Physiol Gastrointest Liver Physiol 279(5): G851-7.

Odleni, P., Valentini, S., Aragno, I., Garibaldi, S., Pronzalo, M.A., Rollandi, E. B Baneca, T. (1998): Oxidative stress in subjects affected by celiac disease Free Radic Res 29(1):17-24.

Perez, M. Barber, A. \& Ponz, F. (1997): Modulation of intestinal paracelluar permeability by intlaCellular mediators and cytoskeleton Can / Physiol phamacol $75(4): 287-92$.

Reifen, R., watas, Z. Zeidel, L., Berkovitch, Z. \& Bujanover, Y. 12000 : Iron supplementaltion may aggravate inflammatory status of colitis in a rat model Dig Dis Sci 4502 : 394.7.

Rooyakkers, D.R., wan Ejjk, H.M. \& Deutz, N.E (1996): Sirmple and sensithe multi-sugar-probe gul: permeability test by high-performance liquid chromatography with fluorescence labelling $/$ chrow. matogr $A 30(1-2): 99-105$.

Siegers, C.P., Bumann, D., Trepkau, H.D., Schadwinkel, B. \& Baretton, G. (1992): lnfluence of dietary iron overload on cell proliferation and intestinal tumorigenesis in mice Cancer left $65(3): 245 \% 9$.

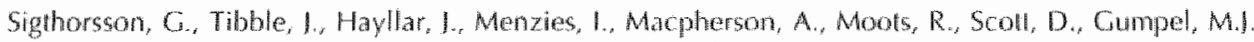

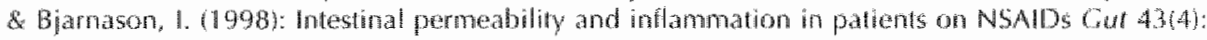
$506-11$

Smecuol, E, Bai, J.C., Vazquez, H., Kogan, Z, Cabanne, A., Niveloni, S., Padreira, S., Baber, 1., Maurino, E. \& Meddings; 1.B. (1997): Gastromestinal permeabihy in celiac disease Casmoen ferology $112(4): 1129-36$

Sriginthar, K. E Nair, K.M. 1998: Iron-deficient intestine is more susceptible to proxidative damage during iron supplementation in tats Free Radic Brol Med 25(6): 660.5.

Sriginhar, K. \& Nair, K.M. (2000): Supplemention with apha tocopherol or a combination of alphatocopherol and ascothic acid protects the gastrointestinat tract of irondeficiant rats againgt ironinduced oxidative damage dering iron repletion Br . Nut 84(2). $165-7$ \%

Srigirithar, K. Nair, K.M. Subramanian, R. \& Simgotamu, L. 2001: Oral repletion of iron induces free ndical mediated alterations in the gastrointestinal Iract of rat Mol Coll Brochem 219(1-2): $91-83$.

Thomson, A.B., Keelan, M., Thiesen, A., Clandinin, M.T., Ropeleski, M.]. \& Wild, G. 2000, Smal bowel review: part $1 \mathrm{Can}$ ) Gastroenterol 149:791-816. 
Troost, F.J. Saris, W.H. Haenen, G.R., B.ast, A. \& Brummer, R.t. (2003): A new method to study oxidative damage and antioxidants in the human small bowel: effects of iron application Am / Physiof Gastronlest Liver Physiol 28521: C354-C359.

van Nieuwerhowen, M.A., Geerling, B.J. Deuz, N.E., Brouns, F. \& Brummer, R.). (1999): The sensi. tivity of the lactulose/rhamnose gut permeability test Eur / Clin Invest 29(2): 160-5.

Yamada, T. \& Grisham, M.B. (1991): Role of neutrophil-derived oxidants in the pathogenesis of intestinal inflammation kin Worhenschr 69(21-23): $988-94$. 
CHAPTER 3

\section{A NEW METHOD TO STUDY OXIDATIVE DAMAGE AND ANTIOXIDANTS IN THE HUMAN SMALL BOWEL: EFFECTS OF IRON APPLICATION}

Freddy J Troost, Wim HM Saris, Guido RMM Haenen, Aalt Bast, RobertJan M Brummer

American Journal of Physiology-Gastrointestinal and Liver Physiology, 2003; 285(2): G354-359 


\begin{abstract}
Background Iron may induce oxidative damage to the intestinal mucosa by its catalyzing role in the formation of highly reactive hydroxyl radicals. This study aimed to determine iron-induced oxidative damage provoked by a single clinical dosage of ferrous sulfate and to elucidate the antioxidant defence mechanisms in the human small intestine in vivo.

Design $A$ double lumen perfusion tube was positioned orogastrically into a $40-\mathrm{cm}$ segment of the proximal small intestine in six healthy volunteers $(25 \pm 5 \mathrm{y})$. The segment was perfused with saline and subsequently with saline containing $80 \mathrm{mg}$ iron as ferrous sulfate at a rate of $10 \mathrm{~mL} / \mathrm{min}$. Intestinal fluid samples were collected at 15 -min intervals.

Results Thiobarbituric acid reactive substances (TBARS) concentrations as indicator of lipid peroxidation increased significantly from $0.07(0-0.33) \mu \mathrm{M}$ during saline perfusion to 3.35(1.19-7.27) $\mu M$ during iron perfusion ( $P<0.05)$. Non-protein antioxidant capacity increased significantly from 474(162-748) $\mu M$ to 1314(674-1542) $\mu M(P<0.05)$.

Conclusion These data show that a single dosage of ferrous sulfate induces oxidative damage and the subsequent release of an antioxidant in the small intestine in vivo in healthy volunteers.
\end{abstract}




\section{Introduction}

The prevalence of iron deficiency anaemia in Europe and North America is $1 \%$ in adult males and $14 \%$ in adult females (DeMaeyer \& Adiels-Tegman, 1985). The usual treatment of iron deficiency anaemia involves oral iron supplementation with ferrous salts. Ferrous salts, prescribed in amounts up to $195 \mathrm{mg}$ of elemental iron/d divided over three single dosages as ferrous sulfate, fumarate or gluconate respectively (Frewin, Henson \& Provan, 1997), are commonly preferred over ferric salts because of their higher bioavailability. Oral ferrous iron therapy may, however, induce oxidative stress due to its catalyzing role in Fenton chemistry, resulting in the production of highly reactive hydroxyl radicals (Fodor \& Marx, 1988; Srigiridhar \& Nair, 1998). They can react with any molecule in their direct environment, resulting in a cascade of reactions in which lipids, proteins and DNA may get damaged. The production of reactive oxygen species (ROS), such as superoxide anion radicals, hydroxyl radicals and hydrogen peroxide, is normally balanced by the antioxidant system. Excessive ROS production, however, induces a disturbance in the pro- and antioxidant balance, resulting in oxidative damage.

Oral iron therapy, commonly indicated in people with an elevated risk for developing iron deficiency, such as children, adolescents, the elderly, (pregnant) women, vegetarians and athletes, may induce considerable gastrointestinal (Cl) side effects, such as nausea, vomiting, heartburn, abdominal pain and constipation, in contrast to intravenous iron treatment (al-Momen et al., 1996). Iron-induced oxidative damage in the intestine after oral ingestion of iron supplements may in part be responsible for these Gl side effects. Additionally, oral iron therapy in patients suffering from gastrointestinal disorders associated with an impaired mucosal or systemic antioxidant capacity, such as Inflammatory Bowel Disease or celiac disease, may attribute to the development of major oxidative damage (Geerling et al., 1998; Lih-Brody et al, 1996; Marx \& van Asbeck, 1996; Odetti et al., 1998; Yamada \& Grisham, 1991).

Oral iron supplements were shown to aggravate lactic acid-induced damage to the barrier function of the small intestine epithelium (Gonzalez et al, 1997), to promote colon tumorigenesis in mice (Siegers et al., 1992) and inflammatory processes in rats with colitis(Aghdassi et al, 2001) (Reifen et al., 2000). Moreover, EPR spectroscopy in rats in vivo showed that oral iron therapy with ferrous sulfate resulted in iron mediated oxidative stress through hydroxyl radicals in the small intestine. This stress resulted in a decrease in cell turnover, shortening of microvillus height and partial or complete erosion of the microvilli in the duodenum(Srigiridhar et al, 2001). Epidemiological studies showed a role of dietary iron in the development of colon cancer (Wurzelmann et al., 1996). Additionally, ROS may induce development of several forms of cancer (Blakeborough, Owen \& Bilton, 1989; Nelson et al., 1989).

Because of the complexity of the direct measurement of oxidative damage in the lumen of the human small intestine in vivo, no data are available regarding the effects of clinically prescribed amounts of iron on oxidative damage in the human intestine in vivo. Also, little is known about the antioxidant defence mechanisms against ROS production in the intestine. For this purpose, we developed a perfusion technique to 
directly quantify oxidative damage and antioxidant capacity in wivo in the small intesthe in healthy adults. This study aimed to determine iron-induced oxidative damage provoked by a single clinical dosage of ferrous sulfate in the small intestine in humans and to obtain more information about the antioxidant defence mechanisms in the human small intestine in wivo. 


\section{Methods}

\section{Subjects}

Six healthy non-smoking volunteers ( $25 \pm 5 y, 3$ males, 3 females) without a history of a gastrointestinal disorder participated in the present study. Volunteers were in good physical health at the time of participation as checked by medical interview. All subjects gave their written informed consent before participation. The study protocol was approved by the Ethics Committee of the University Hospital Maastricht, Maastricht, The Netherlands.

\section{Study design}

After an overnight fast, a perfusion catheter was ingested orogastrically by each volunteer. The catheter consisted of three silicon tubes connected to a rubber balloon on the distal end of the catheter. One of the tubes, called the sample port, had three small openings at $5 \mathrm{~cm}$ proximal of the distal end of the catheter to enable fluid sampling from the small intestine at the level of the distal end of the catheter. The other two tubes were connected in an open loop with the balloon to enable fluid and air transport in and out of the balloon. A fourth lumen had a single opening at $45 \mathrm{~cm}$ from the distal end. This port, referred to as the perfusion port, served to administer a test solution directly into the duodenum.

After installation of the catheter tip into the stomach, the rubber balloon was filled with $1.5 \mathrm{~mL}$ of mercury. Subjects were instructed to remain in the supine position on the right hand side with the upper body lifted $45^{\circ}$ and the feet raised $20 \mathrm{~cm}$ until the balloon entered the duodenum. Positioning of the catheter was checked with continuous pH-registration at the tube tip. When the $\mathrm{pH}$ shifted from low (approx. 1-2.5) to approx. 4-6, the mercury was aspirated and the balloon was subsequently inflated with $15 \mathrm{~mL}$ of air. Subjects were instructed to stay in the supine position on the back with the upper body lifted $45^{\circ}$. The catheter propagated subsequently by the peristaltic movements of the Gil tract. Catheter positioning was successful when the perfusion port was placed about $5-10 \mathrm{~cm}$ distally from the pylorus. This was checked by a second $\mathrm{pH}$-registration channel, which was located at $5 \mathrm{~cm}$ proximal from the perfusion port. After positioning, the balloon was deflated to stop it from progressing in the $\mathrm{Gl}$ tract. Throughout the experiment, the $\mathrm{pH}$ of the second $\mathrm{pH}$ channel was continuously registered to ensure proper positioning of the perfusion port. After the perfusion experiment, subjects removed the catheter by pulling it gently.

Through the perfusion port, a saline solution was injected at $10 \mathrm{ml} / \mathrm{min}$ during 195 min. This period was necessary to reach steady state conditions as was observed in pilot experiments (data not shown). Subsequently, a $300-\mathrm{mL}$ saline solution containing $80 \mathrm{mg}$ elementall iron as ferrous sulfate (Merck, Darmstadt, Cermany) was perfused at $10 \mathrm{ml} / \mathrm{min}$ during $30 \mathrm{~min}$. Finally, a saline solution was perfused again for 60 minutes to rinse out the iron solution and inteslinal secretions.

Intestinal fluid samples were obtained by using the lever properties of the catheter. After an initial adaptation period of 195 min, intestinal fluid content was levered 
through the sample lumen into a beaker placed in melting ice. Intestinal fluid excretions were pooled over 15 -min intervals and stored at $-80^{\circ} \mathrm{C}$ until analysis.

\section{Biochemical analysis of intestinal fluid samples}

\section{Thiobarbituric acid reactive substances (TBARS) assay}

The determination of TBARS was based on the formation of a coloured adduct of malondialdehyde (MDA) with 2-thiobarbituric acid (TBA). One hundred $\mu$ sample was added to $900 \mu \mathrm{L}$ of a reagent containing $0.12 \mathrm{~mol} / \mathrm{l} \mathrm{TBA}, 0.32 \mathrm{~mol} / \mathrm{L} \mathrm{o}$. phosphoric acid, $0.68 \mathrm{mmol} / \mathrm{L}$ butylated hydroxytoluene (BHT) and $0.01 \%(\mathrm{~m} / \mathrm{v})$ EDTA). The mixture was incubated for 1 hour at $100^{\circ} \mathrm{C}$ in a water bath. After cooling the MDA-products were extracted with $500 \mu$ butanol. Thirty $\mu \mathrm{L}$ of the butanol layer was injected on a HPLC system (Agilent, Palo Alto, CA, USA) equipped with a fluorescence detector, set on excitation wavelenght of $532 \mathrm{~nm}$ and emission wavelenght of $553 \mathrm{~nm}$, and a Nucleosil C18 column, $150 \times 3.2 \mathrm{~mm}$, particle size $5 \mathrm{\mu m}$ (Supelco Inc. PA, USA). Samples were eluted with $65 \%$ ( $/ \mathrm{w}$ ) $25 \mathrm{mmol} / \mathrm{l}$ phosphate buffer $\mathrm{pH} 4.8$, $35 \%(\mathrm{v} / \mathrm{v}$ ) methanol. A calibration curve was constructed using malonaldehyde bis(diethylacetal) as standard.

\section{Antioxidant capacity assay}

The antioxidant capacity assay was carried out as described previously (Berg van den et al., 1999) with some modifications. The ABTS ${ }^{\circ}$ radical was produced by incubating a solution of $0.23 \mathrm{mmol} / \mathrm{L}$ ABTS and $2.3 \mathrm{mmol} / \mathrm{L}$ ABAP in $100 \mathrm{mM}$ sodium phosphate buffer $\mathrm{pH} 7.4$ at $70^{\circ} \mathrm{C}$ until the absorption of the solution at $734 \mathrm{~nm}$ was between 0.680 and 0.720 . Deproteination was done by mixing the sample with an equal volume of a solution of $10 \%(\mathrm{w} / \mathrm{V})$ trichloro-acetic acid. In the reaction of antioxidants with the blue/green ABTS radical, the blue green colour disappears. This decolourisation after 5 minutes is determined spectrophotometrically at $734 \mathrm{~nm}$. The reduction in absorbance is related to that of trolox, a synthetic, hydrophilic vitamin E analogue, which gives the trolox equivalent antioxidant capacity (TEAC) value. The TEAC value is calculated as molar trolox equivalents of the sample.

\section{Glutathione assay}

Total glutathione was determined using the recycling method (Vandeputte et al, 1994). To $50 \mu \mathrm{L}$ of a sample $100 \mu \mathrm{L}$ of a $0.4 \mathrm{mmol} / \mathrm{L}$ NADPH $/ 0.3 \mathrm{mmolL}$. DTNB solution in $143 \mathrm{mmol} / \mathrm{L}$ phosphate buffer pH 7.4, containing $6.3 \mathrm{mmol} / \mathrm{L}$. EDA, is added in a 96-well plate. Then the reaction is started by adding $50 \mu \mathrm{L}$ of a solution containing $4 \mathrm{U} / \mathrm{mL}$ glutathione reductase. The increase of the absorption (A/min) is followed brators and the concentration of total glutathione is calculated.

\section{Uric acid assay}

Uric acid was detemined in ultra filtrates using a HPLC method described previously (Lux, Naidoo \& Salonikas, 1992) with minor modifications. The sample was filtered over a $3 \mathrm{kD}$ filter unit (Centrex UF 0.5, Schleicher \& Schuell, Dassel, Germany) by 
centrifugation for 45 minutes at $14.000 \times \mathrm{g}$ and $44^{\circ} \mathrm{C} .25 \mu \mathrm{L}$ of the filtrates was analyzed on the HPLC. The system (Agilent, Palo Alto, CA, USA) consisted of an Hypersil BDS C-18 end-capped column, $125 \times 4 \mathrm{~mm}$, particle size $5 \mu \mathrm{m}$ (Agilent, Palo Alto, CA, USA) with a mobile phase of $5 \mathrm{mmol} / \mathrm{L}$ sodium phosphate buffer $\mathrm{pH}=3.3$. Detection was performed using a variable wavelength detector set on a wavelength of $292 \mathrm{~nm}$. Concentrations of uric acid were calculated using a calibration curve of uric acid.

\section{Statistics}

Differences were assessed by Univariate Analyses of Variance using SPSS 10.0 software. Differences were regarded as significant when $p<0,05$. Multiple comparisons, used to localize time differences, were adjusted with the Least Significant Difference.

\section{Results}

One to two hours after ingestion of the catheter, the distal end of the catheter entered the duodenum. Catheter positioning was completed within 5 to $8 \mathrm{~h}$ in all volunteers. The TBARS levels were significantly higher at $15,30,45$ and $60 \mathrm{~min}$ after the start of the ferrous sulfate perfusion compared to the baseline level measured at $t=0(P<$ 0.05 ) and returned to baseline levels after $90 \mathrm{~min}$ (Figure 1). The TEAC of the intestinal fluid was significantly higher at 30 and $45 \mathrm{~min}$ after the start of the ferrous sulfate perfusion compared to the baseline level measured at $t=0(\mathrm{P}<0.05)$ (Figure 1$)$.

Figure 1. Lipid peroxidation and antioxidant capacity
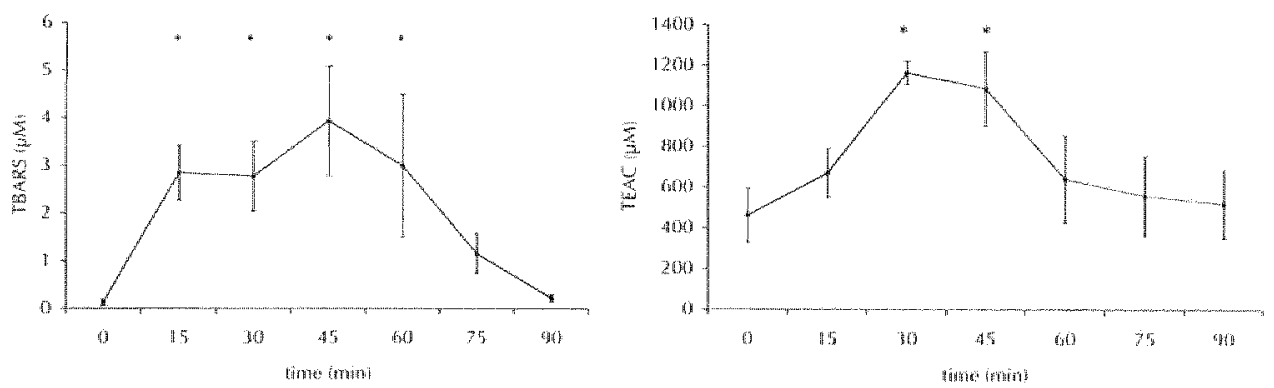

Thobarbituric Acid Reactive Substances (TBARS) concentrations, an indicator of lipid peroxidation, and Trolox Equvalen Antoxidant Capacity (TEAC), an indicator of total antioxidan capacity, in intes. that perfusion samples, collected over 15 min intervals during perfusion of a $40 \mathrm{~cm}$-segment in the proximal small intestine in 6 subiects. Baschine values at $t=0$ mere oblained during saline pentusion. Subsequently saline containing bo mg elemental iron as ferrows sulfate was pertused for 30 min, and hinally saline was periused for $60 \mathrm{~min}$ at $10 \mathrm{~mL} / \mathrm{mim}$ (mean $\pm S E M$; differences vs $t=0$ tested with Analysis of Variance, * $P<0.05$. 
Table 1 . Uric acid concentrations in intestinal periusion samples pooled over 15 min periods

\begin{tabular}{cl}
\hline fime (min) & Uric acid $(\mu M)$ \\
\hline 0 & $37.9 \pm 15.6$ \\
15 & $34.4 \pm 15.7$ \\
30 & $32.5 \pm 12.6$ \\
45 & $27.7 \pm 8.2$ \\
60 & $25.2 \pm 4.8$ \\
75 & $28.7 \pm 8.7$ \\
90 & $26.9 \pm 10.2$ \\
\hline
\end{tabular}

Median alkaline phosphatase concentrations of the perfusate samples did not differ significantly between $t=0$ and $t=30$ min $(502 \pm 377$ and $510 \pm 363$ U/L respectively). Uric acid concentrations of the perfusate samples were not significantly different from baseline during the first 75 min after the start of the ferrous sulfate perfusion (Table 1). At $t=90$, uric acid was statistically lower than baseline values $(P<0.05)$.

Glutathione concentrations in the perfusate samples were under the detection limit of the equipment $(<0.10 \mu \mathrm{mol} / \mathrm{L})$.

\section{Discussion}

The present study clearly shows that iron ingestion in wivo induces intestinal oxidative damage as indicated by the occurrence of lipid peroxidation. The magnitude of the TBARS concentration in the intestinal fluid samples as a result of iron ingestion was remarkably high. The TBARS assay was applied to estimate malondialdehyde (MDA) concentration, which is an end product of lipid peroxidation. MDA is a well-accepted parameter of oxidative damage (Hageman, Bast \& Vermeulen, 1992). However, it is not specifically produced as a result of free radicals attack, but may be formed during the ex vivo sample incubation stage. In order to prevent formation of MDA ex vivo, the chain-breaking antioxidant BHT was added. The ability of BHT to prevent TBARS fomation during the analytical assay was checked in ex vivo experiments with intestinal fluid samples. In these experiments, we observed an instantaneous rise in TBARS formation upon ifon addition, but BHT was effective in preventing TBARS formation during the assay. Other possible analytical shortcomings of the conventional TBARSassay are resolved by the use of the applied HPLC technique (Halliwell \& Chirico, 1993). Therefore, in the present study TBARS provides an accurate indicator of oxida* tive damage in vivo. The finding that antioxidant capacity increases in the lumen of the small intestine following an oxidative challenge has not been described previously. The rapid and massive increase in antioxidant capacity of the intestinal fluid samples indicates a powerful defence mechanism of the small intestine against exoge-
nous oxidants. 
The TBARS concentrations in the intestinal fluid samples after the iron challenge are roughly 3-5 times higher than those observed in plasma in healthy adults. This is a highly interesting finding in the view of the dilution of the intestinal fluid samples. In pilot experiments we measured the dilution of the intestinal fluid with the saline or saline/iron sollution in the intestinal segment by addition of an inert marker, lacitulose, to the ingoing solution and subsequent measurement of the lactulose concentration in the perfusate samples. A dilution of approximately 100-fold was found in all samples. This dilution was constant throughout the experiment (data not shown). In view of the fact that sample dilution did not change during the experiment, independently of the presence or absence of iron, intestinal fluid dilution did not interfere with the results of the study and hence was not measured in the present study.

On average, approximately $15 \mathrm{mg}$ of iron is present in the daily diet. Approximately $2.5 \mathrm{mg}$ iron entering the intestine will be absorbed. About $1 \%$ of the dietary iron remains in the lumen in a form that is likely to participate in free radical generation. During oral iron therapy in adults using dosages of 60 to $195 \mathrm{mg}$ iron/d this proportion remains the same, resulting in a much larger amount of iron available for Fenton reactions. During Fenton chemistry, ferrous iron catalyzes the formation of hydroxyl radicals in the presence of superoxide anion radicals and hydrogen peroxide, both produced as a result of normal metabolism. Hydroxyl radicals are highly reactive and can inflict damage to any biologic molecule in its direct environment. The free electron can transfer to another molecule and hence initiate a cascade of damaging reactions. Previously it was shown that the free radical generaling capacity from faeces in healthy volunteers was markedly increased after iron supplementation $(19 \mathrm{mg} / \mathrm{d}$ iron as ferrous sulfate for $14 \mathrm{~d}$ ) (Lund et al, 1999). However, this was measured in faecal samples ex vivo in an in vitro assay. This does not necessarily reflect the conditions from the present study in which the true effects of iron ingestion in the small intestine in wivo were investigated. The results of the present study confirm the finding that iron ingestion leads to an increase in free radical production in the gut. The model used in the present study mimics ingestion of an oral iron supplement, which dissolves in the gastric juice and is subsequently released gradually into the small intestine.

From the data (Figure $\|$ ) it is clear that oxidative damage occurs immediately following iron administration into the small intestine. This damage continues during saline perfusion after the ferrous sulfate perfusion. This is likely due to the low perfusion flow in the experimental setup. After discontinuation of the iron perfusion, it takes some time to rinse out all of the iron and the intestinal juices secreted during the iron perfusion from the small intestine. After $60 \mathrm{~min}$ of saline perfusion, no iron-induced rise in TBARS is observed in the intestinal fluid samples anymore. These clata are in line with those of a rat study where it was shown that high dosages of iron supplements induce lipid peroxidation in the colon (Rimbach et al., 1997). Any effects of iron supplements in the small intestine were not investigated in that study.

The lipid peroxidation observed in the present studly preceded a marked rise in TEAC (Figure 2). From this it may be concluded that iron-induced oxidative stress induces the release of an antioxidative component in the small intestine. As for the TBARS 
concentrations, the TEAC values are also remarkably high, especially in view of the previously mentioned dilution of the intestinal fluid samples with the ingoing solution. The data of the present study indicate that a powerful physiologic mechanism in the small intestine protects against iron-induced oxidative damage. In view of the fast release of the antioxidant(s), it is unlikely that the iron-induced oxidative damage directly induced production of an antioxidative agent, which is subsequently released into the lumen. It is more likely that an antioxidant already present in a storage compartment in the small intestine was released upon oxidative damage. In the present study, all samples were completely deproteinized during the TEAC assay. Sample deproteination is routine practice during the TEAC assay to reduce the analysis of variance. In pilot experiments, we observed that sample deproteination did not affect the average TEAC values compared to duplicate non-deproteinized samples. Hence, the high antioxidant capacity was exclusively caused by a non-protein species. This excludes a role for enzymatic antioxidants or metallothionines in the observed rise in antioxidant capacity.

The rise in TEAC might be explained by lysis of epithelial or mucosal cells. If the membranes of intact cells were disrupted, its cellular content was excreted into the lumen. As a result, the antioxidant capacity would predominantly originate from the cytosolic antioxidant capacity of the epithelial cells. However, this would have been accompanied by a rise in total alkaline phosphatase, which we did not observe. Also, removal of intact epithelial cells present in the intestinal fluid samples by centrifugation did not significantly affect the antioxidant capacity of the samples (data not shown). This suggests that the strong rise in TEAC following iron-induced oxidative stress was not due to cell lysis but was brought about by a specific anti-oxidant mechanism.

Data regarding the non-protein antioxidant capacity of the small intestine are scarce. It was shown in a rat study that the small intestine has a powerful reducing capacity, which is protective against triglyceride hydroperoxides (Mohr et al., 1999). The underlying mechanism or the site of action (luminal, mucosal or epithelial) was not identified. In the present study, glutathione and uric acid were determined in the intestinal fluid samples in an attempt to identify the origin of the rise in antioxidant capacity following iron perfusion. Due to the intestinal fluid dilution by the perfusing solution, glutathione concentrations were below the detection threshold of the equipment used. Uric acid, a powerful antioxidant present in lung- and intestine epithelial lining fluid (Karasawa, Ishi \& Kubota, 1991), was present in low amounts that were not affected by the iron intervention. Vitamin $C$, present in low amounts in most samples, did not show a correlation with antioxidant capacity (data not shown). Hence, neither of these antioxidants was responsible for the rise in antioxidant capacity fol-
lowing the iron challenge in the present study.

The perfusion model to investigate oxidative stress and antioxidant capacity in the human small intestine enabled us to determine the effects of a pro-oxidative agent nique is standardized segment of the small intestine. A major advantage of the technique is the rather non-invasive protocol of the catheter positioning, as this occurred 
using normal peristaltic movements. The technique is applicable to healthy volunteers as well as patients. The perfusion technique can only be used to study a limited segment of the proximal small intestine. Hence, results may not be directly extrapolated to the entire small intestine. However, due to a decreasing nutrient concentration along the small intestine, nutrient-associated oxidative damage probably takes place predominantly in the proximal small intestine. The rate of perfusion needs to be as low as possible to avoid effects of the perfusion experiment on normal functioning of the small intestine. Because of the low perfusion flow, it is not possible to monitor acute, short-term responses in the small intestine. Additionally, sampling occurs at 15min intervals to ensure sufficient sample collection during each collection interval. The perfusion technique provides the unique feature to study oxidative damage and antioxidant capacity in secretions of the small intestine in vivo in humans under strictly standardized conditions. This model is applicable to a variety of intestinal disorders associated with a disturbance in the equilibrium between oxidative stress and the antioxidant defence network. Increased oxidative stress occurs in acute and chronic inflammation, certain drugs and nutrients. Decreased antioxidant capacity may be pre-sent in disorders of mucosal integrity and chronic malabsorption disorders associated with antioxidant deficiencies (Geerling et al., 1998). A disturbance in the equilibrium between oxidative stress and the antioxidant defence network in the small intestine may be an important factor in the pathophysiology of these disorders. Additionally, the perfusion technique can be used to evaluate the efficiency of nutritional antioxidant interventions in restoring a sufficient antioxidant network against oxidative attack in the small intestine.

Iron ingestion induced Fenton-driven oxidative stress in the human small intestine, followed by a massive rise in total antioxidant capacity in the lumen. This rise may reflect the release of a powerful, yet unidentified, non-protein antioxidant. Future work should frocus on identification of this antioxidant and on the possibilities to increase the antioxidlant capacity against oxidative stress with nutritional interventions in disorders related to a high intestinal oxidative stress or a low intestinal antioxidant defence network. 


\section{References}

Aghdassi, E., Carrier, J., Cullen, I., Tischer, M. \& Allard, J.P. (2001): Effect of iron supplementation on oxidative stress and intestinal inflammation in rats with acute colitis Dig Dis Sci 4615: 1088-94.

al-Momen, A.K., al-Meshari, A. al-Nuaim, L., Saddique, A., Abotalib, Z, Khashogii, T. \& Abbas, M. 1996): Intravenous fron sucrose complex in the treatment of iron deficiency anaemia during pregnancy Eur / Obstet Gynecol Reprod Biol $692 \%$; $121-4$.

Berg war den, R., Haenen, C., Berg van den, H. \& Bast, A. (1999): Applicability of an improwed Trolox equivalent antoxidant capacity (TEAC) assay for evaluation of antioxidant capacity measurements of mixlures food Chemistry (66): $511-517$.

Blakeborough, M.H., Owen, RW. \& Bilton, R.F. 19891: Free radical generating mechanisms in the colon: their role in the induction and promotion of colorectat cancer? Free Radic Res Commun $6(6): 359-67$.

DeMaeyer, E. A Adiels Tegman, M. (1985): The prevalence of anaemia in the world World Health Stat. Q $38(3): 302-16$.

Fodlor, 1. \& Marx, 1.) (1988): Lipid peroxidation of raboit small intestinal microvillus membrane vesicles by iron complexes Biochin Biophys Acla $961(1): 96-102$.

Frewin, R., Henson, A. \& Prowan, D. (1997): ABC of clinical haematology. Hron deficiency anaemia $B$ M) $314(7077): 360-3$.

Ceerling, B.J., Badar-Smook, A., Stockbrügger, R.W. \& Brumer, R.J. (1998): Comprehensive nutritional status in pathents with long-standing Crohn's disease currently in remission Am / Clin Nutr $67(5): 919-26$.

Gonzalez, P.K., Doctrow, S.R., Malfroy, B. \& Fink, M.P. (1997): Role of oxidant stress and iron delocalization in acidosis-induced intestinal epithelial hyperpermeability Shock 8(2): 108-14.

Hageman, 1.J., Bast, A. \& Vermeulen, N.P. (1992): Monitoring of oxidative free radical damage in vivo: analytical aspects Chem Biol hoteract 82(3): $243-93$.

Halliwelly B. \& Chirico, S. (1993): Lipid peroxidation: its mecharism, measutement, and significance Am I Clin Nutr 5715 Supply: 71557245 ; discussion 7245-725S.

Karasawa, Y. 1shi, 1.T. \& Kubota, T. (1991): Absorption and metabolism of purines by the small intesline of the chicken Comp Biochem Physiol A 99(1-2): $235-40$.

Lih-Brody, L., Powell, S.R., Collier, K.P., Reddy, G.M., Cerchia, R., Kahn, E, Weissman, G.S., Katz, S., Floyd, R.A., Mckinley, M.l., Fisher, S.E. \& Mullin, G.E. (1996): Increased oxidative stress and de-

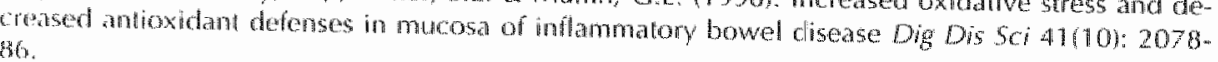

Lund, E.K, Wharf, S.G., Faimeather-Tait, S.l. \& Johnson, I.T. (1999): Oral ferrous sufate supplements increase the free radical-generating capacity of feces from healthy wolunteers $A m /$ Chn Nur $69(2)$ :
250.5 .

L.ux, O. Naidoo, D. Salonikas, C. (1992): Improved HPLC method for the simultaneous measurement of allantoin and uric acid in plasma Am Clin Biochem 29(P 6): 674-5.

Marx, 1. \& wan Asbeck, B.S. (1996): Use of iron chelators in preventing hydroxyl adical damage: adult respiratory distress syndrome as an experimental model for the pathophysiology and treat ment of oxygen radical-mediated tissue damage Ada Haematol 95(1): 49-62.

Mohr. D. Umeda, Y, Redgrave, T.G. \& Stocker, R. 11999): Antioxidant detenses in rat intestine and mesenteric lymplin Retox Rep 40 3) $79-87$. 
Nelson, R.L., Yoo, S.1. Tanure, 1.C. Andrianopoulos, G. \& Misumi, A. (1989): The effect of iron on experimental colorectal carcinogenesis Anticancer Res 9(6): 1477-82.

Odetti, P. Valentini, S., Aragno, 1., Garibaldi, S., Pronzato, M.A., Rolandi, E. \& Barreca, T. (1998): Oxidative stress in subjects affected by celiac disease Free Radic Res 29(1):17-24.

Reifen, R. Matas, Z., Zeidel, L., Berkovitch, Z. \& Bujanower, Y. 2000): Iron supplementation maty aggravate inflammatory status of colitis in a rat model Dig Dis $5 \mathrm{c}$ 45(2): $394-7$.

Rimbach, G., Markant, A., Most, E. \& Pallauf, 1. (1997): Liwer and colon oxidant status in growing rats fed increasing levels of dietary iron / Trace Elem Med Biol 1 12):99-104.

Siegers, C.P., Bumann, D., Trepkau, H.D., Schadwinkel, B. \& Baneton, G. (1992): Influence of dietary iron overload on cell proliferation and intestinal tumorigenesis in mice Cancer lett 65(3):245-9.

Srighidhar, K. \& Nair, K.M. (1998): Iron-deficient intestine is more susceptible to peroxidative damage during iron supplementation in rats Free Radic Biol Med 25(6): 660-5.

Srigiridhar, K., Nair, K.M., Subramanian, R. \& Singolamu, L. (2001): Oral repletion of iron induces free radical mediated alterations in the gastrointestinal tract of rat Mol Cell Biochem 219(1-2):91-8.

Vandeputte, C., Guizon, I., Genestie-Denis, I., Vannier, B. \& Lorenzon, G. (1994): A microtiter plate assay for total glutathione and glutathione disulfide contents in cultured/isolated cells: performance study of a new miniaturized protocol Cell Biol Toxicol 10(5-6): 415-21.

Wurzelmann, J.H., Silver, A., Schreinemachers, D.M., Sandler, R.S. \& Everson, R. B. (1996): Iron intake and the risk of colorectal cancer Cancer Epidemiol Biomarkers Prev 5(7): $503-7$.

Yamada, T. \& Grisham, M.B. (1991): Role of neutrophil-derived oxidants in the pathogenesis of intestinal inflammation Klin Wochenschr 69(21-23): 988-94. 
CHAPTER 4

\section{IN VIVO REGULATION OF GENE EXPRESSION IN THE SMALL INTESTINAL MUCOSA BY IRON-INDUCED OXIDATIVE STRESS}

Freddy J Troost, Robert-Jan M Brummer, Guido RMM Haenen, Aalt Bast, Rachel I van Haaften, Chris T Evelo, Wim HM Saris 


\begin{abstract}
Background Iron-induced oxidative stress in the small intestine may alter gene expression in the intestinal mucosa. The present study aimed to determine which genes are mediated by an iron-induced oxidative challenge in the human small intestine.

Design Ten healthy volunteers $(22+1-2$ y) were tested on wo separate occasions, in a randomized cross-over design. After duodenal tissue sampling by gastroduodenoscopy, a perfusion catheter was inserted orogastrically to perfuse a $40-\mathrm{cm}$ segment of the proximal small intestine with saline and, subsequently, with either 80 or $400 \mathrm{mg}$ iron as ferrous gluconate. After the intestinal perfusion, a second duodenal tissue sample was obtained.

Results Thiobarbituric acid reactive substances (TBARS), an indicator of lipid peroxidation, in intestinal fluid samples increased significanty and dose-dependently at 30 min after the start of perfusion with 80 or $400 \mathrm{mg}$ iron, respectively $(P<0.007)$. During the perfusion with $400 \mathrm{mg}$ iron, the increase in TBARS was accompanied by a significant, momentary rise in trolox equivalent antioxidant capacity (TEAC), an indicator of total antioxidant capaciry $(P<0.05)$. The expression of eighty-nime gene reporters was significantly altered by both iron interventions. Functional mapping showed that six distinct processes were importantly mediated by both iron dosages. Three of those processes involved $G$ protein receptor coupled pathways. The other processes were associated with cell cycle, complement activation and calcium channels.

Conclusion Iron administration in the small intestine induced, dose-dependent, lipid peroxidation and a momentary antioxidant response in the lumen, mediated the expression of at least 89 individual genes, and affected at least six biological processes.
\end{abstract}




\section{Introduction}

It is generally accepted that oxidative stress in the intestine is an aetiological factor in the pathophysiology of several inflammation-associated disorders, such as Inflammatory Bowel Disease (IBD) and celiac disease (Geerling et al., 1998; Lih-Brody et al, 1996; Marx \& van Asbeck, 1996; Odetti et al., 1998; Yamada \& Grisham, 1991). Dietrelated components may be important mediators of oxidative damage. Previous studies showed that iron supplements induce oxidative damage to the small intestine, owing to its catalyzing role in Fenton chemistry, which results in the production of highly reactive hydroxyl radicals (Fodor \& Marx, 1988; Srigiridhar \& Nair, 1998). Furthermore, iron intake was associated with impairment of the barrier function of the small intestine epithelium (Gonzalez et al, 1997), the development of inflammation in ulcerative colitis (Aghdassi et al., 2001) (Reifen et al., 2000), a decrease in cell turnover, shortening of microvillus height and erosions of the microvilli in the duodenum (Srigiridhar et al., 2001) and the development of colon cancer (Siegers et al., 1992) (Wurzelmann et al., 1996). We recently showed that a single iron dose administered directly into the small intestine induces lipid peroxidation and the release of, yet unidentified, antioxidants in the lumen of the small intestine (Troost et al., 2003). The cellular mechanisms involved in the intestinal oxidative stress and defence responses are not clear. The rapidly evolving CDNA microarray technology provides a sophisticated method to synchronously monitor the expression of thousands of genes in order to obtain essential information about the regulation of numerous biochemical processes in the intestinal mucosa on the transcriptional level. This technique has the potential to elucidate complex biochemical or physiological pathways, such as intestinal oxidative stress and its consequences.

The present study aimed to assess iron-induced oxidative damage and the antioxidant response in the human small intestine ir vivo after administration of commonly used irom substitution dosages, and to investigate the effects of intestinal oxidative stress on genome-wide gene expression in the smal! intestine, in order to obtain detailed information about intestinal transcriptomics in vivo. 


\section{Methods}

\section{Subjects}

Eight healthy non-smoking volunteers $(24 \pm 4$ y (average $\pm s d$ ), 8 males, 2 females) without a history of gastrointestinal disorders participated in the study. Volunteers were free of medication and in good physical health. All subjects gave their written informed consent before participation. The study protocol was approved by the Ethics Committee of the University Hospital Maastricht, Maastricht, The Netherlands.

\section{Study design}

This study was designed to conform to a randomized cross-over design. Each subject was tested on two separate days. Baseline duodenal biopsies, taken by standard forceps in the proximal horizontal part of the duodenum $(15 \mathrm{~cm}$ distally from the pylorus), were obtained by flexible gastroduodenoscopy. Biopsies were imbedded in tissue-tek (Electron Microscopy Sciences, Washington, PA, USA), snap-frozen in melting isopentane and liquid nitrogen respectively, and stored at $-80^{\circ} \mathrm{C}$ until analysis. After obtaining the mucosal samples, a guide wire was inserted with the distal tip positioned about $60 \mathrm{~cm}$ distally from the pylorus, facilitated by the duodenoscopy. After retraction of the endoscope, a double lumen perfusion catheter thome made from PVC tubing, inner diameter $2.5 \mathrm{~mm}$, outer diameter $4 \mathrm{~mm}$ ) was inserted over the guide wire into the proximal small intestine with the tip of one lumen, which served as an injection port, located in the proximal descending duodenum and the tip of the second lumen, with three small holes in the last $3 \mathrm{~cm}$ to serve as a sample port, $40 \mathrm{~cm}$ distally from the injection port. After positioning, the guide wire was removed. The whole procedure was performed under short interval fluoroscopic control. To check positioning of the injection port in the duodenum throughout the experiment, intraluminal $\mathrm{pH}$ was continuously measured at $5 \mathrm{~cm}$ proximal of the injection port by a $\mathrm{pH}$ electrode (Single Crystal Antimony Multi-Use pH Catheter, Synectics Medical, Quelux, portugali. The $40-\mathrm{cm}$ segment of the proximal small intestine was perfused with saline at $10 \mathrm{ml} / \mathrm{min}$ using a peristaltic pump for $195 \mathrm{~min}$ to be sure to have obtained steady state conditions (Troost et al., 2003). After reaching steady state, either 80 or $400 \mathrm{mg}$ iron as ferrous gluconate dissolved in $300 \mathrm{~mL}$ saline was perfused. The iron solutions were perfused over a 30 -min period. Finally, saline was perfused for another $60 \mathrm{~min}$. All ingoing solutions were kept at $37^{\circ} \mathrm{C}$ in a water bath. Throughout the perfusion experiment, intestinal fluid samples were obtained continuously using the lever properties of the catheter. After the initial $180 \mathrm{~min}$ adaptation period, intestinal fluid was levered through the sample lumen into a beaker placed in melting ice. Intestinal fluids were pooled over 15 -min intervals and stored at $-80^{\circ} \mathrm{C}$ until analysis.

Fifteen minutes after the perfusion experiment, the perfusion catheter was removed and a second gastroduodenoscopy was performed to obtain tissue samples from the same intestinal region after the iron challenge. The entire protocol was repeated on another day, approximately two weeks after the first experiment, to investigate the affects of the other iron dosage. The administration of dosages was in random order. 


\section{Gene expression analysiis}

Total RNA was isolated from each tissue sample and RNA quality was assessed by SDS-page gel electrophoresis. After quality check, at least one tissue sample from 3 out of 8 subjects provided low quality RNA and hence, all tissue samples from these subjecis were excluded from the microarray analyses. The remaining 5 subjects were pooled into two groups (samples from subjects 1 and 2 were pooled in pool 1, samples from subjects 3,4 and 5 were pooled in pool 2). Microarrays were carried out on both pools at baseline, after the low and after the high dosage intervention respectively.

\section{CRNA preparation and in vitro transcription}

$10 \mu \mathrm{g}$ total RNA was used as starting material for the CDNA preparation. The first and second strand cDNA synthesis was performed using the SuperScript II System (Invitrogen, Taastrup, DK) according to the manufacturers instructions except using an oligodT primer containing a T7 RNA polymerase promoter site. Labelled CRNA was prepared using the BioArray High Yield RNA Transcript Labelling Kit (Enzo, Farmingdale, NY, USA). Biotin labelled CTP and UTP (Enzo) were used in the reaction together with unlabeled NTP's. Following the IVT reaction, the unincorporated nucleotides were removed using RNeasy columns (Qiagen, Hilden, GE).

\section{Array hybridisation and scanning}

Fifteen $\mu$ g of cRNA was fragmented at $94^{\circ} \mathrm{C}$ for $35 \mathrm{~min}$ in a fragmentation buffer containing $40 \mathrm{mM}$ Tris-acetate $\mathrm{pH} 8.1,100 \mathrm{mM} \mathrm{KOAC}, 30 \mathrm{mM} \mathrm{MgOAc}$. Prior to hybridisation, the fragmented CRNA in a $6 \times S S P E-T$ hybridisation buffer $(1 \mathrm{M} \mathrm{NaCl}, 10 \mathrm{mM}$ Tris $\mathrm{pH} 7.6,0.005 \%$ Triton), was heated to $94^{\circ} \mathrm{C}$ for $5 \mathrm{~min}$ and subsequently to $45^{\circ} \mathrm{C}$ for $5 \mathrm{~min}$ before loading onto the Affymetrix $\mathrm{HG}$ U133A probe array cartridge. The probe array was then incubated for $16 \mathrm{~h}$ at $45^{\circ} \mathrm{C}$ at constant rotation $(60 \mathrm{rpm})$. The washing and staining procedure was performed in the Affymetrix Flluidics Station. The probe array was exposed to 10 washes in 6XSSPE-T at $25^{\circ} \mathrm{C}$ followed by 4 washes in $0.5 \times S S P E-T$ at $50^{\circ} \mathrm{C}$. The biotinylated CRNA was stained with a streptavidinphycoerythrin conjugate, final concentration $2 \mathrm{mg} / \mathrm{ml}$ (Molecular Probes, Eugene, OR) in $6 \times S S P E-T$ for $30 \mathrm{~min}$ af $25^{\circ} \mathrm{C}$, followed by 10 washes in $6 \times S S P E-T$ at $25^{\circ} \mathrm{C}$. Subsequently, an antibody amplification step was performed, using normal goat $\mathrm{gg}$ as blocking reagent, final concentration $0.1 \mathrm{mg} / \mathrm{ml}$ (Sigma, Copenhagen, DK) and biotinylated anti-streptavidin antibody (goat), to obtain a final concentration of $3 \mathrm{mg} / \mathrm{ml}$ (Vector Laboratories, Burlingame, CA, USA). This was followed by a staining step with a streptavidin-phycoerythrin conjugate, final concentration $2 \mathrm{mg} / \mathrm{ml}$ (Molecular Probes, Eugene, OR) in 6xSSPE-T for $30 \mathrm{~min}$ at $25^{\circ} \mathrm{C}$, and 10 washes in 6xSSPE-T at $25^{\circ} \mathrm{C}$. The probe arrays were scanned at $560 \mathrm{~nm}$ using a confocal laser-scanning microscope (Hewlett Packard GeneArray Scanner G2500A). The readings from the quantitative scanning were analysed with the Affymetrix Gene Expression Analysis Software.

Each gene on the U133A chip was represented by 11 pairs of 25-mer oligodeoxyribonucleotide probes. Each probe pair consists of a perfect match oligonucleotide that 
precisely matches the gene sequence, and a mismatch oligonucleotide that differs only in one single nucleotide mismatch in the centre position. The data from the different sets of probe pairs were used to perform the statistical analyses. For comparison from array to array, all signal data from the quantitative readings were scaled to a global intensity of 150, as previously published (Birkenkamp-Demtroder et al, 2002; Thykjaer et at, 20011 .

The signal intensities from the microarrays were scaled and further analyzed using the Affymetrix Microarray Suite version 5.0 software (Affymetrix, Sianta Clara, CA). Relative MRNA changes were expressed as differences in gene expressions between the 80. or the $400 \mathrm{mg}$ iron challenge compared to baseline samples, respectively. The definition of increase, decrease or no change of expression for individual genes was based on p-values of the comparisons of the normalized signal intensities, as calculated by the software. Genes that were either up- or down regulated in the same direction in both pools were further investigated. If the expression of a gene was increased in one pool while it did not change or decreased in the other pool, it was assumed that the gene expression was not mediated by the iron interventions. Likewise, only those genes that were mediated in the same direction by both the low and the high iron dosage interventions were further investigated.

To allow functional mapping of expression profilles, the annotation of individual probes with the Swissprot (http:/us.expasy.org/sprot/sprot-top.html (Boeckmann et al., $2003)$ database ID for the corresponding protein was used. Using these 1Ds, expression changes for each of the four, pooled, samples were studied using functional MAPPs (MicroArray Pathway Profiles) available from the GenMapp initiative (htp://www genmapp.org/) with GenMapp $v 1.0$ beta sofware (Dahlquist et al., 2002). MAPPs generated trom the Gene Ontology database (http:/www.geneontology.org/ (Consortium, 2001)), the Gi.Protein Coupled Receptor Database (http://Www.gpcr.org (Horn, Vriend \& Cohen, 2001), plus a small number of MAPPS based on the KEGG database (http./Www.genome.ad.jp/kegg/ (Kanehisa et al, 2002)) and MAPPs specifically designed for GenMapp (so called local MAPPs) were used. MappFinder software was used to select the MAPPs with relatively high numbers of differentially expressed genes with a fold change of at least 2.3 , as was indicated by the individual $Z$-scores. The Z-scone increases when higher numbers of changing genes are found, taking into account the number of genes present in the MAPP that are represented on the array, and the total number of genes involved in the concerning MAPP. MAPPs were selected for further study if all four samples reached an arbitrary $Z$-scone of at least 1 on that $M A P P$.

\section{Real-time polymerase chain reaction (RT-PCR)}

In order lo validate the observed mRNA changes from the microarray analyses, RTPCR was performed on seven randomly selected genes. CDNA was synthesized from single samples previously analyzed on GeneChips. The microarray gene expression profiles of the 7 genes, with Unigene cluster IDs nm_005410, nm_001924, nm_002306, nm_005118, nm_00075, nm_003355 and nm_003056, were compared with RT-PCR. Reverse transcription was performed using Superscript II RT (Invitrogen). $1 \mu \mathrm{g}$ total RNA and $3 \mathrm{~mL} 150 \mathrm{pmol} / \mathrm{mL}$ random nonamer-primer in a total volume of 
$12 \mathrm{ml}$ was incubated $4 \mathrm{~min}$, at $70^{\circ} \mathrm{C}$ and chilled on ice. After adding $4 \mathrm{ml} / \mathrm{st}$ Strand Buffer (from supplier), $2 \mathrm{ml} \mathrm{DTT}(0,1 \mathrm{M}), 1 \mathrm{mldNTP}$ mix (10mM), and $1 \mathrm{~m} / \mathrm{SuperScript}$ $\mathbb{R T} \|(200 \mathrm{U} / \mathrm{ml})$ the reaction was incubated 1 hour at $45^{\circ} \mathrm{C}$, and finally $15 \mathrm{~min}$. at $70^{\circ} \mathrm{C}$. The CDNA was diluted 1:20 for use in Real Time PCR. Real-tinte PCR analysis was performed on the selected genes using primers, designed with PrimerExpress sottware from Applied Biosystems (Foster City, CA). Triple determinations were performed on ABI PRISMB 7000 Sequence Detection System using the SYBRO Gireen PCR Master Mix (Applied Biosystems). The PCR reaction consisted of $12.5 \mathrm{~m} / \mathrm{SYBR}$ Green PCR Master Mix, $300 \mathrm{nM}$ of forward and reverse primers, and $2.0 \mathrm{ml} 1.20 \mathrm{di}-$ luted template CDNA in a total volume of $25 \mathrm{ml}$. The reaction was thermocycled using the default settings of "ABI Prism 7000 SDS Software $1.0^{\prime \prime}: 2 \mathrm{~min}$. at $50^{\circ} \mathrm{C}, 10 \mathrm{~min}$. at $95^{\circ} \mathrm{C}$, followed by 40 rounds of $15 \mathrm{sec} 95^{\circ} \mathrm{C}$ and 1 min at $60^{\circ} \mathrm{C}$. A dissociation protocol was added after thermocycling, determining dissociation of the PCR products from $65^{\circ} \mathrm{C}$ to $95^{\circ} \mathrm{C}$. All samples were normalized to GAPDH, as was applied previously (Birkenkamp-Demtroder et al, 2002).

\section{Biochemical analysis of intestinal fluid samples}

\section{TBARS assay}

The determination of thiobarbituric acid reactive substances (TBARS) was based on the formation of a coloured adduct of malondialdehyde (MDA) with 2-thiobarbituric acid (TBA). $100 \mu /$ sample was added to $900 \mu \mathrm{L}$ of a reagent (containing $0.12 \mathrm{~mol} / \mathrm{l}$ TBA, $0.32 \mathrm{~mol} / \mathrm{L}$ o-phosphoric acid, $0.68 \mathrm{mmol} / \mathrm{L}$ butylated hydroxytoluene (BHT) and $0.01 \%(\mathrm{~m} / \mathrm{v})$ EDTA). The mixture was incubated for 1 hour at $100{ }^{\circ} \mathrm{C}$ in a water bath. After cooling, the TBARS-products were extracted with $500 \mu$ butanol. Thirty $\mu$ L of the butanol layer was injected on a HPLC system (Agilent, Palo Alto, CA, USA), equipped with a fluorescence detector, set on excitation wavelength of $532 \mathrm{~mm}$ and emission wavelength of $553 \mathrm{~nm}$, and a Nucleosil C18 column, $150 \times 3.2 \mathrm{~mm}$, particle size 5 Hm (Supelco Inc. PA, USA). Samples were eluted with $65 \%$ (v/v) $25 \mathrm{mmol} / \mathrm{phos-}$ phate buffer $\mathrm{pH} 4.8,35 \%(\mathrm{~V} / \mathrm{v})$ methanol. A calibration curve was constructed using malonaldehyde bis(diethylacetal) as standard.

\section{Antioxidant capacity assay}

The antioxidant capacity assay was carried oult as described previously (Berg van den et al. 1999) with some modifications. The ABTS+ radical was produced by incubating a solution of $0.23 \mathrm{mmol} / \mathrm{L}$. ABTS and $2.3 \mathrm{mmol} / \mathrm{L}$. ABAP in $100 \mathrm{mmol} / \mathrm{L}$ sodium phosphate buffer $\mathrm{pH} 7.4$ at $70^{\circ} \mathrm{C}$ untill the absorption of the solution at $734 \mathrm{~mm}$ was between 0.680 and 0.720 . Deproteination was obtained by mixing the sample with an equal volume of a solution of $10 \%(w / v)$ trichloro-acefic acid. In the reaction of antioxidants with the blue/green ABTS radical, the blue green colour disappears. This decolourisation after 5 minutes was determined spectrophotometrically at $734 \mathrm{~nm}$. The reduction in absorbance is related to that of trolox, a synthetic, hydrophilic vitamin $\mathrm{E}$ analogue, which gives the trolox equivalent antioxidant capacity (TEAC) value. The TEAC value was calculated as molar trolox equivalents of the sample. 


\section{Statistics}

Statistical analyses of the scaled microarray data were performed with the Affymetrix Microarray Sutte version 5.0 sofware package, applying Wilcoxon's signed rank lests to detect differences between arrays. Time effects of MDA and TEAC within each iron intervention, compared to baseline values obtained at $t=0$, were investigated with ANOVA Repeated Measures. Significant time differences were located with Scheffé post hoc analyses, including Bonferroni correction for multiple comparisons. Uniwariate Analyses of Variance were used to assess differences between the two iron dosages. Differences were reganded as significant if $P<0.05$.

\section{Results}

\section{Gene expression}

After normalization of the microarray signals, 8542 gene reporters showed a significant expression in both pools at baseline. Another 476 gene reporters were marginally expressed according to the Affymetrix default cut-off values, whereas the remaining 13271 reporters were not expressed in the duodenal tissue samples.

The microatray analyses showed that the expressions of 89 reporters were consistently increased or decreased compared to baseline by both iron challenges in both pools; 61 genes were decreased (Table 1 a), whereas 28 genes were increased (Table 1b).

Mapping the individual genes to shared biological pathways using MAPPFinder software revealed that, considering the biological processes observed in both pools, 6 biologically processes were mediated by both iron dosages. Three out of those six processes involved $G$ protein coupled receptors, whereas the other three processes were associated with complement activation, calcium channels and cell cycle. The processes, which were mediated by the two interventions in both sample pools, are listed in Table 2 . The table shows the smallest number of gene reporters, mediated by any pool in any intervention. Furthermore, it shows the number of gene reporters involved in each process, which were represented on the microarray chip, and the total number of genes imvolved in each process, as was defined by the databases described in the Methods section.

RT PCR analyses of 7 selected genes showed good similarity with microarray analyses of the same genes, considering the direction of changes in gene expression profiles tollowing the iron interventions (Table 3).

\section{TBARS and TEAC}

The TBARS concentration in intestinal fluid samples after administration of 80 mg iron increased significanty from $0.2 \mu \mathrm{molh} \pm 0.16$ at baseline $10.2 .9 \mathrm{mmol} / \mathrm{L} \pm 1.2,2.3$ $\mu \mathrm{mol} / \mathrm{L} \pm 1.5$ and $2.4 \mu \mathrm{mol} / \mathrm{L} \pm 1.4$ at 30,45 and $60 \mathrm{~min}$ respectively after the start of the iron perfusion ( $P<0.0001$ ). The TBARS concentration after administration of 400 mg iron increased significantly from 0.4 fmol/L \pm 0.5 at baseline to $3.8 \mu$ mol/L \pm 1.1 . $4.1 \mu \mathrm{mol} / \mathrm{L} \pm 1.4$ and $3.8 \mu \mathrm{mol} / \mathrm{L} \pm 1.5$ at 30,45 and $60 \mathrm{~min}$ after the start of the iron perfusion $(P<0.001)$. Univariate analysis of variance showed that TBARS production atter administration of $400 \mathrm{mg}$ iron was significantly higher compared to $80 \mathrm{mg}$ iron (P<0.001; Figure 1). 
The TEAC concentration after administration of $80 \mathrm{mg}$ iron increased from $597 \mu \mathrm{mol} / \mathrm{L}$ \pm 187 at baseline to $1032 \mu \mathrm{mol} / \mathrm{L} \pm 609$ at $30 \mathrm{~min}$ after the start of the iron perfusion. Statistical analysis did not detect an overall time effect. The TEAC concentration after administration of $400 \mathrm{mg}$ iron intervention increased significantly from $806 \mu \mathrm{mol} / \mathrm{L} \pm$ 293 at baseline to $1889 \mu \mathrm{mol} / \mathrm{L} \pm 635$ and $1490 \mu \mathrm{mol} / \mathrm{L} \pm 413$ at 30 and $45 \mathrm{~min}$ respectively after the start of the iron perfusion $(P<0.05)$.

Univariate analysis of variance showed that TEAC after administration of $400 \mathrm{mg}$ iron was significantly higher than after $80 \mathrm{mg}$ iron ( $P<0.001$; Figure 1).

Figune 1. Lipid peroxidationand antioxidant capacity
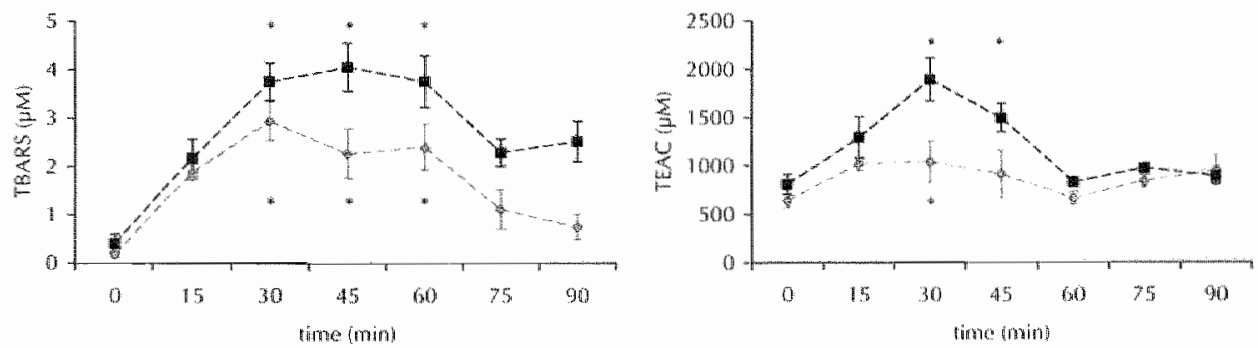

Thiobarbituric Acid Reactive Substances (TBARS) concentrations, an indicator of lipid peroxidation, and Trolox Equivalent Antioxidart Capacify (TEAC), an indicator of total antioxidant capacity, in intes. thal perfusion samples, collected ower 15 min intevals during perfusion of a $40 \mathrm{~cm}$-segnent in the proximal small intestine in 8 subjects. Baseline values at $t=0$ were oblained alter 780 min saline perfusion. Saline containing 80 (grey lines) or $400 \mathrm{mg}$ (black lines) elemental iron as ferrous gluconate was perfused for $30 \mathrm{~min}$, followed by saline perfusion for $60 \mathrm{~min}$ at $10 \mathrm{~mL} / \mathrm{min}$ (mean $\pm 92 \mathrm{M}$ : differences: compared to baseline, $P<0.001$ ). 
Table lla. Genes consistently dewnegutated by periusion of a small intestinal segment with 80 and $400 \mathrm{mg}$ iron, on wwo separate test days. Probe idertification numbers (Probe $10 \mathrm{~s}$ ) refer to the Affymetrix reference number of the measured probe pairs.

\begin{tabular}{|c|c|c|c|}
\hline Probe ID & Gene fithe & Probe ID & Gene title \\
\hline $200617 \ldots$ & MAdh 2 gene product & 209777 S_dil! & $\begin{array}{l}\text { solure canter lamily } 19 \text { folate trans. } \\
\text { porten, } 1\end{array}$ \\
\hline $201009 \mathrm{~s}$ & thiordoxin stherating produm & $209782_{-} s_{2} a t$ & $\begin{array}{l}\text { O site of atbumin purmoter binding } \\
\text { protein }\end{array}$ \\
\hline 201275 , 74 & Gatrosyl diphosphate syrthase & 210095.5. at & $\begin{array}{l}\text { insulin-like growth ractor binding } \\
\text { potein } 3\end{array}$ \\
\hline $201790 \leq 5$ all & 7-dehydrocholesterol seductase & $210830_{3}{ }_{3} a !$ & \\
\hline 2968976 an & paratumbonsen 2 & $211576 \ldots 50$ & \\
\hline 202017 and & 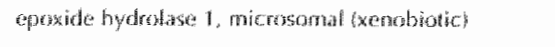 & 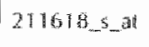 & \\
\hline $202025 x_{-} a t$ & 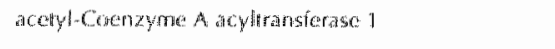 & $211699 x_{\text {a }}$ all & hemogiobin, alystha 1 \\
\hline $202122,5,31$ & mannose 6 phosphattio rectpitor bind ing protein & $211745 x_{-}$an & hentoglotsin, atpha 2 \\
\hline $202,43,3 \mathrm{at}$ & UDP-gatectose mansponter relathd & $211922 \ldots 5$ att & \\
\hline 202700 _all & & $213706, a t$ & \\
\hline $2094 \mid A_{-}$_inl & monocyte to mac rophage difierentation-associatod & 213797 s all & \\
\hline 2018633 at & 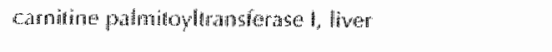 & 21427 때 5 . तal & \\
\hline 2039413 a dit & kireesin tianrily menteten $3 B$ & $216474 \ldots x_{\text {and }}$ & \\
\hline 2040393 & 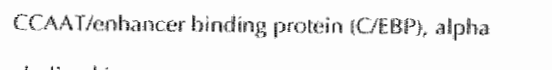 & $216894 \mathrm{x}_{\sim} \mathrm{all}$ & $\begin{array}{l}\text { cyclin-dependent kinase inhib. IC } \\
(15 \%, \text { Kip }\end{array}$ \\
\hline $204233_{\text {_5 att }}$ & choline kimase & $217414_{-\infty} x_{-} a t$ & hemoghobin, alpha 2 \\
\hline 204266.503 & choolane kinase & $2174788_{-} s_{-} a t$ & \\
\hline 2044205 at & $\begin{array}{l}\text { solute carrer family } 2 \text { (hachlitaled glucosedructose } \\
\text { transporter, } 5\end{array}$ & 2018094 s.at & chromosome 20 open readieg frame 35 \\
\hline $204544, \ldots a t$ & alpha integun binding prolein 63 & 218421 忨 & hypotheltical protein F1.123239 \\
\hline 204607 . 64 & 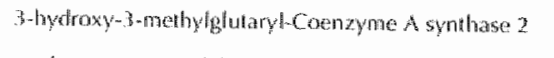 & $2186888_{\text {_ath }}$ & DKF $2 P 586 B 1621$ protein \\
\hline 204760 s_at & 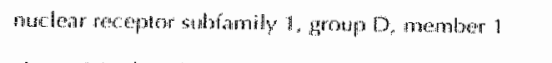 & $219398 \ldots 11$ & protwin FLEOQ7 similar to $15 \mathrm{P} 27$ \\
\hline 204007 , is & glycerd I phesphate dehydrogenase 1 isolubles & $219534 \times \ldots$ & 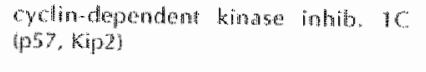 \\
\hline 206071 & 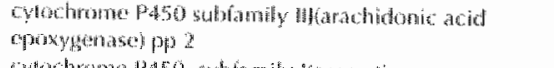 & 220070 at & 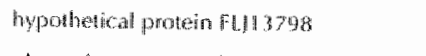 \\
\hline $28074^{4}$ & 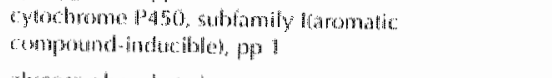 & 2215295 - $a 4$ & $\begin{array}{l}\text { pasnalomma vesicle assonated pro- } \\
\text { tein }\end{array}$ \\
\hline $200 \mathrm{H} 108 \mathrm{~s}, \mathrm{at}$ & 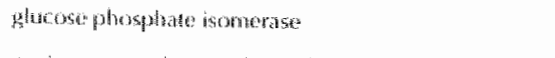 & 221552 all & Miprase protein: \\
\hline 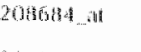 & 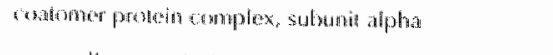 & $2216795 \mathrm{at}$ & liphase protagon \\
\hline $20 \mathrm{hom}$ an & 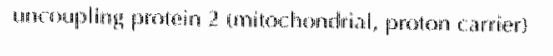 & 221951 at: & \\
\hline 209122 an & 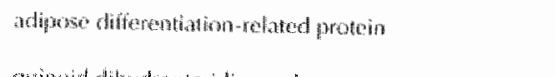 & 316.97 s at & "wclean receptor subiamily 1, grotup D. \\
\hline 279421 i & Guincid dihydropletidine reductase & $38159 \ldots a t$ & $\begin{array}{l}\text { extrof spindte poles, s. cerevisiae, } \\
\text { homolog of }\end{array}$ \\
\hline 909355 & Whosphatidic acid phesphatice type $2 \mathrm{~b}^{2}$ & $4528 \mathbb{H}_{1}$ & Jupase protenton \\
\hline $20975 \times a t$ & 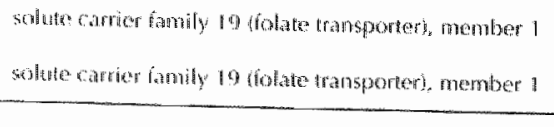 & $\begin{array}{l}65630 \text { at } \\
209777_{2} s_{m} \mathrm{atl}\end{array}$ & 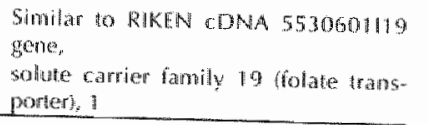 \\
\hline
\end{tabular}


Table 1 b. Genes consistently upregulated by perfusion of a small intestinal segment with 80 and 400 mg iron, on two separate test days. Probe identification numbers (Probe 10 s) refer to the Affymetrix reference number of the measured probe pairs.

\begin{tabular}{|c|c|c|c|}
\hline Probe ID & Giene tille & Probe ID & Gover lithe \\
\hline $201362^{2}$ & WSt-binding protein & 204921 . 5 . तit & Soring \\
\hline $2091368_{-}$at & & 20394952 & gatecting 3 \\
\hline $201427 \leq \leq \mathrm{Bt}$ & selenoprotein $\mathrm{P}$. plasma. I & 209901 _at & C.autbonac anthydrase II \\
\hline 201605 s a & audeoside phosphorylase & $210177_{-} \mathrm{at}$ & Tripatita motifucontaning 15 \\
\hline $20192 \sigma_{4} s_{-}$砇 & $\begin{array}{l}\text { decay accelerding factor lor } \\
\text { connplement }\end{array}$ & 211548,501 & 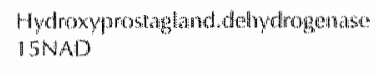 \\
\hline 203287 a & Vadinin 1 & $21196 \underline{2}_{-} s_{-} \mathrm{d}$ & \\
\hline $2035744_{\mathrm{mat}}$ & mulear factor, interleukin 3 reguhlated & $212130 x_{m} a t$ & \\
\hline 203725 _all & $\begin{array}{l}\text { growh arrest and OMla- } \\
\text { danage inducible, alphat }\end{array}$ & $213372_{2} \mathrm{an}$ & \\
\hline 201824 _all & $\begin{array}{l}\text { transmentarane } 4 \text { supenfatmily } \\
\text { menber } 3\end{array}$ & $215363 \times$ and & \\
\hline $20,3914 \times \ldots a !$ & $\begin{array}{l}\text { hydromprostaglandin dehydro- } \\
\text { genase } 15 \text {-(NAD) }\end{array}$ & $2177601 \ldots$ al & StPl protein \\
\hline 205769 ath & $\begin{array}{l}\text { forty-acidrCoennme A ligase, } \\
\text { very long-chain }\end{array}$ & 210500 & gl hocosominyl (N-acelyl transiterase 3 \\
\hline 205771 s.at & A. Kannase (PRKA) anchoor protein 7 & $2206399_{\mathrm{ma}} \mathrm{al}$ & hypothetical proten Fuzzan \\
\hline $205860 \ldots x_{\text {ant }}$ at & $\begin{array}{l}\text { Golate hydrolase prostate- } \\
\text { specific menbrane antigen } 1\end{array}$ & $222303 \_a t$ & \\
\hline 205969 at & arylacelamide deacatylase lesterasej & 40016._B all & KHAAU,303 protein \\
\hline
\end{tabular}

Table 2. Processes in small intestinat mucosal, affected by iron administration.

\begin{tabular}{llc}
\hline Process & MAPP & $\begin{array}{c}\text { Gene reporters changed/ } \\
\text { measured/total }\end{array}$ \\
\cline { 2 - 3 } Cell cycle & KEGG & $6 / 9 / 104$ \\
GPCRs, Class C & CPCRDB Mapp & $3 / 12 / 18$ \\
Calcium channels & LoCal Mapps & $7 / 22 / 28$ \\
Complement activation, & LoCal Mapps & $4 / 12 / 16$ \\
dassical pathway & Local Mapps & $9 / 45 / 69$ \\
Peptide GPCRs & GPCRDBMapp & $22 / 112 / 289$ \\
GPCRs, classA &
\end{tabular}

Processes most strongly mediated by the two iron interwentions in both poots, identificd by Mapplinder as described in the Methods sectron. The second column shows which database was used lor the idenwhication of the biological pathway. The number of mediated gene reponters, changed nowe than 2.3 fold by both iron interwentions in both poots, the total number of gene reponters involwed in each process and represented on the microaray chips (HG U133A), and the tolal number of gene reporters involved in each process as specified by the consecutwe databases, are fisted in the right hand cotแกาก. 
rable 3. Comparison of RT wPR-and microarray results

\begin{tabular}{|c|c|c|c|c|c|}
\hline Genbank & & 12 & $1 \mathrm{H}$ & $2 L$ & $2 \mathrm{H}$ \\
\hline $\mathrm{nm}$ & $\begin{array}{l}\text { RT-PCR } \\
\text { microarray }\end{array}$ & $\begin{array}{l}1.30 \\
1.26\end{array}$ & $\begin{array}{l}1.90 \\
1.68\end{array}$ & $\begin{array}{l}2.04 \\
1.39\end{array}$ & $\begin{array}{l}1.56 \\
1.24\end{array}$ \\
\hline nm_001924 & $\begin{array}{l}\text { RT.PCR } \\
\text { microarray }\end{array}$ & $\begin{array}{l}1.62 \\
1.62\end{array}$ & $\begin{array}{l}2.92 \\
1.76\end{array}$ & $\begin{array}{l}2.56 \\
1.69\end{array}$ & $\begin{array}{l}2.44 \\
1.98\end{array}$ \\
\hline nm_00230\% & $\begin{array}{l}\text { RT-PCR } \\
\text { microarray }\end{array}$ & $\begin{array}{l}1.56 \\
1.46\end{array}$ & $\begin{array}{l}1.96 \\
1.66\end{array}$ & $\begin{array}{l}2.26 \\
1.32\end{array}$ & $\begin{array}{l}3.20 \\
1.39\end{array}$ \\
\hline $\mathrm{nm} 005118$ & $\begin{array}{l}\text { RT.PCR } \\
\text { microarray }\end{array}$ & $\begin{array}{l}7.06 \\
2.12\end{array}$ & $\begin{array}{l}13.53 \\
2.05\end{array}$ & $\begin{array}{l}8.32 \\
2.29\end{array}$ & $\begin{array}{l}11.80 \\
1.95\end{array}$ \\
\hline nm_000775 & $\begin{array}{l}\text { RT-PCR } \\
\text { microanty }\end{array}$ & $\begin{array}{r}-1.31 \\
-1.38\end{array}$ & $\begin{array}{l}-1.29 \\
-1.37\end{array}$ & $\begin{array}{l}-1.21 \\
-1.12\end{array}$ & $\begin{array}{l}-1.36 \\
-1.35\end{array}$ \\
\hline $\mathrm{nm} \quad 003355$ & $\begin{array}{l}\text { RT-PCR } \\
\text { microarray }\end{array}$ & $\begin{array}{l}-1.29 \\
-1.28\end{array}$ & $\begin{array}{l}-1.17 \\
-1.18\end{array}$ & $\begin{array}{l}-1.41 \\
-1.36\end{array}$ & $\begin{array}{l}-1.44 \\
-1.62\end{array}$ \\
\hline nm_003056 & $\begin{array}{l}\text { RT PCR } \\
\text { microalray }\end{array}$ & $\begin{array}{r}-1.76 \\
-1.71 \\
\end{array}$ & $\begin{array}{r}-1.75 \\
-1.76 \\
\end{array}$ & $\begin{array}{r}1.57 \\
-1.44 \\
\end{array}$ & $\begin{array}{l}-1.62 \\
-1.77 \\
\end{array}$ \\
\hline
\end{tabular}

RT-PCR andysis of selected genes (top rows) and microaray data from the same genes (bottom rows). Data are expressed as fold-changes compared to baseline. The first column ( $L$ ) shows the gene expression data irom poot I after adminisiration of the low dosage iron compared ro baseline, column I $H$ shows data from pool 1 after administration of the thigh won dosages. The thind and fourth column 2 $L$ and 2 HI) show the data from poof 2 atter administration of the low and high iron dosage respec. tively.

\section{Discussion}

In the present study, state of the art-methods to study nutrient-gut interactions and nutrient-gene interactions in the human small intestine were combined to synchronously investigate several intestinal responses to luminal oxidative challenges, provoked by different iron dosages. Acute exposure of the proximal small intestine to either a low or a high dosage of ferrous iron induced dose dependent lipid peroxidation, as was indicated by TBARS concentrations, in the intestinal lumen and a synchronous increase in luminal antioxidant capacity. The acute, single-dose, iron challenge mediated gene expression of a number of genes. Both iron interventions strongly affected at least six distinct biological pathways on the transcriptional level.

We recently showed that perfusion of a $40 \mathrm{~cm}$ duodenum segment with $80 \mathrm{mg}$ iron as ferrous sulfate induced lipid peroxidation and the release of an unknown antioxidant (chapter 3). The rise in antioxidant capacity following iron ingestion was not caused by ex vivo TBARS formation during the analytical assay, cell Jysis of epithelial cells, glutathiome, uric acld or vitamin $C$ and was of non-protein origin (Troost et al., 2003). The present study, applying ferrous gluconate, confirmed the catalyzing effects of ferrous iron administration in the small intestine to induce oxidative damage and the release of antioxidants into the intestinal lumen. At baseline, during the initiall saline perfusion, TBARS were only marginally present. After ingestion of either the low or the high iron dosage. TBARS concentrations increased in a dose-dependent manner. This 
increase was accompanied by a similar dose-dependent increase in TEAC. The TBARS and TEAC concentrations were wery high in view of the highly diluted intestinat fluid with the saline solution used for perfusion of the intestinal segment. All samples consisted mainly of the ingoing saline solution, mixed with small amounts of intestinal secretions. This suggests that the iron administration resulted in powerful antioxidant responses. In an attempt to identify the origin of the antioxidant response, NMR spectra from samples with high and low anti-oxidant capacity were taken. Although differences between spectra were observed, it has not been possible to identify the compound(s) responsible for these differences (data not shown). Further analyses are required.

The cDNA chip used enabled simultaneous monitoring of the expression in vivo of more than 20,000 gene reporters. Anong numerous processes that were stightiy mediated by the iron interventions, six distinct processes were strongly regulated, as listed in Table 2. Three out of these six processes inwolved G protein coupled receptors (GPCRs). However, two of these three processes were identified using the GPCRDB database, whereas one was identified by local MAPPS, as was described in the Methods section. We cannot exclude that some gene reporters were attributed to one process in the CPCRDB database, and at the same time to the GPCR process identified by local MAPPS, hence causing an overestimation of the genes involved in GPCRs-associated processes. However, from the results it is clear that GPCRs were strongly mediated by the iron interventions. GPCRs comprise the largest superfamily of proteins in the body. Ligands, for these receptors are biogenic amines, peptides, glycoproteins, lipids, nucleotides, ions and proteases. All GPCRs are able to recruit and regulate the activity of intracellular $G$ proteins, which regulate a large array of intracellular processes (Gether, 2000). The observation that GPCRs were regulated by iron induced oxidative stress may indicate a, yet unknown, function of G protein associated processes in response to cellular stress. The observation that complement activation is regulated by the iron administrations suggests that the iron-induced oxidative damage triggered immune activation in the duodenal mucosa. Complement activation has previously been associated with mucosal damage in ulcerative colitis (Ueki et al., 1996\%. whereas it was also established that mucosal damage owing to autologous complement activation can be prevented by endogenous regulatory mechanisms (Andoh et al, 1993). Furthermore, it was shown that intestinal epithelial cells are able to produce components of complement activation, and that this production can be mediated by cytokimes in the intestinal epithelium (Andoh et al, 1993). Increased complement activation, as observed in the iron perfusion experiments, may induce complement-induced damage. Future studies will need to elucidate the consequences of complement activation in duodenal mucosa. The functional role of the cell cycle- and calcium channels related processes, which were affected by the iron interventions, is not yet described to our knowledge, and needs to be elucidated. Interestingly, it was shown that mice fed a low selenium-diet, which is a trace mineral with antioxidant properties, appeared to have an increased activation of genes involved in cell cycle control (Rao, Puschner \& Prolla, 2001). This suggested that selenium medi ates cell cycle control, which may account for its anti-tumorigenic properties. The present observation that cell cycle processes were mediated by iron-induced oxidative 
stress, in addition to the previous data about the effects of the antioxidant selenium on cell cycle control, suggests that this process may mediate the initiation of carcinogenesis if the oxidantantioxidant balance is disturbed.

Genes involved in the regulation of iron absorption mechanisms have drawn the attention of many investigators, especially in the view of their causal role in the pathogenesis of hereditary haemochromatosis. Several proteins are involved in the direct regulation of iron uptake from the duodenal lumen. Divalent metal transporter 1 (DMT1, a transmembrane transporter for divalent metals including ferrous iron, plays an important rolle in the absorption of iron from the gut lumen into enterocytes, whereas ferroportin1 (FPI) is a iransmembrane iron exporter molecule, involved in the basolateral iron transport from enterocytes into the circulation. In a recent study in mice, iron supplementation for two weeks downregulated the levels of transcripts of DMT1, ferroportint (FP1) and transferrin receptor 1 (TFR1), whereas feeding an irondeficient diet resulted in an increase of these transcripts (Dupic et al., 2002). Furthermore, duodenal gene expression of an iron responsive element-splice variant of DMT1 was significantly downregulated one hour after intragastric iron administration in rats (Frazer et al., 2003). In the present study we showed that the gene expression of DMT1 and TRR 1 tended to decrease by approximately $25 \%$ in both sample pools following administration of the low and the high iron dosage into the duodenum, although these genes were not regarded as significantly changed after statistical analysis (data not shown). Unfortunately, FP1 was not represented on the gene chip. Our findings contribute to the ongoing debate of the precise regulation of intestinal iron absorption. It is commonly acknowledged that high iron levels in the enterocytes downregulate DMT1 expression (Frazer et al, 2003). The finding of the present study that acute iron ingestion may downregulate DMTH and TRR1 expression suggests that intestimal iron concentrations directly mediate transcription of these proteins, as was shown previously only for DMT1 expression (Zoller et al, 2001) (Frazer et al., 2003).

The genome-wide microarrays used yielded information about the expression of a myriad of genes. The major advantage of this technique is the ability to synchronously monitor many biological processes. However, the present study design has some limitations. The duodenal mucosal tissue samples comprised a variety of mucosal and submucosal cell types. Changes in gene expression that only occur in one cell type were, therefore, diluted by the presence of other cell types and, hence, may not have reached significance. In addition, gene expression levels differ between individuals. Pooling samples from different wolunteers and the inclusion of only those gemes that were affected by both the low and the high iron closage in both pools for further analysis, as was applied in the present investigation, reduced the effects of inter-and intra-individual variations in gene expression. We cannot exclude that, using this approach, some relevant genes that were mediated by the iron interventions were erroneously excluded from further analyses. On the other hand, the procedure followed to identify iron-mediated biological pathways minimized the risk of false positive results. The study results reveal the most important, strongest mediated processes.

Finally, the microarray assay itself could have induced false-positive signals due to cross-hybridization or non-specific binding to the probe pairs. This seems highly un- 
likely in view of previously published studies, in which the data of Affymetrix microarray chips were successfully compared to RT-PCR analyses (Gerhold et al, 2001; Xiao et al., 2001). In the present study, we also confirmed the microarray data of seven genes that were mediated by the iron interventions with RT-PCR analyses. Table 3 shows that the changes in gene expression profiles in both pools after both iron interventions were roughly the same, either applying RT-PCR or microarray analyses. Some differences between the two methods were present, as can be observed from the results of gene nm_.005118. RT-PCR analysis showed a 13.53 fold change in the expression of this gene reporter, whereas microarray analysis showed only a 2.05 fold change in expression. This difference may be attributed to the low baseline level of this gene, which is a common concern in the interpretation of microarray results (Gerhold et al., 2001), especially if results are expressed as fold change. Because all RTPCR data show the same direction in changes in gene expression profiles, we assume that the microarray data provide valid gene expression profiles for all gene reporters. It was not possible to establish the functional consequences of the regulation of the processes, identified in Table 2. The impact of the iron interventions on gene expression profiles differed between the two pools, owing to biological, inter-individual variation. Future studies of the functional consequences of changes in the gene expression profiles, as identified in this study, need to be designed to determine the biological impact of the present investigation.

This study showed that iron administration in the human small intestine induced lipid peroxidation, and a strong rise in antioxidant capacity of the small intestinal secretions, in a dose-dependent fashion. Both iron dosages mediated the expression of many genes. Besides considerable inter-and intra-individual differences in gene expression profiles, we identified six processes, which appeared to be strongly and consistently regulated by iron administration or iron induced oxidative stress in the small intestine. Further studies are needed to establish the functional consequences of acute and chronic iron administration and oxidative stress in the human small intestine. 


\section{References}

Aghdassi, E., Carrier, 1., Cullen, 1. Tischier. M. A Alard, I.P. 2001): Effect of irom supplementation on oxidative stress and intestinal inflammation in rats with acute colitis Dig Dis So 4615 ) $1088-94$.

Andoh. A. Fujpyama, Y., Bamba, T. \& Hosoda, S. (1993): Differential cytokine regulation of complement $\mathrm{C}$, $\mathrm{C} 4$, and factor synthesis in human intestinal epithellal cell line, Caco-2 / mmunol $15183): 4239-47$.

Berg wan den, R., Haenen, G., Berg van den, H. \& Bast, A. (1999): Applicability of an improved Trolox equivalent antioxidant capacity (TEAC) assay for evaluation of antioxidant capacty measurements of mixtures food Chemistry (66): $571-517$.

Burkenkamp-Demtroder, K., Christensen, L.L, Otesen, S.H., Frederiksen, C.M., Laho, P., Aatronen, L.A., Laurlizerg, S., Sorensen, F.B., Hagemann, R. \& TF, OR. (2002): Gene expression in colorectal Cancer Cancer Res 62(15): 4352-63.

Boeckmann, B., Bairoch, A., Apweiler, RR, Blatter, M.C., Estreicher, A., Gasteiger, E., Martin, M.l. Michoud, Kn, ODonovan, C. Phan, I., Pilbout, S. Schneider, M. (2003): The SWISSPROT pron tein knowledgebase and is supplement THEMBL in 2003 Nucleic Acids Res 3101):365-70.

Consontum, Y.G.O. (2001): Creating the gene ontology resource: design and implementation Cenone Res T118): 1425-33.

Dahlquist, K.D., Salcmonis, N, Vranizan, K, Lawlor, S.C. \& Conkin, B.R. (2002): GenMAPP, a new lool for viewing and analyzing microarray data on biological pathways Nat Geret 31(1): 19-20.

Dupic, F, Fuchon, S., Bensaid, M, Loreal, O., Brissot, P., Borot, N., Roth, M.P. \& Coppin, H. (2002): Duodenal mRNA expression of iron related genes in response to iron loading and iron deficiency in four strains of mice Gut 51(5): $6488-53$.

Fodor, 1. \& Marx, I. J. (1988): Lipid peroxidation of rabbit small intestinal microvillus membrane vesin cles by iron complexes Biochim Biophys Acta 96111 : $96-102$.

Frazer, D.M., Wilkins, S.I., Becker, E.M., Murphy, T.L., Vulpe, C.D., McKie, A.T. \& Anderson, G.I. 2003): A rapid decrease in the expression of DMT1 and Dcytb but not Iregl or hephaestin explains the mucosal block phenomenon of iron absorption Gut 52(3): 340-6.

Geching, H.1. Badart-Smook, A. Stockbugger, R.W. \& Brumer, R.J. (1998): Comprehensive nutritional satus in pattents with long-standing Cohn's disease currently in remission Am / Clin Nutr $675): 91926$.

Genthold, D., Lu, M., Xu, J., Austin. C., Caskey, C.T. \& Rushmore, T. 2001): Montoring expression of genes involved in drug metabolism and toxicology using DNA microarrays Physiol Genomics $5(4)$ : $161-70$.

Gether, U. (2000): Uncovering molecular mechanisms involved in activation of G protein-coupled recepters findoct Rev $21(1): 90-113$.

Gonzalez, P.K. Doctrow, S.R., Malfroy, B. \& Fink, M.P. 11997 : Role of oxidant stress and iron delo-

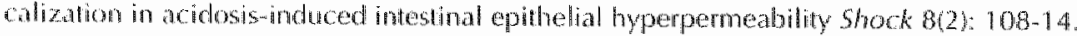

Hom, F. Vriend, G. \& Cohen, F. F. (2001) Collecting and harvesting biological data: the GPCRDB and NucleaRDB information systems Nuclecic Acidis Res. 2911: 3469.9.

Kanehisa, M. Goto, S. Kawashma, S. Nakaya, A. 2002): The KEGG databases at GenomeNet Nucleic Acids Re: 3017$): 42-6$.

Lih-Brody, L., Powell, S.R., Collier, K.P., Reddy, G.M., Cerchia, R., Kahn, E., Weissman, G.5., Katz, S., Floyd. R.A., McKinley, M.I. Fisher, S.E. \& Mullin, G.E. (1996): Increased oxidative stress and de- 
creased antioxidant defenses in mucosa of inflammatory bowel disease Dig Dis $5014110 \% 2078$ 86.

Marx, J.J. \& van Asbeck, B.S. (1996): Use of iron chelators in preventing hydroxyl radical damage: adut respiratory distress syndirome as an experimental model for the pathophysiology and treatment of oxygen-radical-mediated tissue damage Acta tiaematol 95 (1): 49-62.

Odetti, P., Valentini, S., Aragno, 1., Garibaldi, S. Pronzato, M.A. Rolandi, E. Barreca, T. (1998): Oxidative stress in subjects affected by celiac disease Free Radic Res 29(1): 17-24.

Rao, L. Puschner. B. \& Prolla, T.A. (200t): Gene expression protiling of low selenium slatus in the mouse intesine: transcriptional activation of genes linked to DNA damage, cell cycle control and oxidative stress / Nuir 131(12): 3175-81.

Reifen, R., Matas, Z, Zeidel, L., Berkovitch, Z. \& Bujanover, Y. (2000): Iron supplementation may aggravate inllammatory status of colitis in a rat model Dig Dis $5 c$ i 45(2): 394-7.

Siegers, C.P., Bumann, D., Trepkau, H.D., Schadwinkel, B. \& Baretton, G. (1992): Iniluence of dietary iron overload on cell proliferation and intestinal tumorigenesis in mice Cancer tert 65(3):245-9.

Srigiridhar, K. \& Nair, K.M. (1998): Iron-deficient intestine is more susceptible to peroxidative damage during inom supplementation in rats Free Radic Biol Med 25(6): 660-5.

Srigiridhar, K., Nair, K.M., Subramanian, R. \& Singotamu, L. 12001): Oral repletion of iron induces tree radical mediated alterations in the gastrointestinal fract of rat Mol Cell biochem 219(1-2): $91-8$.

Thykjaer, T., Workman, C., Kruhoffer, M., Demtröder, K., Woll, H., Andersen, L.D., Frederiksen, C.M., Knudsen, S. \& Orvtoft, T.F. (2001): Identification of gene expression patterns in superficial and invasive human bladder cancer Cancer Res 61(6): 2492-9.

Troost, F.J., Saris, W.H., Haenen, G.R., Bast, A. \& Brummer, R.l. (2003): A new method to study oxidative damage and anfioxidans in the human small bowel: effects of iron application Am I Physiol Gastrointest Liver Physiol 285(2): G354-G359.

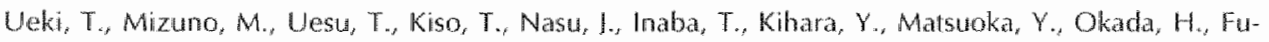
jita, T. \& Tsuji, T. (1996): Distribution of activated complement, C3b, and its degraded fragments, $\mathrm{iC3b} / \mathrm{C} 3 \mathrm{dg}$, in the colonic mucosa of ulcerative colitis (UC) Clin Exp Immunol $104(2): 286-92$.

Wurzelmann, 1., Siver, A., Schreinemachers, D.M., Sandler, R.S. \& Everson, R. B. (1996): Iron intake and the risk of colorectal cancer Cancer Epidemol Biomatkers Prev 577: $503-7$.

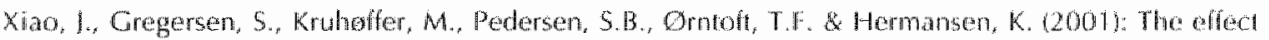
of chronic exposure to fatty acids on gene expression in clonal insulin-producing cells: studies wsing high density oligontuleotide microaray Endocrinology $142(11)$ : 4777-844.

Yamada. T. \& Grisham, M.B. (1991): Role of neutrophil-derwed oxidants in the pathogenesis of indes. tinal inflammation kin Wocherschr 6921-23): 988-94.

Zoller, H., Koch, R.O., Theurl, 1., Obrist, P., Pietrangelo, A., Montosi, G. Haile, D.J., Voget, W. \& Weiss, G, (2001): Expression of the duodenal iron transponters divalent-metal transponter 1 and fertroportin 1 in iron deficiency and iron overload Gastroenterology $120(6): 1412-9$. 
CHAPTER 5

\section{IRON SUPPLEMENTS INHIBIT ZINC- BUT NOT COPPER ABSORPTION IN VIVO IN ILEOSTOMY SUBJECTS}

Freddy J Troost, Robert-Jan M Brummer, Jack R Dainty, Jurian A Hoogewerff, Vicky J Bull and Wim HM Saris

The American Journal of Clinical Nutrition, 2003; 78 , in press 


\section{Abstract}

Background Iron supplements may inhibit intestinal zinc and copper uptake because these elements may compete for binding to at transporter molecule (DMT1), located at the apical side of the small intestine epithelium. This study aimed to quantify the interaction between different levels of iron administration and zinc and copper absorpthion in humans.

Design Eleven subjects with an ileostomy $(55 \pm 9 \mathrm{y})$ ingested a stable isotope-labelled zinc/copper solution containing $12 \mathrm{mg} z$ zinc $\left({ }^{66} \mathrm{Zn}\right.$ and $\left.{ }^{67} \mathrm{Zn}\right)$ and $3 \mathrm{mg}$ copper $\left({ }^{65} \mathrm{Cu}\right)$ in the presence of 0,100 or $400 \mathrm{mg}$ iron as ferrous gluconate respectively on three different test days. Subsequently, $1 \mathrm{mg}$ of ${ }^{70} \mathrm{Zn}$ was injected intravenously. Subjects collected ileostomy effluent for $24 \mathrm{~h}$ and urine for $7 \mathrm{~d}$ respectively. Zinc status and true zinc absorption were calculated from the urinary excretion of the zinc isotopes. Apparent copper absorption was calculated from ileostomy effluent excretion of the orally administered copper isotopes.

Results Zinc status did not differ between the experiments. Zinc absorption was significantly higher in the absence of iron compared with the concomitant ingestion of 100 or $400 \mathrm{mg}$ iron $(44 \pm 22,26 \pm 14$ and $23 \pm 6 \%$ respectively, $\mathrm{P}<0.05)$, whereas zinc absorption did mot significantly differ between 100 or $400 \mathrm{mg}$ iron. Apparent copper absorption was $48 \pm 14,54 \pm 26$ and $53 \pm 7 \%$ in the presence of 0,100 or $400 \mathrm{mg}$ iron respectively, and did not differ between any of the experiments.

Conclusions Oral iron therapy may impair zinc absorption and thus zinc status in a dose-independent fashion, but does not affect copper absorption. 


\section{Introduction}

Approximately 2 billion people worldwide suffer from iron deficiency (WHO, 1999). Iron deficiency is often accompanied by other nutrient deficiencies such as zinc and copper deficiencies, especially when the iron deficiency was caused by insufficient dietary intake of micromutrients as is the case in developing countries (Allen, 1994; Solomons \& Ruz, 1997). As a result, supplements containing iron, multiple trace elements and minerals are used by millions of people worldwide. It is important to provide detailed information regarding safe upper limits of supplements to minimise adverse effects on mineral absorption caused by mineral-mineral interactions. It has long been recognized that iron metabolism interacts with the metabolism of several other micronutrients, such as zinc and copper. The discovery of Divalent Metall Transporter 1 (DMT1) (Gunshin et al., 1997), provided an explanation of previous indications of the competitive absorption of iron, zinc and copper from the small intestine. Iron was shown to decrease zinc absorption in humans in a dose-dependent way when given in a water solution but not when given with a meal (Valberg, Flanagan \& Chamberlain, 1984) (Sandström et al., 1985). Iron supplements have been reported to depress zimc absorption in pregnant women(Simmer \& Thompson, 1985), whereas lower serum zinc concentrations are observed in teenage pregnant women taking iron supplements (Dawson, Albers \& McGanity, 1989). However, other human studies showed that iron supplementation did not alter markers of zinc status or zinc absorption (Donangelo et al., 2002) (Davidsson et al., 1995) (Sheldon et al., 1985).

The iron-copper interaction may pose a health risk because marginal copper deficiency greatly increases the effect of iron deficiency (Snedeker \& Greger, 1983) (Whittaker, 1998). Animal experiments have shown that iron supplementation diminishes copper status in rats and sheep (Yu et al., 1995).

In the present study, the interactions between iron, zinc and copper, iron and isotopically enriched zinc and copper were administered orally in an aqueous solution after an overnight fast, as is generally advised to ensure maximal micronutrient absorption. Zinc and copper absorption were calculated from the appearance of the isotopically enriched stable isotopes in ileostomy effluent and urine. Subjecis with an ileostomy were recruited to ensure complete recovery of test drinks. This study aimed to investigate the acute effects of moderate (100mg) and high (400mg) doses of iron roulinely used in a clinical setting on the absorption of copper and zinc in adults. 


\section{Methods}

\section{Subjects}

Eleven subjects $(9$ male, 2 female; 55 y \pm 91 with an ileostomy were recruited for participation. When the indication for proctocolectomy was Crohn's disease, subjects were permitted to the study only if they had been in remission for at least three years and less than $10 \mathrm{~cm}$ of the terminal ileum was remowed. All participants were free of medication affecting normal functioning of the upper gastrointestinal tract, none had symptorns of an absorptive disorder or nutrient deficiencies. Additionally, all subjects were free of inflammation associated acute phase response of the immune system, as determined by measurement of blood serum C-reactive protein. Detailled information about the study was given orally and in writing. All subjects signed a written informed consent before participation. The Ethics Committee of the University Hospital Maastricht, Maastricht, The Netherlands approved the study.

\section{Preparation of isotopes}

The zinc isotopes ${ }^{6} \mathrm{Zn}$ (enriched to $99 \%$ abundance), ${ }^{67} \mathrm{Zn}$ (enriched to $90,6 \%$ abundance, "Zn (enriched to $95 \%$ abundance) were obtained as zinc metal (Chem Gas, Boulogne, France). Both oral and intravenous zinc doses were prepared in the Dose Preparation Unit (DPU) at the Instifute of Food Research. Elemental zinc was dissolved in concentrated $\mathrm{HCl}$ and evaporated to drymess. The precipitate was dissolved in trisodium citrate and the $\mathrm{pH}$ adjusted to 7 using sodium bicarbonate. The final solution was filtered through a $0.2 \mu \mathrm{m}$ filter to remove pyrogens. The oral doses were aliquoted in the DPU, whilst the individual iv doses were sub-sampled, autoclaved and sub. jected to sterility testing at the Ipswich Hospital Pharmacy, Ipswich, UK.

The copper isotope ( ${ }^{65} \mathrm{Cu}$, enriched to $99.8 \%$ abundance) was obtained as elemental copper foil (ChemGas, Boulogne, France) and individual oral doses were prepared in the DPU. Elemental copper was dissolved in conc. nitric acid (AristaR) on a hot plate at $150^{\circ} \mathrm{C}$. The solution was evaponated to virtual dryness and then redissolved in concentrated HCl (AristaR). The solution was sub-boiled to dryness and the residue redissolved in $6 M$ hydrochloric acid and removed from the heat. Sterile water was added and the pH adjusted to $\mathrm{pH} 5$ with $1 \mathrm{M} \mathrm{NaOH}$. The solution was made up to the appropriate volume with sterile water and filtered through a $0.22 \mathrm{~mm}$ filter. However, liltering proved to be progressively difficult and $\mathrm{HCl}$ was added to adjust the $\mathrm{pH}$ to 3.5 allowing the remaining solution to be filtered. The final solution was sub-sampled into individual doses in the DPU and stored at $-20^{\circ} \mathrm{C}$ until required.

\section{Study design}

For a period of three days prior to the first test day and on the day of testing, subjects kept a weighed food intake diary to record their habitual diet. The food diary was used to ensure that volunteers consumed an identical diet prior to all three experimental days. The study was a randomised crossover design. 
Chapter 5
Iron supplements inhibit zinc-but not copper absorption in wivo in leostomy subjects

At $0800 h$, following an overnight fast, ileostomy effluent and urine were collected in acid-washed containers at wake-up as baseline samples. A venous blood sample was taken from an antecubital vein in the forearm for measurement of serum ferritin and blood haemoglobin and haematocrit as indicators of iron status, and serum C-reactive protein to confirm the absence of inflammation associated acute phase response. After blood sampling, a test drink, as described below, was consumed, and subsequently all ileostomy effluent was collected for the following $24 \mathrm{~h}$. Effluent samples were immediately frozen on dry ice and stored in plastic air-tight boxes at $-20^{\circ} \mathrm{C}$ prior to analysis. Complete 2 th urine collections were made for 7 days post-dosing and $100 \mathrm{~mL}$ fractions were also stored at $-20^{\circ} \mathrm{C}$ until analysis. All sample containers were acid-washed prior to sample collection.

\section{Test solutions}

The test beverages contained $300 \mathrm{~mL}$ of an isotonic maltodextrin solution. To this lest. beverage, isotope solutions containing $7 \mathrm{mg}{ }^{67} \mathrm{Zn}, 5 \mathrm{mg}$, $\mathrm{Zn}$ and $3 \mathrm{mg}$ Cu were added. The test beverage was ingested on three occasions. Once without addition of an iron supplement, one with synchronous ingestion of a pill containing $100 \mathrm{mg}$ iron as ferrous gluconate (Numico, Wageningen, The Netherlands) and once with synchronous ingestion of $400 \mathrm{mg}$ iron as ferrous gluconate.

Zinc was abundantly present as ${ }^{67} \mathrm{Zn}$ and ${ }^{66} \mathrm{Zn}$. Ingestion of $7 \mathrm{mg}$ of ${ }^{67} \mathrm{Zn}$ was needed to ensure sufficient urinary ${ }^{67} \mathrm{Zn}$ enrichment. The, less expensive, $\mathrm{Zn}$ was added to the test beverages to increase the amount of zinc to a total amount of $12 \mathrm{mg}$.

Immediatelly after oral administration of the test beverage, 1 $\mathrm{mg}{ }^{20} \mathrm{Zn}$ was administered intravenously into an antecubital vein in the forearm. The exact amounts of oral and intravenous isotopes were determined for each individual. Subjects refrained from eating for $4 \mathrm{~h}$ but were allowed water 'ad libitum' after one hour post-dosing. After $4 \mathrm{ht}$ post-dosing, volunteers consumed their habitual diet as described above.

\section{Sample processing}

All glassware, crucibles and other equipment or containers used during sample proc. essing were acid-washed before use.

lleostomy effluent was freeze-dried, autoclaved and ground using a grinder with no metal parts in the grinding basket. All 24-h effluent samples were pooled and homogenized and subsamples were ashed at $450{ }^{\circ} \mathrm{C}$ for $48 \mathrm{~h}$. Aliquots and an internal standard of ${ }^{6,2} \mathrm{Zn}$ were accurately weighed into crucibles and dissolved in $4 \mathrm{~mol} / \mathrm{L} \mathrm{HCl}$ while heating for $2 \mathrm{~h}$ on hot plates.

Urine aliquots were accurately weighed into $150 \mathrm{~mL}$ beakers, concentrated on hot plates, transferred to silica crucibles, heated to dryness and ashed at $450{ }^{\text {to }} \mathrm{C}$ for $48 \mathrm{~h}$. Subsequently the ash was dissolved in $0.5 \mathrm{~mol} / \mathrm{L} \mathrm{HCl}$ while heating for $2 \mathrm{~h}$ on hot plates.

Subsequenty, zinc was extracted from urine samples using anion exchange chromatography. An anion exchange resin (Type AGIX-8, BioRad Laboratories, Hercules, CA) was soaked in deionised water for at least $24 \mathrm{~h}$ before use. Two mL of pre-soaked resin was packed into acid washed glass collumns (1 $\mathrm{mL}$ pipette $t i p s$, Sarstedi, Nüm- 
brecht, DE). The columns were connected to a peristaltic pump (Watson Marlow, Falmouth, UK) with a flow rate of $1 \mathrm{mLmin}$ and washed with $2 \mathrm{~mol} / \mathrm{L} \mathrm{HNO}_{3}$ for 1 h to remove any minerals. The resin was reconstituted to the chloride form using $0.5 \mathrm{~mol} / \mathrm{L}$ $\mathrm{HCl}$, which was pumped through for $60 \mathrm{~min}$. The sample solutions were loaded onto the columns, columns were washed with $0.5 \mathrm{~mol} / \mathrm{L} \mathrm{HCl}$ during $30 \mathrm{~min}$ and finally zinc was eluted with 1 mol/L HNO,. This fraction was collected and the total zinc concentration was adjusted to 1 ppm before for zinc isotopic enrichment determination using Micromass "Isoprobe" Multi Collector Inductively Coupled Plasma Mass Spectrometer (MC-ICP-MS) as described below. For copper extraction from the ileostomy fluid samples, presoaked resins were washed with $2 \mathrm{~mol} / \mathrm{L} \mathrm{HNO}$, for $1 \mathrm{~h}$ and regenerated into the chloride form by pumping $6 \mathrm{~mol} / \mathrm{L} \mathrm{HCl}$ for $1 \mathrm{~h}$. Subsequenty samples were loaded and the columns were washed with $6 \mathrm{~mol} L \mathrm{LCL}$ for $30 \mathrm{~min}$. Copper was eluted with $2.5 \mathrm{~mol} / \mathrm{L} \mathrm{HCl}$, dried down under a hot lamp and made up for MS-ICP-MS analysis in $2 \%$ ultra pure $\mathrm{HNO}_{3}$.

Stable copper-and zinc isotope ratios were determined using a MC-ICP-MS combined with a Cetac "Aridus" desolvator at the Institute of Food Research (Norwich, UK). The samples were run with bracketing standards and instrument blanks. For correction of instrumental mass bias a simple linear correction between sample and bracketing standards was applied. For reference copper NIST 976 (certified for isotopic composition, was used in the Cu analysis. For zinc, Spectrosol. (BDH, Poole, UK) was used for reference in absence of a certified isotopic standard and the $\mathrm{Zn}$ isotopic composition was assumed to be the average natural composition as defined elsewhere (Rosman \& Taylor, 1998).

The external reproducibility of the calculated $\mathbf{Z n}$ isotope enrichment, based on the isotopic variation in the baseline urine samples, was $0.6,4.9$ and $10.1 \%$ for the 66:64, 67/64 and 70/64 isotope ratios respectively. The extemal reproducibility of the calculated copper isotope enrichment, based on the baseline ileostomy effluent samples, was $4.0 \%$.

\section{Calculations}

\section{Zinc absorption}

The mass spectrometric ratios of the urine samples, measured by the MC-ICP-MS, were converted into mole fractions of recovered dose (oral and iv) using the equations set out in Lowe et al (Lowe ef al., 1997). It was assumed that 48 hours after dose administration, the zinc from the oral and IV doses would have equilibrated and thereafter any 24 hour pooled sample would be adequate to calculate the true zinc absorp. tion of the oral dose. Thus, for the second 24 -hour sample $(t=48 \mathrm{~h})$ this is given by:

True Absoption $(t=48 h)=\frac{\text { mole fraction arit }}{\text { mole fraction } w} \cdot \frac{\text { dose } w}{\text { dose aral }}$

Where "mole fraction wal" $^{\text {and }}$ "mole fraction" are the mole fractions of the oral and IV doses (respectively) from a single 24-hour pooled urine sample collected at least 48 hours post dose. Also, "dose orat and "dosew" are the quantities of labelled zinc given as oral and IV doses. 
This can obviously be repeated for all subsequent 24 -hour samples $(t=72 \mathrm{~h}, 96 \mathrm{~h}, 120 \mathrm{~h}$, $144 \mathrm{~h}, 168 \mathrm{~h})$. The final true absorption value can then be calculated as the mean of these six values.

\section{Copper absorption}

Since copper only has wo stable isotopes, faecal monitoring is the method used to calculate the apparent absorption. The details of this are contained in a separate publication (Harvey el al, 2002). Briefly, the following formula was used:

Apparent Absorption $=\frac{\text { dose onal }- \text { recovered oral }}{\text { dose oral }}$

Where, "recovered and "dose oral" is the quantity of copper found in the oral dose.

\section{Exchangeable Zinc Pool (EZP)}

This method is based on the technique developed by Miller et al (1994). It is assumed that the endogenous zinc contained in the pool exchanges with any newly absorbed zinc in the plasma within 2 days. As mentioned previously, it is possible to use the mass spectrometer ratios to calculate the mole fractions of the individual sources of zinc in the study. These are the oral and $N$ tracers and the naturally abundant (NA) tracee. Enrichment in any particular urine sample is defined as the ratio of the mole fraction of zinc from the IV source (mole fraction, ) to the mole fraction of zinc from the NA source (mole fraction $\operatorname{Nin}_{\text {in }}$ ).

Enrichment $=\frac{\text { mole fraction } \mathrm{N}}{\text { mole fraction } \mathrm{NA}}$

By plotting the natural logarithm of this ratio against time (for $1>48$ hours), fitting a straight line through the data and extrapolating back to $t=0$, the size of the EZP can be obtained. This assumes that the entire IV dose was equilibrated in the EZP instantane. ously and that extrapolation back to $=0$ compensates for any loss of $1 \mathrm{~V}$ cose from the EZP.

\section{Statistics}

Exchangeable zinc pool, zinc and copper absorption during the three different interventions were compared with ANOVA for repeated measures. Differences were regarded as statistical significant if $P<0.05$. Statistically significant results were further analysed using Scheffé post hoc tests $(P<0.05)$. Statistics were computed using the Statview 5.0 software package for the Macintosh.

\section{Results}

All volunteers had normal iron status; the average serum ferritin was $117.1 \pm 85.4$ $\mu \mathrm{g} / \mathrm{L}$, blood haemoglobin was $9.5 \pm 0.7 \mathrm{mmol} / \mathrm{L}$ and blood haematocrit was $44.2 \pm$ $3.3 \mathrm{~L} /$, whereas $C$-reactive protein was below $9 \mathrm{mg} / \mathrm{L}$ in all volunteers. 
The size of the total exchangeable zinc pool was $126 \pm 28,120 \pm 27$ and $19 \pm 35$ mg on the day of ingestion of 0,100 or $400 \mathrm{mg}$ iron respectively. No statistical significance in EZP was observed between any of the experimental days.

All subjects completed the intervention study. The data from one volunteer for one experimental day were withdrawn from further analyses due to contamination of the samples.

True zinc absorption, calculated from urinary zinc isotope excretion. was significantly lower in the presence of 100 and $400 \mathrm{mg}$ iron compared to the zinc absorption in the absence of iron taverage \pm sd zinc absorption was $26.4 \% \pm 14.4,22.9 \% \pm 6.4$ and $44.5 \% \pm 22.5$ of the administered dose respectively; $P<0.05 \%$. Zinc absorption did not differ between the 100 - and $400 \mathrm{mg}$ iron intervention (Figure 1).

Apparent copper absorption was $47.8 \% \pm 13.6,54.1 \% \pm 26.1$ and $52.8 \% \pm 7.3$ of the administered dose (average $\pm \mathrm{sd}$ ) in the presence of 0,100 or $400 \mathrm{mg}$ irom as ferrous guconate respectively. No significant differences were observed between any of the interventions (Figure 2).

Figures 1 and 2. Zinc and copper absorption
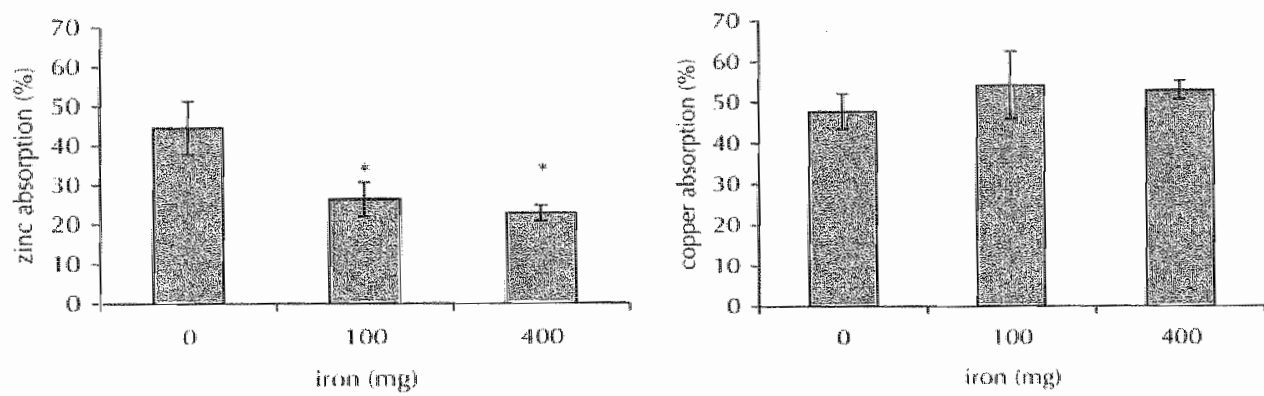

True zinc absorption and apparent copper absorption from a water solution conaining 12 mg zinc and

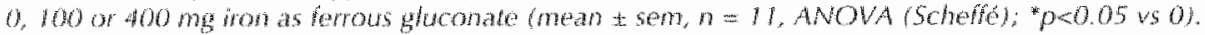

\section{Discussion}

The present study clearly shows that iron supplements decrease zinc absorption when given in an aqueous solution. The marked drop in zinc absorption in the presence of 100 and $400 \mathrm{mg}$ iron as ferrous gluconate shows that chronic oral iron supplementation increases the risk of developing or maintaining zinc deficiency. Previous studies have shown that iron, zinc and copper compete for absorption if given as an aqueous solution (Sandström et al., 1985; Valberg et at, 1984). However, this was not the case when iron and zinc were given with a meal, although data from different studies are equivocal (Davidsson ef al., 1995; Sandström et al, 1985; Sheldon et al, 1985; Valberg et al., 1984). 
The earlier supplementation studies warrant further investigation of iron-, zinc- and copper absorption interactions in vivo in humans (Sandström, 2001). In the present study we used a validated and accurate in vivo model to assess zinc and copper absorption and at the same time measured the exchangeable zinc pool as a meaningful indicator of zinc status.

During the 24 hours ileostomy effluent collection period, zinc isotopes were excreted into the ileostomy effluent. This zinc was not only the unabsorbed fraction of stable isotope-labelled zinc that was administered via the test meal but also absorbed zinc isotopes, which were rapidly re-excreted in the intestinal fumen. Calculation of zinc absorption from zinc isotopes enrichment in ileostomy effluent would therefore have caused underestimation of zinc absorption. To avoid this problem, zinc absorption was determined using urinary excretion of stable zinc isotopes.

The observed effect of iron on zinc absorption may deteriorate zinc status. Zinc deficiency is associated with an impaired immune function, growth, appetite and wound healing and mucosal dystrophy. The absence of a dose-response relationship between the two iron dosages indicates that the mechanism by which iron and zinc compete for absorption seems to be saturated by ingestion of $100 \mathrm{mg}$ of ferrous iron.

The low, $100 \mathrm{mg}$ iron dosage is medically used as an oral supplement in the treatment of iron deficiency anaemia, whereas the amount of zinc present in the test drink equals the average habitual daily intake of zinc and is also present in comparable quantities in food supplements. The high, $400 \mathrm{mg}$ iron dosage is occasionally prescribed for rapid oral iron replenishment therapy.

The interaction between iron and zinc absorption may be explained by competitive binding to the transporter protein Divalent Metal Transporter 1 (DMTI, formerly called DCT1 or Nramp2) located at the apical membrane in the small intestine, or by an iron-induced decrease in expression of DMT1. Although the exact mechanism of iron absorption is still under investigation, it is clear that DMT1-mediated iron transfer accounts for most iron absorption from the intestine (Andrews, 1999; Gunshin et al, 1997). After reduction by a ferric reductase, ferrous iron crosses the apical membrane of the gut by binding to DMT1. Furthermore, DMT1 also transports other divallent cations such as zinc and copper (Andrews, 1999; Gunshin et al, 1997). Its expression is regulated by the iron concentration in epitheliall cells of the small intestine (frazer et al. 2003; Moos, Trinder \& Morgan, 2002). A decrease in DMT1 expression may have caused the observed decrease in zinc absorption. It is, however, not likely that a single dose of iron significantly affects DMT1 expression in the proximal small intestine where most iron absorption takes place, especially considering the relatively short transit period of this segment of the intestine. Furthermore, recent data suggest that the shared absorption pathway for iron and zinc is distinct from binding to DMT1, allthough the actual absorption mechanism remains to be elucidated (Yamaji et al., 2001). However, in that study, using Caco-2 cells, the effects of 50 and $100 \mu \mathrm{M}$ iron respectively on zinc absorption were investigated, in contrast to the millimolar iron concentrations, which were applied in the present study. Because different absorption routes may be involved in the presence of higher iron concentrations, the data from the in vitro study may not fully apply to the present in vivo investigation. 
We showed competitive absorption of ron and zinc. The data show that zinc uptake in the human small intestine is not solely dependent on an absorption route that competes with iron. This confirms data from previous in vitro studies that identified several specific zinc transporters, which may serve an important role in mediating zinc absorption from the gut lumen (Cragg et al., 2002; Lioumi et al., 1999). Future research is needed to identify functional zinc transporters in the brush border membranes in humans.

The absence of a dose-response relation between the two iron dosages suggests that the mechanism by which iron and zinc compete for absorption is saturated by ingestion of $100 \mathrm{mg}$ of ferrous iron.

The presence of a feedback mechanism of zinc status mediating zinc absorption, as is the case for iron, is speculative but may indeed be present. Zinc status may change within days as a result of the diet consumed. Therefore, in the present study all subjects were instructed to maintain and record their habitual diet during the three days prior to and on the first test day and to repeat the same diet during the following two test periods to minimize confounding effects of zinc status on zinc absorption. Zinc status was assessed by measuring EZP which provides an accurate, validated indicator of zinc status (Miller et al, 1994). This indicator of zinc status was the same at each lest period. Hence, the results of the present study were not affected by changes in either zinc status. Iron status was assessed at the start of the first experiment. It was assumed that iron status does not change within a few weeks provided the same habitual diet is consumed.

It may be concluded that zinc absorption is impaired by botth the low and the high dosage of iron. The absorbed zinc fraction in the iron intervention experiments was transported from the gut lumen by mechanisms, which do not compete with iron.

Previous human and animal studies have shown that increased iron intake is associm ated with decreased serum copper levels and the corresponding activity of cuproenzymes. Animal studies provide indications of competitive absorptive mechanisms for of iron and copper. Moderate iron supplementation results in decreased copper levels and copper absorption in rats (Yu et al., 1995). In pregnant rabbits with marginal Cu intake, high iron intake resulted in a very severe Cu deficiency, which causes serious probllems for the neonate. In humans, iron-folate supplements decreased copper status (Bums \& Paterson, 1993), whereas zinc supplementation lowered iron and copper status in adult females(Yadrick, Kenney \& Winterfeldt, 1989). These studies do not provide direct proof for nutrient absorption interactions in the intestine. In the presert study, we showed that iron administration does not inhibit copper absorption. This finding is supponted by a previous study in Caco-2 cells. It was shown that copper uptake is not merely mediated by DMT1, but that another mechanism must be involved in copper uptake (Arredondo, Uauy \& Gonzalez, 2000). Recently, a newly discovered human copper transporter (hCirl) was identified and characterized (Lee et al., 2002). This protein serves an important role in cellular copper uptake from the plasma, and may also prove to be important in copper absorption from the intestine. However, the exact mechanism of copper absorption in humans remains to be elucidated. 
Copper absorption was determined in the present study by the assessment of the intake/output balance of copper isotopes. It was not possible to apply the technique of urinary isotope excretion to measure copper absorption as was applied for calculation of zinc absorption because copper only has two stable isotopes forms, which disables the intravenous administration of a third stable copper isotope. Furthermore, a relation between urinary copper excretion and copper absorption or copper status thas not been established. The results of the present study show that "despite previous findings, the DMT1 route is not a rate limiting factor in copper absorption in wivo in humans. This confirms an important role for other copper trans-porters such as hCir 1 in the small intestine.

The ileostomy patients recruited for participation had a normal functioning small intestine, as shown by normal serum C-reactive protein concentrations and medical interviews. Iron-, zinc- and copper absorption mainly takes place in the small intestine. The ileostomy model provides an accurate model to determine true absorption of nutrients (Konings et al., 2002; Langkilde et al., 1990). It guarantees full test meal recovery, whereas complete faecal collection is often problematic in healthy volunteers. Unfortunately, it cannot be applied to estimate zinc absorption, owing to an unknown rate of re-excretion of absorbed stable zinc isotopes, as mentioned above.

We conclude that therapeutic amounts of iron inhibit zinc- but not copper absorption in the human small intestine. Iron supplements may impair zinc status, especially in populations with inadequate dietary micronutrients intake. This should be taken into careful consideration when micronutrient supplements are indicated. 


\section{References}

Allen, L.H, (1994): Nutritional infuences on linear growth: a general review Eur ) Chin Nutr 48 Suppl 1: $575-89$.

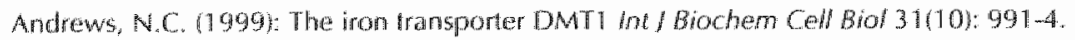

Arredondo, M., Uauy, R. \& Gonzalez, M. 2000): Regulation of copper uptake and transport in intestinal cell monolayers by acute and chronic copper exposure Biochim Biophys Acta 1474(2): 169 76.

Burns, ). \& Paterson, C.R. (1993): Effect of iron-folate supplementation on serum copper concentration in late pregnancy Acta Obstel Gynecol Scand 72(8): 6! 6-8.

Cragg, R.A. Chrstie, G.R., Phallips, S.R, Russi, R.M., Kury, S. Mathers, I.C., Taylor, P.M. \& Ford, D. 2002\%: $A$ nowel zinc-reguated human zinc transporter, hZTLT, is localized to the enterocyte api. cal membranes Biol Chem 277(25): 2278997.

Davidsson, L. Almgren, A, Sandström, B. Q Hurrell, R.F. (1995): Zinc allasorption in adult humans: the effect of iron fortification Br / Nutr 74(3):417-25.

Dawson, E.B., Albers, 1. \& McGanity, W.J. (1989). Serum zinc changes due to iron supplementation in teen-age pregnancy Am / Clin Wut 50(A): $848-52$.

Donangelo, C.M., Woodhouse, L.R. King, S.M. Viteri, F.E. \& King, J.C. (2002): Supplemental zinc lowers measures of iran status in young women with low iron reserves / Nutr 132(7): 1860-4.

Frazer, D.M., Wilkins, S.I., Becker. E.M. Murphy, T.L., Vulpe, C.D., Mckie, A.T. \& Anderson, G.I. (2003): A rapid decrease in the expression of DMT1 and Dcytb but not Ireg or thephaestin explairs the nucosal block phenomenon of iron absorption Gut 526): 340-6.

Gunshin, H., Mackenzie, B., Berger, U.V., Gunshin, Y., Romero, M.F., Boron, W.F., Nussberger, S., Gollan, J.L. \& Hediger, M.A. (1997): Cloning and characterization of a mammalian protoncoupled metal-ion transporter Narure 388(6641): 482-8.

Harvey, L.J. Majsak-Newman, G., Dainty, J.R., Whart, S.G., Reid, M.D., Beattie, I.H. \& FairweatherTait 5.). (2002): Holmium as a faecal marker for copper absorption sfudies in adults Chin SCi $102(2): 23340$.

Konings, E.J., Troosh, F.J. Caslenmiller, J.1. Roomans, H.H., Van Den Brand, P.A. R Saris, W.H. (2002): Intestinal absorption of different types of folate in heafliy subjects with an illeostomy Br J Nuts Ba(3): $235-42$.

Langkilde, A.M., Anderson, H., Schweizer, T.F. \& Tordottir, 1. (1990): Nutrients excreied in leostomy affluents after consumption of mixed diets with beans or potatoes. I. Minerals, protein, fat and energy Eur / Clin Nut 44(8): 559-66.

Lee, J., Pena, M.M. Nose, Y. \& Thiele, D.J. 2002): Biochemical characterization of the human copper transporter Cut / Biol Chen 27.76): 4.380-7.

Lisumi, M., Ferguson, C.A., Sharpe, P.T., Freeman, T, Marenholz, 1., Mischke, D., Heizmann, C. \& Ragoussis, I. (1999): Hsolation and characterization of tuman and mouse ZIRTL, a member of the IRTI family of transporters, mapping within the epidermal differentiation compllex Genomics 62(2): 272-80.

Lowe, N.M. Shames, D.M. Woodhouse, L.R., Matel, 1.S., Roehl, R., Saccomani, M.P., Tofiolo, G., Cobelli, C. \& King, I.C. (1997): A compartmental model of zinc metabolism in healthy women using orat and intravenous stable isotope tracers Am/ Clin Nutr 65(6): 1810.9. 
Miller, L.V., Hambidge, K.M., Naake, V.L. Hong, Z, Westcott, J.L. \& Fennessey, P.V. (1994): Size of the zinc pools that excliange rapidly with plasma zinc in humans: alternative techniques for measuring and relation to dietary zinc intake / Nutr 124:(2): 268-76.

Moos, T. Trinder, D. \& Morgan, E.H. (2002): Effect of iron status on DMT1 expression in duodenal enterocytes from beta2-microglobulin knockout mice Am / Physiol Gastromest Liver bhysiof 283131: G687-94.

Rosman, K. \& Taylor, P. (1998): Isotopic compositions of the elements 1997 Pure \& Applied Chemismy $70: 217-235$.

Sandströn, B. (2001): Micronutrient interactions: effects on albsorption and bioawailability Be / Nutr 85 Suppl 2: S181-5.

Sandström, B., Davidsson, L., Cederblad, A. \& Lönnerdal, B. (1985): Oral iron, dietary ligands and zinc absorption / Nutr 115(3): 411.4 .

Sheldon, W.L., Aspillaga, M.O., Smith, P.A. \& Lind, T. (1985): The effects of oral iron supplementation on zinc and magnesium levels during pregnancy $B_{5} /$ Obstet Cynaecol 92(9):892-8.

Simmer, K. \& Thompson, R.P. (1985): Maternal zinc and intratterine growth retardation Clin Sci 68 (4): $395-9$.

Snedeker, S.M. \& Greger, J.L. (1983): Metabolism of zinc, copper and iron as affected by dietary prom tein, cysteine and histidine / Nutr 1130): 644-52.

Solomons, N. \& Ruz, M. (1997): Zinc and iron interaction: concepts and perspectives in the develop ing world Nutrition Research 17(1): 177-185.

Valberg, L.S. Flanagan, P.R. \& Chamberlain, M.J. (1984): Eüfects of iron, tin, and copper on zinc absorption in humans $A m$ / Clin Nutr 40(3): 536-41.

Whitaker, P. (1998): Iron and zinc interactions in humans Am / Chin Nutr 6822 Steppll: 442S-4465.

WHO (1999): Prevention and Control of Iron Deficiency Anaemia in Women and Children. In Report of the UNCEF/WHO Regional Consultation edited, Geneva, Switzerland.

Yadrick, M.K., Kenney, M.A. \& Winterfeldt, E.A. (1989): Iron, copper, and zinc status: response to supplementation with zinc or zinc and iron in adult females Am / Clin Nut 49(1): 145-50.

Yamaji, S., Tennant, I., Tandly, S., Williams, M. Singh Srai, S.K. Sharp, P. (2001): Zinc regulateg the function and expression of the iron transporters DMTI and IREG1 in human intestinal Caco-2 cels FEBS LetI $507(2): 137-41$.

Yu, S., Beems, R.B., Joles, J.A., Kaysen, G.A. \& Beynen, A.C. (1995) Iron and copper metabolism in analbuminaemic rats fed a high-iron diet Comp Brochem Phystof A Physiol 110(2): $131-8$. 


\section{CHAPTER 6}

\section{GASTRIC DIGESTION OF BOVINE LACTOFERRIN IN VIVO IN ADULTS}

Freddy J Troost, Jan Steijns, Wim HM Saris, Robert-Jan M Brummer

The Journal of Nutrition, $2001 ; 131(8): 2101-4$ 


\section{Abstract}

Background Lactoferrin, an iron-binding glycoprotein present in milk and other endocrine and exocrine secretions, may exert a number of physiologic effects in the intestine. To study the effects of oral lactoferrin supplementation in vivo in the gastrointestinal tract, information about the gastric survival of lactoferrin in vivo is of importance. Design We tested twelve healthy volunteers (age $21 \pm 0.3 y$ ) on three separate days according to a randomized cross-over design. A test drink containing $4.5 \mathrm{~g}$ of bovine lactoferrin (20\% iron saturated; apoLF) in the presence of a gastric pH buffer $(0.1$ mol/L sodiumcitrate / citric acid) (apoLFbufl, apoLF without the buffer (apoLF) or ironsaturated lactoferrin (holot.F) was administered into the stomach using nasogastric intubation.

Results Gastric emptying rate, determined by a marker dilution technique, did not differ between any of these drinks. Substantial gastric survival of lactoferrin, analyzed by gelpermeation chromatography under denaturing conditions, was observed after ingestion of all test drinks $(64 \%, 62 \%$ and $79 \%$ of the lactoferrin in the apoLfbuf, apoLF and holoLf test drink respectively survived gastric transit). Addition of the gastric $\mathrm{pH}$ buffer resulted initially in a lower intragastric $\mathrm{pH}$ because of its hydroxide buffering effect. However it failed to elevate intragastric $\mathrm{pH}$ during a prolonged period of time in order to inhibit intragastric lactoferrin breakdown.

Conclusion We conclude that, after oral administration, a substantial amount of apoLfF and holoLF survives gastric transit. 


\section{Introduction}

Lactoferrin is a protein of the transferrin family. It is present in milk, saliva, tears, bile,

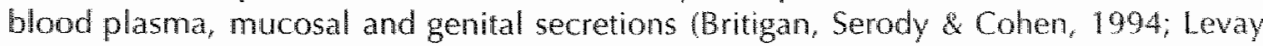
\& Viljoen, 1995). Lactoferrin is able to bind ferric iron ( $\mathrm{Fe}^{3+}$ ) with a high affinity, even in an acidic environment (Anderson et al., 1989; Lonnerdal \& lyer, 1995). Because of this strong iron binding capacity, a number of physiologic effects have been pioposed, as reviewed extensively by several investigators (Baker et al., 1991; Iyer \& Lönnerdal, 1993; Levay \& Viljoen, 1995; Lönnerdal \& lyer, 1995).

Lactoferin is proposed to act as an antioxidative (Baldwin, Jenny \& Aisen, 1984: Da vidson \& Lönnerdal, 1989; Gutteridge et al., 1981). Iron bound to lactoferrin may not be able to catalyze Fenton chemistry. This however has not yet been investigated in wivo. Lactoferrin is also involved in the immune system of the body. It is released by neutrophil specific granules (Davidson \& Lönnerdal, 1989). Other cells of the immune system, macrophages and monocytes, can bind lactoferrin by specific lactoferrin receptors on their cell surfaces which enables the presence of lactoferrin at sites where the immune system is active. Several studies were able to show a regulatory function of lactoferrin on interleukin-6 and tumor necrosis factor alfa in wivo in mice (Machnicki, Zimecki \& Zagulski, 1993; Zimecki et al., 1998). Also, lactoterrin was shown to exert antibacterial activity in vivo (Zagulski et al, 1998a; Zagulski et al., 1998b) in mice and recently lactoferrin ingestion with food was shown to facilitate demophylosis cure in guinea pigs (Wakabayashi et al., 2000). Lactoferrin is proposed to serve a role in facilitating iron absorption from the gut by a mechanism, which is still poorly understood. Previously, both a facilitating effect (McMillan, Landaw \& Oski, 1976) and an inhibitory effect (Vet \& Gool, 1974) of lactoferrin on iron absorption were described. These findings indicate that lactoferrin supplementation may be of value in patients prone to intestinal damage, such as people undergoing oral iron therapy, patients with Inflammatory Bowel Disease or patients suffering from intestinal stress in general.

The effects of oral lactoferrin supplementation could be potentially diminished tio a certain extent by gastrointestinal breakdown of the lactoferrin molecule. It is not known to what extent lactoferrin is digested in the stomach or in the intestinc in vivo. In vitro incubation of lactoferrin with proteolytic enzymes results in the formation of several lactoferin fragments. It was shown that lactoferrin is less rapidly digested in gastric juice than casein and transferrin in an acidic environment (Britton \& Koldovsky, 1989). An important factor interfering this degradation process is the degree of iron saturation of the lactoferrim. Apolactoferrin, with an iron saturation of apm proximately $20 \%$, is more easily digested than hololactoferrin $1100 \%$ iron saturated) (Brines \& Brock, 1983; Brock et al., 1976). As the biological activity of lactoferin is located in the intestine it is necessary to look at survival of the molecule during passage through the stonach.

The present study was designed to study the exttent of gastric degradation of lactoferrin in vivo. Also, the effect of buffering gastric $\mathrm{pH}$ on possible breakdown of lactoferrin was studied. 


\section{Methods}

\section{Subjects}

Twelve healthy volunteers ( 5 males, 7 females, age $21.3+0.3$ ) without a history of gastrointestinal complaints were recruited for this study. All subjects received full information about the protocol and gave their written informed consent before particim pation. This study was approved by the Ethics Committee of Maastricht University, Maastricht, The Netherlands.

\section{Study design}

Subjects were tested acconding to a randomized cross-over design with a washout period of at least 7 days. On the evening prior to testing, all subjects were instucted to consume a standardized meal ad libitum (rice and sweet/sour sauce, Uncle Ben, The Netherlands). After an overnight 12 hours fasting period, subjects arrived at the laboratory. Subjects remained seated until the end of the experiment.

After arrival, a nasogastric tube was inserted. Vila the nasogastric tubing, the stomach was emptied and rinsed with water until no further residue was obtained. A recovery test was done for control of the tube tip position (Hassan \& Hobsley, 1970). Forty-five minutes after gastric aspiration, a liquid test drink (composition described below) was administered in the stomach through the tube. Subsequently the double sampling technique determining gastric emplying rate of a test drink was applied. This method was described in detail previously (Beckers et al, 1988; Beckers et al., 1991; George, 1968). According to this technique, $188 \mathrm{mg}$ of the inert marker Polyethylene Gly col(PEG, PEG 4000, Sigma, Germany) was added to each test meal. After ingestion of the test drink, gastric content was mixed thoroughly by aspiration and reinjection of gastric content during 1 minute and $5 \mathrm{~mL}$ of gastric contents were sampled for meas. urement of tolal gastric content volume. At each 10 -min interval, $2.5 \mathrm{~mL}$ of the gastric content was aspirated, and $5 \mathrm{~mL}$ PEG solution $(6 \mathrm{~g} / 100 \mathrm{~mL}$ water was added to the gastric content via the nasogastric tube. Subsequenly, gastric content was mixed thoroughly, and $2.5 \mathrm{~mL}$ was aspirated. This protocol was followed at $10 \mathrm{~min}, 20 \mathrm{~min}$ and 30 min respectively after administration of the test drink. The PEG concentration before and after addition of the PEG solution was measured. From these data the total volume of gastric contents at each time point was calculated (George, 1968). Also, the amount of test meal sill present in the stomach and the amount of gastric secretion per 10 min intervals was calculated using calculations as described by Beckers at al. (Beckers et al, 1988). In the samples obtained at 10min intervals before adding the PEG solwtion, the amount of intact lactoferrin was determined as described below. After aspiration, each sample was put directly into liquid nitrogen and stored at - $80^{\circ} \mathrm{C}$ until analysis to stop degradation processes after sampling.

\section{Test drinks}

Three test drinks were investigated in a randomized cross-over order. Each beverage consisted of a $300 \mathrm{~mL} 80 \mathrm{~g} / \mathrm{L}$ maltodextrin $M$ MD20, AVEBE, Veendam. The Nether. lands) solution in water with $4.5 \mathrm{~g}$ bovine lactoferrin (LF) (DMV international, Veghel, 
The Netherlands) dissolved. The lactoferrin had an iron saturation degree of approximately $20 \%$ (apolactoferrin) and $100 \%$ (hololactoferrin) respectively. Apolactoferrin was ingested on two occasions. Once without a buffer and once in the presence of a citrate buffer in order to buffer gastric $\mathrm{pH}$. The citrate buffer was made by mixing 0.1 mol/ $L$ citric acid monohydrate with $0.1 \mathrm{~mol} / \mathrm{L}$ trisodiumcilrate dihydrate in a volume ratio of $56: 44 \mathrm{~mL} / \mathrm{L}$ test drink respectively. Citric acid was purchased from Merck (Darmstadt, Germany), trisodiumcitrate was purchased from Ferak (Berlin, Germany).

\section{Analytical methods}

PEG concentration in the gastric juice samples was determined spectrophotometrically using a spectronic 1001 device (Bausch en Lomb, Bergen op Zoom, the Nethelands). Carbohydrates and proteins were removed by precipitation. In the test drinks and in each sample $\mathrm{pH}$ was measured using a standard $\mathrm{pH}$ analyzer (radiometer, Copenhagen, Denmark).

A new method was developed and validated to measure LF and LF digestion fragments in gastric samples. This method uses gell permeation chromatography under denaturing conditions. We found that LF degradation may proceed on the column in samples containing a relatively large proportion of gastric juice compared to residual test drink. When the sample contained more than $50 \%$ gastric juice, the elution from the column had to occur within 5 hours to prevent LF degradation by gastric pepsin at the low $\mathrm{pH}$ of the elution buffer.

Sample pretreatment: $100 \mu \mathrm{L}$ gastric juice or LF standard are mixed with $450 \mu \mathrm{L} 8 \mathrm{M}$ urea (Merck, Germany), $\mathrm{pH}$ 8.5. After solubilization $450 \mu \mathrm{L}$ of a mixture of $\mathrm{H}_{2} \mathrm{O} /$ acetonitrile/trifluoroacetic acid ( $600 / 400 / 1 \mathrm{v} / \mathrm{v}$ ) is added. The resulting solution is then filtered over $0.2 \mu \mathrm{m}$ PVDF filter (Gelman Sciences). $20 \mu \mathrm{L}$ is subsequently applied to the column (Shodex KWV-803; Showa Denko) and eluted with the mixlure of water/acetonitril / TFA in 25 min at a flowrate of $0.6 \mathrm{~mL} / \mathrm{min}$ (Pharmacy / LKB HPLC). Proteins and peptides are detected at $220 \mathrm{~nm}$. Intact LF elutes after about $11 \mathrm{~min}$, whereas LF fragments elute later. Calibration of counts for intact LF was done with concentrations between 1.3 and $13 \mathrm{mg} / \mathrm{mL}$ and a straight line was obtained. Lactoferrin fragments between 9 and $80 \mathrm{kDa}$ fitted a straight line obtained with protein $\mathrm{MW}$ markers (LF, BSA, B-lactoglobin, o-lactalbumin and glycomacropeptide).

\section{Calculations}

Calculations of gastric emptying and secretion rates were based on the formulas proposed by Beckers et al. Beckers et al., 1988). For these calculations, PEG concentrations in the gastric juice samples were used to determine gastric content wolume at each time point and gastric secretory rate at 10 -min intervals. A gastric emptying curve was constructed according to a non-linear regression formula using specialized softwane (GraphPad Prism, San Diego, USA). From this curve, gastric emptying half time of the test drink was determined.

The amount of intact lactoferrin entering the intestine was determined by calculating the area under the curve (AUC) of the gastric emptying curve and gastric lactoferrin 
concentration. The AUC of the gastric emptying curve was considered to represent emptying of the ingested amount of $4.5 \mathrm{~g}$ lactoferrin into the small intestine. Hence, gastric lactoferrin breakdown was calculated by subtracting the AUC of lactoferrin breakdown from the AUC of the gastric emptying curve. Lactoferrin delivery to the intestine was calculated by subtracting the gastric lactoferrin breakdown from the ingested amount of $4.5 \mathrm{~g}$ lactoterrin.

\section{Statistics}

Differences in gastric emptying and in gastric pH were analyzed using oneway ANOVA for repeated measures with Scheffé post-hoc testing. Differences in lactoferrin appearance in the small intestine beween the three drinks were analyzed using ANOVA factorial analysis with the amount of lactoferin as the dependent variable, test drink as factor and volunteer as covariate. Differences were considered as being significant at the probability level of $\mathrm{P}<0.05$. All statistical analyses were carried out using Statview software (SAS institute, Cary, NC, USA)

\section{Results}

Gastric emptying rate is expressed as gastric emptying half time $\left(t_{1 / 2}\right)$ of the test drink. Gastric emptying half times were $6.79 \pm 2.36,8.46 \pm 4.07$ and $7.03 \pm 2.14$ min for apoLfbuf, apolf and holoLf, respectively (mean $\pm \mathrm{sd}$ ). Gastric emptying rate did not differ between any of the test drinks (One-way ANOVA).

The starting $\mathrm{pH}$ of the apolactoferrin test drink in the presence of the $\mathrm{pH}$ buffer was 5.95, the starting $\mathrm{pH}$ of the apolactoferrin solution without buffer was 7.12 and starting $\mathrm{pH}$ of the hololactoferrin solution without buffer was 7.10. Intragastric $\mathrm{pH}$ of the apolactoferrin solution with the citrate buffer during the period of testing was significantly lower directly after ingestion of the test drink compared to both the apo- and the hololactofermin solution without buffer. Ten minutes after ingestion intragastric pH was still lower following ingestion of the apolactoferrin solution with buffer compared to the hololactoferrin, but not compared to the apolactoferrin drink. Twenty and thirty minutes after administration, no differences were observed in intragastric pH between any of the test drinks. Also, no differences in $\mathrm{pH}$ were observed at any time between the non-buffered test drinks (Figure 1).

After 30 min, all test drinks were nearly completely emptied into the intestine. During this period 64,62 and $79 \%$ respectively of the lactoferrin present in the apolfbut. apolf and holotf test drinks entered the intestine in the intact form. No statistical differences in lactoferrin survival were observed between any of the test drinks although the hololactoferrin solution tends to be more resistant to degradation than the apolactoterrin solution $(\mathrm{P}=0.09$ ) (Figure 2 ). 
Figure 1. Acidity of gastric fluid

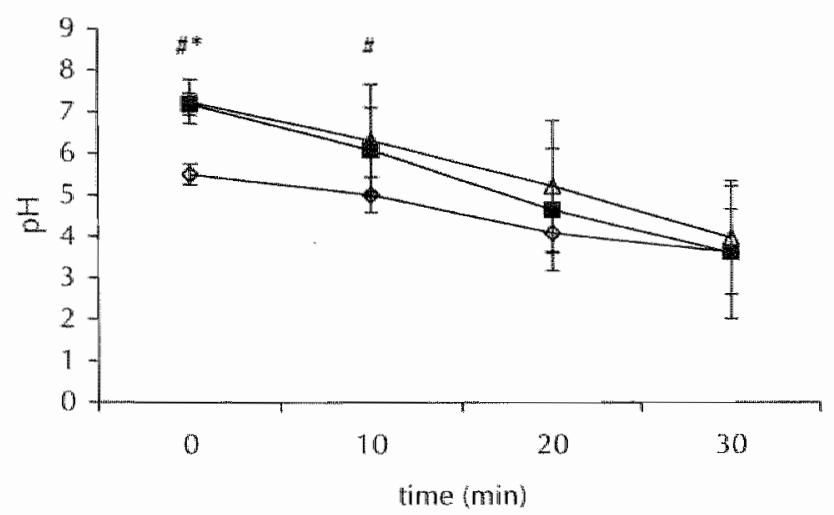

Intragastric $\mathrm{pH}$ after ingestion of $4.5 \mathrm{~g}$ bovine apolactoferm with citrate buffer $10 \%, 4.5 \mathrm{~g}$ bovine apolactolerrin without buffer (1) and $4.5 \mathrm{~g}$ bovine hololactofernin without buffer (A). All drinks cona ain $80 \mathrm{~g} / \mathrm{L}$ mathodextrin in $300 \mathrm{~mL}$ water. Values are means $+5 d, n=12 .{ }^{*} P<0.05$, drink 1 ws drink 2: \#P<0.05, drink 7 ws drink 3 .

Figure 2. Lactoferrin enptied from the stomach

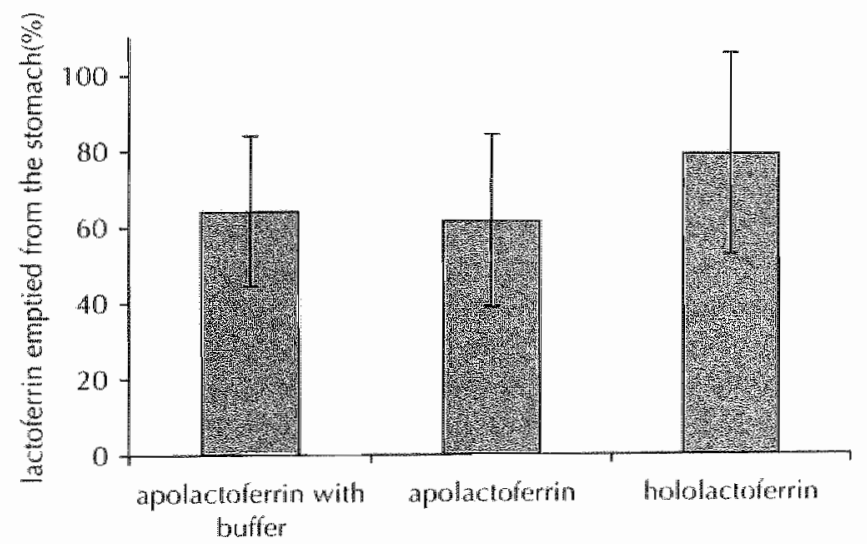

Total amount of intact bovine lactoferm emptied from the stomach, expressed as a percentage of the amournt of bowne lactoferm intragastrically achoinistered. Values are means $+5 d, n=12$ (all $n .5$. 


\section{Discussion}

All test drinks were emptied from the stomach at the same rate. Within about ten min half of all beverages was already emptied. Because of this rapid gastric emptying of the lactoferrin during which only a small portion of the lactoferrin was digested a significant amount of lactoferrin entered the small intestine in the intact form.

Irom binding was shown previously to stabilize the bovine and human lactoferrin molecule (Brines \& Brock, 1983; Brock et al., 1976), causing hololactoferrin to be less susceptible to degradation than apolactoferrin. This was shown after incubation with trypsin and chymotrypsin. We did not observe a significant difference in degradation rate between any of the test drinks although hololactoferrin tended to be more resistant to degradation then apolactoterrin $(P=0.09)$. This indicates that the observed difference in susceptibility lo degradation between apo- and hololactoferrin from these in vitro studies is not reflected in the same manner in our in wivo study of intragastric degradation of lactoferrin, in which pepsin probably is the major cause of LF degradation. One has to bear in mind that the apolactoferrin used in the present study was 20 $\%$ iron-saturated. Considering that iron binding to lactoferrin causes a diminished susceptibility of lactoferrin to digestion, apolactoferrin containing no iron may be digested in the stomach more rapidly than the apolactoferrin used in the present study.

Other investigations showed a minor degradation of lactoferrin both in vivo in the entire digestive tract in newborns (Spik et al., 1982) as well as ex vivo in gastric juice of preterm infants (Britton \& Koldovsky, 1989), although the latter study did show some degradation. In the present study we show partial lactoferrin degradation in the adult gastrointestinal tract in wivo.

Intragastric $\mathrm{pH}$ was higher during the first ten minutes after ingestion of both the apoand the hololactoferrin drink without citrate buffer compared to the apolactoferrin solution with addition of a $0.1 \mathrm{~mol} / \mathrm{L}$ sodiumcitrate buffer. The buffer was responsible for keeping intragastric pH relatively constant throughout the test. After twenty minutes, most of the citrate buffer was emptied from the stomach in concordance with the rest of the beverage, causing a decrease in buffering capacity and consequently intragastric pH was cletermined mainly by gastric acid secretion. From in witro work done at our lab we know that lactoferrin is resistant to degradation at a pH above 4 . We observed this in an experiment in which we incubated lactoferrin in gastric juice ex vivo. This can partly be explained by the previous finding that iron is released from lactolerrin at pH lower than 4.0 (Mazurier \& Spik, 1980). Iron is known to stabilize the lactoferrin molecule. Thus, iron release causes the lactoferrin molecule to be more prone to digestion (Brines \& Brock, 1983; Brock et al., 1976). Addition of the citrate buffer failed to prevent gastric breakdown of lactoferrin in the present study because the buffer was emptied before it could be effective in preventing further acidification of gastric contents. Athough gastric pH did not fall below 4.0 until the last 10 min of the experiment, when most of the test drink was already emptied from the stomach, we observed a considerable lactoferrin breakdown in the stomach. Hence, intragastric lactoferrin digestion in wivo occurs also at a $\mathrm{pH}$ higher than 4.0 . This indicates a difference between the results of in vitro and in wivo experiments. 
Intact lactoferrin. which has a size of approximately $79 \mathrm{kDa}$ consists of two lobes: the $\mathrm{C}$ - and the $\mathrm{N}$-lobe. Incubation of lactoferrin with pepsin leads to formation of a 39.5 KDa fragment, most likely the C-terminal half of lactoferrin (Bluard-Deconinck et al., 1978. After incubation of lactoferrin ex vivo in gastric juice of preterm infants, lactoferrin fragments of $33,34,41$ and $42 \mathrm{kDa}$ were formed, probably also representing half-molecules of the lactoferrin molecule (Britton \& Koldovsky, 1989). The $\mathrm{N}$ terminal half of lactoferrin was more prone to digestion by pepsin than the C-terminal half (Line, Sly \& Bezkorovainy, 1976). After incubation with pepsin, the remaining Cterminal half of the lactoferrin molecule still has iron-binding capacity. However, after incubation with trypsin and chymotrypsin wo fragments were obtained the $C$ terminal and the N-terminal half of lactoferrin (Bluard-Deconinck et at, 1978). Both of these lactoferrin fragments are still able to bind iron ions. In other studies, in witro incubation of lactoferrin with trypsin causes the lactoferrin molecule to break down to fragments with molecular sizes of $20,30,40$ and $50 \mathrm{kDa}$ (Legrand et al, 1990). Also, after lactoferrin ingestion in adult mice, lactoferrin fragments containing a peptide called lactoferricin were detected in the faeces of these mice. Lactoferricin, also formed after hydrolysis with pepsin, is a biological active component of the lactoternin molecule of approximately $3.2 \mathrm{kDa}$. It was shown to have bactericidal activity against gram-positive and especially against gram-negative bacteria (Bellamy et al., 1992; Yamauchi et al, 1993). The lactoferricin shows a stronger antibacterial activity than the intact lactoferrin molecule, indicating a functional role of gastric hydrolysis for optimal biological activity (Bellamy et al., 1992).

In our study we found lactoferrin fragments of several different sizes at ten minutes after ingestion of the test drinks. Most abundant were fragments with a molecular weight of 76 and $41 \mathrm{kDa}$, although we did not quantify these fragments. The presence of the $76 \mathrm{kDa}$ fragments indicated a rapid hydrolysis of small parts of the lactoferrin molecule. In the present study we did not regard lactoferrin molecules of $76 \mathrm{kDa}$ or smaller as being intact lactoferrin since any biological activity of intact lactoferrin may be different from the $76 \mathrm{kDa}$ fragments. The $41 \mathrm{kDa}$ fragment probably is the C. terminal half of the lactoferrin molecule. We did not examine the precise nature of the fragments. With radial immunodiffusion we established that, immediately afteir drinking the test drinks, the recovery of intact LF was $100 \%$ (data not shown).

When digestion of LF occurred, as evidenced from the HPLC pattern, we could demonstrate that LF fragments larger then $35 \mathrm{kDa}$ still were able to bind to the antibodies directed against the intact LF (data not shown).

One has to take into account that in this study LF was intragastrically administered and that $45 \mathrm{~min}$ before administration the stomach was rinsed. This was necessary for the protocol used to measure gastric emptying and tube tip control. During the 45 min before test drink ingestion subjects remained seated. Considering a nomal average gastric juice production of $1500 \mathrm{~mL} / \mathrm{day}, 45 \mathrm{~min}$ is sufficient to restore normal resting gastric juice volume of $50 \mathrm{~mL}$. Theoretically it is possible that orally administered lactoferrin is degraded differently from what we showed in the present study but we believe the protocol reflects the normal physiological digestive environment. 
A number of biological effects are attributed to lactoferrin such as an antioxidative (Baldwin et al, 1984; Davidson \& Lönnerdal, 1989; Gutteridge et al, 1981), an antiinflammatory, a bactericidal effect (Akin et al., 1994; Bellamy et al., 1992; Saito et al., 1994; Turchany, Aley \& Gillin, 1995; Yamauchi et al, 1993) and a facilitating role in iron absorption (McMillan et al. 1976). To exert these effects, lactoferrin or biologically active lactoferrin fragments must survive passage through the stomach. To our knowledge this is the first study to show that a major proportion of orally administered bovine lactoferrin to survive passage through the stomach in adults. Intragastric degradation is not significantly affected by the iron saturation of the lactoferrin molecule and addition of a citrate buffer did not influence breakdown either. These findings are essential in interpreting results of studies concerning biological effects of lactoferin in the gastrointestinal tract. 


\section{References}

Akin, D.T. Lu, M.Q., lu, S.I. Kendal, S., Rundegren, 1. \& Arnold, R.R. (1994): Bactericidal activity of different forms of lactoferrin Adv Exp Med Biol 357: 61-70.

Anderson, B.F., Baker, H.M. Norris, G.E., Rice, D.W. \& Baker, E.N. (1989): Structure of Human Lactoferrin: cfystallographic structure analysis and refinement at 2,8 A resolution !. Mol. Brol. 209: $711 \cdot 34$.

Baker, E.N., Anderson, B.F., Baker, H.M., Haridas, M., Jameson, G.B., Norris, G.E, Rumball, S.V. \& Smith, C.A. (1991): Structure, function and llexibility of human lactolerin int / Biof Macromol $13(3): 122-9$

Baldwin. D.A., lenny, E.R. \& Aisen, P. (1984): The effect of human serum transferrin and milk lactoferrin on hydroxyl radical formation from superoxide and hydrogen peroxide / Biol Chem 259021: $1339 \pi-4$.

Beckers, E.J, Rehrer, N.1. Brouns, F., Ten, H.F. \& Saris, W.H. 1988): Determination of total gastric volume, gastric secretion and residual meal using the double sampling technique of George Gut $29(12): 1725-9$

Beckers, E.J., Rehrer, N.J., Saris, W.H., Brouns, F., Ten, H.F. \& Kester, A.D. (1991): Daily variation in gastric emptying when using the double sampling technique Med Sci Sports Exerc 230101: 121022.

Bellamy, W. Takase, M., Yamatichi, K., Wakabayashi, H. Kawase, K. \& Tomila, M. (1992): Identification of the bactericidal domain of lactoferin Biochim Biophys Acta 1121(1-2): 130-6.

Bluard-Deconinck, J.M., Williams, J. Evans, R.W., van Snick, J., Osinski. P.A. \& Masson, P.1. (1978): Iron-binding fragments from the $\mathrm{N}$-terminal and C-terminal regions of human lactolerrin Biochemical Journal 171(2): $321-7$.

Brines, R.D. \& Brock I.H. (1983): The effect of trypsin and chymotrypsin on the in vitro antimicrobial and iron-binding properties of lactoferrin in human milk and bovine colostrum. Unusual resistance of human apolactoferrin to proteolytic digestion Biochim Biophys Acta 759(3): 229-35.

Britigan, B.E., Serody, 1.S. \& Cohen, M.S. (1994): The role of lactoferin as an anti-inflammatlory nolecule Adv Exp Med Bio: 357: 143-56.

Briton, J.R. \& Koldovsky, O. (1989): Gastric luminal digestion of lactoferm and transfervin by protern infants Early Hum Dev 19(2): 127-35.

Brock, Jitt. Arzabe, F., Lampreave, F. \& Pineiro, A. (1976): The effect of uppsin on bovine transterrin and lactorerin Biochm Bophys Acta $446(1): 214-25$.

Davidsom, L.A. \& Lönnerdal, B. (1989): Fe-saturation and proteslysis of human hactoforint offect on

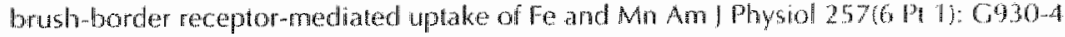

George, 1.D. (1968): New clinical method for measuring the nate of gastric emptying: the double sampling test meal cut $9(2): 237-42$.

Gutteridge, I.M., Paterson, S.K., Segal, A.W. \& Halliwell, B. (1987): linhibition of Lipid Peroxidation by the fron-Binding Protein Lactoferin Biochem-1 1990 (1):259-61.

Hassan, MA. \& Hobsley, M. (1970): Positioning of subject and of nasogastric tube during a gastric secretion study Br Med/ /(694): 458-60.

Wyer, S. \& Lomerdal, B. (1993): Lactofernin, lactoferrin receptors and iron motabolism fur / Clin Nim 47: $232-241$. 
Legrand, D. Mazurier, 1., Colavizza, D., Montreuil, I. \& Spik, $G$. 11990): Properties of the ironbinding site of the N-terminal fobe of human and hovine lactotransferrins. Importance of the glycar motety and of the nonwcovalent interactions between the $\mathrm{N}$ - and Coterminal lobes in the stability of the iron-binding site Biochem / 2662): $575-81$.

Lovay, P.F. : Viljoen, M. (1995): Lactolerin: a general review Haemotologica 80: $252-267$.

Line, W. Sty, D. \& Bezkorovany, A. 11976): Limited cheavage of human lactoterrin with pepsin Int I Biochent: 203-208.

Lönnerdal, B. \& Iyer, S. (1995): Lactoferrin molecular structure and biological function Annu Rev Nutr $15(93): 93-110$.

Machnicki. M., Zimecki, M. \& Zagulski, T. (1993) Lactofermin regulates the release of tumour necrosis factor alphia and interteukin 6 in wivo ho / Exp Pathol $74(5): 433-9$.

Mazurier, 1. \& Spik, 6 . 1930k: Comparative study of the iron-binding properties of human transferrins. 1. Complete and sequential iron saturation and desaturation of the lactotransterrin Biochion Biophys Acia 6290$)$ : $399-408$.

McMillan, I.A., Landaw, S.A. \& Oski, F.A. (1976): Iron sufficiency in breastfed infants and the availahilily of iron from human milk Pediatrics 58: 686-91.

Saito, H., Takase, M., Tamura, Y., Shimamura, 5. \& Tomita, M. (1994): Physicochemical and antibacterial properties of lactoferrin and its bydrolysate produced by heat treatment at acidic pH Ad' Exp Med Biof 357: 219-26.

Spik, G. Brunet, B., Mazunier-Dehaine, C, Fontaine, G. \& Montrewil, 1. (1982): Characterization and properties of the human and bovine lactotransferrias extracted from the faeces of newbom intants Acta Padedatr Scand 7l(6): 979-85.

Turchany, JAM., Aldy, S.B. \& Gillin, F.D. (1995): Giardicidal activity of hactolerrin and N-teminal peptides infect finmun $63(17): 4550-2$.

Vet, d.B.J.C.M. \& Gool, v.l. (1974): Lactoferin and tron Absorption in the Small Intestine Acta Med 5rand 196: $393-402$.

Walkabayasta, H., Uchida, K., Yamauchi, K., Teraguchi, S., Hayasawa, H. \& Yamaguchi, H. (2000): Lactoter in giwen in food facilitales dermatophylosis cure in guinea pig models/Antimicrob Chemothor $46441 ; 595-602$.

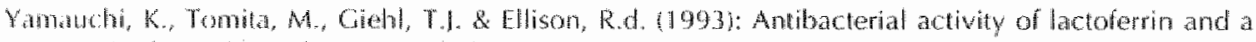

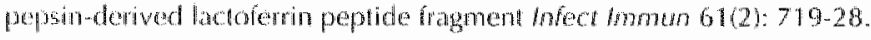

Zamulski, T., lanzabok, Z, Zagulska, A. \& Zimecki, M. (1998a): The main systemic, highty effective, and quickly acting antimicrobial mechanisms generated by lactoferrin in mammals in vivo. Activity in healh and disease Adv Exp Med Brol 443: 24750 .

Zagulski, T. Lipinski, Pr. Zagulka, A. \& barzabek, Z. (1998b): Antibacterial system generated by lacm foferrin an anice in wo is primarily a killing system /m / Exp Pathof 79(2): 117-23.

zimekk, M. Whaczoyk, A., Zagulski, T, \& Kubler, A. (1998): Lactoferrin lowers senum interleukin 6 and umor necrosis factor alpha levels in mice subjected to surgery Arch Immunot Ther Exp 462 ): $97-104$. 
CHAPTER 7

SURVIVAL OF ORALLY INGESTED HUMAN LACTOFERRIN AND ENDOGENOUS LACTOFERRIN SECRETION IN THE STOMACH AND SMALL INTESTINE IN VIVO IN WOMEN. A STUDY USING THE ILEOSTOMY MODEL

Freddy J Troost, Wim HM Saris, Robert-Jan M Brummer

The Journal of Nutrition, 2002; 132(9):2597-2600 


\section{Abstract}

Background Lactoferrin (I.F), a glycoprotein present in milk and other secretions, may provide a nutritional ingredient in the treatment of intestinal disorders associated with hyperpermeability, oxidative stress and inflammation. The aim of the study was to determine the survival rate of orally administered recombinant human lactoferrin (rthlF) in the upper Gl tract and in the small intestine in wivo in humans.

Design Eight female ileostomy patients (age 44,43-57 y) ingested a test drink containing $5 \mathrm{~g}$ thLF and collected full ileostomy output for $24 \mathrm{~h}$. Test drink passage was monitored using radio-opaque markers. Intact LF in ileal effluent was quantified by ELISA.

Results The entire test drink passed the small bowel during the 24 -h ileal effuent collection period. If was excreted at a low but constant rate $(0.35 ; 0.28-0.47 \mu \mathrm{g} L \mathrm{~F} / 2 \mathrm{~h})$. A correlation between gastrointestinal (Cil) passage of the test drink and LF excretion over time in ileal effluent was not observed. In total, a median amount of $4 \mu \mathrm{g} L \mathrm{LF}$ was excreted over the 24.h collection period whereas $5 \mathrm{~g}$ rhLF was ingested.

Conclusions Dietary rhLF is digested in the upper $\mathrm{G}$ tract and does not reach the colon. Intact LF appearing in illeostomy effluent is likely to originate from an endogenous source. 


\section{Introduction}

Lactoferrin (LF) is a protein of the transferrin family. It is present in milk, saliva, tears, bile, blood plasma, mucosal and genital secretions. LF is able to bind ferric iron $\left(\mathrm{Fe}^{3+}\right.$ ) with a high affinity at two different lobes. A number of physiologic effects are attributed to LF. Previous studies have shown bactericidal (Akin et al., 1994; Bellamy et al., 1992; Zagulski et al., 1998a; Zagulski et al., 1998b), anti-inflammatory (Nuijens, van Berkel \& Schanbacher, 1996), antiviral (lkeda et al., 2000; Murphy et al., 2000; Swart et al., 1998) and antioxidative properties (Baldwin, Jenny \& Aisen, 1984; Davidson \& Lönnerdal, 1989; Gutteridge et ai., 1981) of the LF molecule.

It has been suggested that LF has an anti-inflammatory potential. This effect seems to be partly mediated by attenuating TNF-alpha response (Crouch, Slater \& Fletcher, 1992). It is known that TNF-alpha is involved in the pathogenesis of inflammatory bowel disease (IBD) (Sandborn \& Hanauer, 1999). Hence, from a theoretical point of view, LF could be a potential anti-inflammatory agent in IBD. An anti-inflammatory effect would be expected after topical mucosal administration of the drug as in mesazaline- and controlled ileal released budesonide therapy.

It is not known to what extent LF is degraded in the gastrointestinal (G) thact in vivo in adults. Digestion may deteriorate bioactivity of LF in the intestine. Oral LF supplementation may provide a nutritional tool to improve gut health in humans. In this regard, the colon is of special interest. However, in order to exert any effects in the coIon, LF has to survive upper GI transit. If it is digested in the stomach or in the small intestine, LF degradation should be avoided by the use of ileal release capsules or by other ways such as administration via enemas when studying its effects in the colon.

We showed previously that LF is only partly degraded in the stomach in vivo in adults (Troost et al., 2001). The metabolic fate of orally ingested LF in the small intestine has not been investigated in vivo in adults previously. The present study aimed to determine the survival rate of orally administered recombinant human lactoferrin (rhLLF) in the upper $\mathrm{Gl}$ tract and in the small intestine in vivo in humans using the ileostomy model and to quantify the amounts of LF entering the colon in vivo. 


\section{Methods}

\section{Study 1. Lactoferrin supplementation}

\section{Subjects}

Eight female wolunteers with an ileostomy imedian age $44 ; 43-57$ y) participated in the study. In all wolunteers, a total colectomy was performed at least 3 years before parlicipation, enabling a steady state situation atter the initial adaptation phase to the colectomy. Volunteers with Crohn"s disease were only permitted to participate in the study if they had been in remission during the previous three years and if less than 7.5 $\%$ of the entire leum was removed during previous surgery. All volunteers were free of any medication and had no known abnormalities of the digestive system apart from the absence of the colon. All wolunteers were informed about the aims and the protocot of the study orally and in writing and signed a written informed consent before participation. The study was approved by the Ethics Committee of the University Hospital Maastricht (Maastricht, The Netherlands).

\section{Ditetary restriction}

Subjects were not allowed to consume any dairy products on the day prior to and on the day of the investigation to avoid dietary LF intake. All subjects had to consume a standardized diet on each occasion. During breakfast at 0800 h and during lunch at 1300 h at the day prior to testing bread rolls of any kind and non-dairy drinks were allowed ad libitum. Dinner at $1800 \mathrm{~h}$ consisted of prepared meals, mainly consisting of chow mein (Dinner 2 today, Bami Goreng. Honig, Koog a/d Zaan, The Netherlands). On the day of testing volunteers were not allowed to consume any food until breakfast at $1000 \mathrm{~h}$. Subsequently the diet was the same as described for the day prior to testing.

\section{Study design}

After an owernight fast subjects were admitted to the laboratory at $0800 \mathrm{~h}$. On four separate test days, subjects had to ingest a test drink containing $5 \mathrm{~g}$ rhLF (produced by Aspergillus Awamori, Agennix incorporated, Houston, USA) dissolved in $0.10 \mathrm{~L}$ demineralised water. Immediately after ingestion of the test drink, the stoma effluent bag was trashed as performed routinely. During the following $14 \mathrm{~h}$, all stoma effluent was collected by replacing the stoma bag at 2-h intervals. Each stoma bag had to be placed separately in a small plastic airtight box on dry ice. Stoma effluent was col lected every $2 \mathrm{~h}$ during daytime until $2200 \mathrm{~h}$. Subsequently, volunteers collected ileal effluent at $0300 \mathrm{~h}$ and at $0800 \mathrm{~h}$.

Twenty radio-opaque plastic pellets (Sizmarks $02 \mathrm{~mm}$, Konsyl Pharmaceuticals Inc. Fort Worth, TX) were added to the test drink. These inert pallets cannot be absorbed from the lumen and hence provide a marker for test drink recovery in the lleal effluent. 


\section{Measurements}

Atter collection, each ileostomy effluent sample was weighed to determine each 2 -h and total 24-h illeal effluent production. All samples were $X$-rayed to count the number of radio opaque pallets in each sample. These parameters yeld information regarding the Git transit of the test drink. In the lleostomy effluent samples, the amount of intact Lf was determined by enzyme-linked immunosonbent assay (Lactof-EIA, Biotech, Oxisresearch, Portland, Oregon). The coefficient of variation of repeated measurements of this assay was below $6 \%$ as measured in spiked ileal effluent samples. The sensitiviry of the assay was $1 \mu \mathrm{g} / \mathrm{L}$. Data were expressed as LF excretion over 2 -h periods.

\section{Study 2. Basal endogenous lactoferrin levels}

In an additional in vivo pilot experiment the endogenous LF excretion from the small intestine was investigated. On a separate day, four of the above mentioned volunteers collected ileal effluent during the last five $h$ of the night. Emptying of the ileostomy bag at approximately $0300 \mathrm{~h}$ is common practice for most ileostomy patients. Ileal effluent collection took place from approximately 0300 to $0800 \mathrm{~h}$. On the day prior to this collection, subjects consumed the same diet as during the first in vivo study. In a subsample of these ileal effluent samples, the LF concentration was measured by Flisa (see above).

\section{Statistics}

The amount of intact LF excreled in the ileal effluent during the 24-h period was expressed as LF excretion over 2 -h intervals. Differences were assessed using nonparametric statistics (Wilcoxon signed rank test, $P<0.05$ was regarded as statistically significant difference). The median (10-90 percentiles) illeal effluent production and LF excretion on each time point were calculated and presented by Box-and-Whisker displays.

\section{Results}

\section{Study 1. Lactoferrin supplementation}

One hundred fifty-seven of the total number of 160 plastic radio-opaque pallets ingested with the test drinks (pooled over all experiments) were excreted in the illeal effluent over the 24 -h collection period. During the first wo h after ingestion, no radio-opaques were excreted. In the ileal effluent samples collected between 4 to $10 \mathrm{~h}$ after ingestion of the lest drink, 147 radio opaques were emptied into the stoma bags, whereas only 10 radio-opaques were excreted into the bags during the following $9 \mathrm{~h}$. During the last 5 -h collection period no radio-opaques were excreted (Table 1).

Heal effuent production did not statistically differ between any of the 2-h collection periods. The median total ileal effluent production over the 24-h collection period was $616(456-865) \mathrm{g}$ (Figure 1). 
Table 1. Excretion of radio-opaque pallets in ileal effluent, as indicator of test drink recovery after passage through the gastrointestinal tract in female fleostomists.

\begin{tabular}{|c|c|c|}
\hline \multicolumn{2}{|c|}{ time of collection } & \multirow{2}{*}{$\begin{array}{c}\text { Cumulative number of recovered radio-opaques in ileal } \\
\text { effuent }\end{array}$} \\
\hline 0 & -2 & \\
\hline 2 & -4 & 32 \\
\hline 4 & -6 & 72 \\
\hline 6 & -8 & 108 \\
\hline 8 & -10 & 147 \\
\hline 10 & -12 & 150 \\
\hline 12 & -14 & 154 \\
\hline 14 & $-\quad 19$ & 157 \\
\hline 19 & $-\quad 24$ & 157 \\
\hline
\end{tabular}

Eight subjects, each subject ingested a test drink containing 20 radio opaque pallets.

LF content of the ileal effluent samples did not statistically differ between any of the samples. The median $2-h$ LF excretion was $0.35(0.28-0.47) \mu g$ (Figure 1 ). In total, a median amount of 4.01 (2.75-9.97) $\mathrm{Hg}$ LF was excreted over the $24 \mathrm{Hh}$ period by each volunteer (Table 2).

Table 2. Lactofertin excretion in leal effluent after oral ingestion of $5 \mathrm{~g}$ recombinant human lactoferrin in female bleoslomists

\begin{tabular}{|c|c|c|}
\hline \multicolumn{2}{|c|}{ time of collection (h) } & \multirow{2}{*}{$\begin{array}{l}\text { median cumulative lactoferrin in illeal } \\
\text { effluent ( } \mu \text { g) }\end{array}$} \\
\hline 0 & -2 & \\
\hline 2 & -4 & $0.6(0.22-2.02)$ \\
\hline 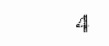 & -6 & $0.9(0.73-2.97)$ \\
\hline 6 & $-B$ & $1.3(0.97 .3 .53)$ \\
\hline 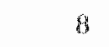 & -10 & $1.8(1.18-3.88)$ \\
\hline 10 & $-\quad 12$ & $2(1.63-4.61)$ \\
\hline 12 & -14 & $2.22 .02-5.261$ \\
\hline 14 & -19 & $3(2.24-8.77)$ \\
\hline 19 & -24 & $4(2.75-9.97)$ \\
\hline
\end{tabular}

Vulugs are expresscd as median cumulative excretion of lactoferrin from the small intestine after each Heat ewhent collection period. The 25 - and 75 percentiles are displayed in parentheses, $n=8$. 
figure 1. Aleal effluent production and tactoferin excretion
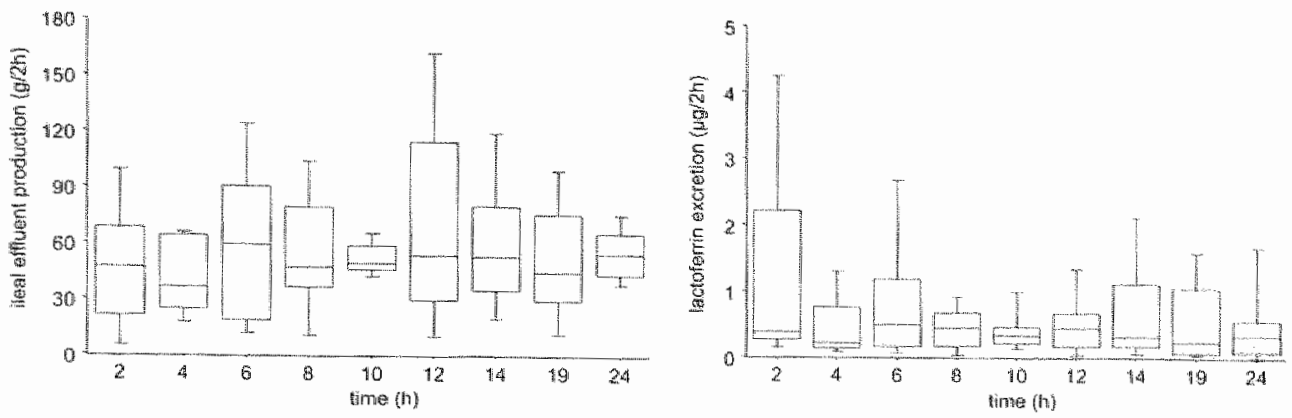

Twenty-four h ileal effuent production and lactoferin production of eight female ileostomists after ingestion of $5 \mathrm{~g}$ recombinant humar lactolerrin, expressed as producioni $2 \mathrm{~h}$ and excretion/2h, respec. wively. Median 25.75 percentiles) values are displayed in boxes, 1090 percentiles are dispinyed in wiskers.

\section{Study 2. Basal endogenous lactoferrin levels}

In the absence of any dietary LF ingestion, the 5-h ileal effuent of the four ileostomy patients contained 33 (24-52) $\mu \mathrm{g}$ LF/L ileostomy fluid. In the LF supplennentation study we found a median 5 -h ileal effluent LF concentration of 7 (6-9) $\mu \mathrm{g} / \mathrm{L}$ in these 4 subjects.

\section{Discussion}

We showed that small amounts of intact LF appeared in the ileostomy effluent after oral ingestion of a LF containing solution. The LF was excreted at a constant rate over the 24-h effluent collection period. We did not observe a correlation beween the re covery of the transit markers of the test drink and LF excretion in ileal effluent.

Most if not all LF present in bile and intestinal secretions originates from specific granules of activated neutrophils (Birgens, 1985; Furmanski \& Li, 1990; Pereira ef al., 1998a). Plasmatic LF is secreted through bile into the inlestine (Harada et al., 1999). Biliary LF, in healthy adults present at a concentration of approximately $1 \mathrm{mg} / \mathrm{L}$, is increased to approxmately $3 \mathrm{mg} / \mathrm{L}$ in patients with $\mathrm{BBD}$ (Pereira et al. $1998 \mathrm{~b}$ ). Additionally, faecal LF can be regarded as a diagnostic marker for immune system activation and hence disease activity in IBD patients (Sugi et as, 1996). In the faeces of healthy volunteers with an intact Gl tract, an average $\mathrm{LF}$ excretion of $210 \mathrm{Hg} / \mathrm{d}$ was observed previously, whereas patients with inactive ulcerative collitis or inactive Crohn's disease were reported to excrete approximately $5106 \mathrm{mg} / \mathrm{d}$ (5ugi et al., 1996 ). In the present study we found an average LF production of $4 \mathrm{Hg} / \mathrm{d}$ in ileostomists. The discrepancy between these observations can be explained by the hypothesis that the major part of LF in the Gl tract originates from leucocytes in the colon. This seems to be a plausible conclusion because leucocytes are the major source of LF. We propose 
that the LF excreted in the ileal effluent may have originated from an endogenous source, and not from the diet.

This is confirmed by the observation of the second in wivo study. In these lleall effluent samples we found equal or, if any, higher LF concentrations in these background samples without prior dietary LF ingestion compared to the samples collected over the same time period during the LF supplementation study. We did not detect a statistical difference between these experiments. Although only four subjects participated in the background study, we may conclude that the LF detected in ileal effluent in both studies originates from an endogenous source.

The observation that orally ingested LF does not survive passage through the small bowel confirms the findings of a LF breakdown study in the small bowel in rats (Kuwata et al., 2001). In that study it was shown that during Gl digestion of bovine LF, smaller fragments are formed that exert biological activity against fungi (Wakabayashi et al, 1996) and bacteria (Bellamy et al., 1992). This implies that, although LF is dim gested completely in the upper Gl tract and in the small intestine, oral LF ingestion may exert effects at any site in the Gl tract through the action of LF fragments. We were not able to situdy the appearance of these fragments in ileal effuent because of technical limitations in the quantitative analysis of LF fragments in the complex illeal efflwent-matrix. Moreover, the present study does not exclude any biological activity of intact LF in the upper $G$ tract before degradation.

The rate of radio-opaque excretion clearly shows that the test drink was emptied from the small intestine within the 24-h ileal effluent collection period. This confirms the validity of the ileostomy model for studying Gl survival of nutrients as we did in the present study. Incomplete recovery of the marker's was observed on two occasions. The omission of two markers in the ileal effluent of one volunteer and of one marker in another volunteer may be caused by a solid particle which temporarily retained in an intestinal fold. We may conclude that the test meal was completely emptied from the small intestine during the $24 \mathrm{~h}$ collection period.

The lleostomy model was applied because it ofters the unique feature to collect complete ileal effluent after the full transit of the test meal through the upper Gl tract. Hence, the bio-availability of any nutrient from the diet to the colon can be assessed. It is a well-accepted method to study digestion of nutrients and extrapolate the findings to subjects with an intact al tract since the ileostomy patients participating in the present study have an intact upper digestive system.

A prerequisite for this technique of studying LF digestion in the Gl tract in ileostomists is the stability of LF ex vivo after emptying into the illeostoma bag. LF may stay in the bag for maximally $2 \mathrm{~h}$. Digestion may continue in the bag. Therefore we studied ex vivo LF degradation in illeal effluent. We did not observe any LF degradation during 2 h of incubation in fresh ileal effluent at $37^{\circ} \mathrm{C}$ (data not shown). This is in accordance with a previous report in which no degradation of LF was observed during two h of incubation at $37^{\circ} \mathrm{C}$ in faeces of healthy volunteers (Sugi et al, 1996).

We sudied digestion of recombinant human LF, produced in Aspergillus awamori. From three-dimensional structure comparisons it was shown that this type of rhLF has the same three-dimensional structure as the native human LF, present in human breast 
milk (Baker \& Lindley, 1992). Dynamic properties of recombinant and native human LF are also similar. The only difference between the two LF forms is the composition of the glycans attached to the molecule due to the fungal system in which the rhLF is produced (Sun et al., 1999). The ELISA method used for quantification of intact LF present in ileal effluent detected native human as well as recombinant human LF. Iron binding was shown previously to affect the stability of the LF molecule. Ironsaturated LF (holoLF) is more resistant to degradation than iron-free LF (apoLF) (Brines \& Brock, 1983; Brock et al, 1976). The rhLF studied in the present study was free of iron. This is in contrast with studies using apoLF of animal origin in the natural state, which is known to have an iron saturation of 15-20\% (Steijns \& van Hooijdonk, 2000). Therefore, rhLF used in the present study may be more susceptible to GI degradation than LF of animal origin.

We showed that recombinant human $L F$ is completely degraded during passage through the stomach and the small intestine in vivo in humans. Intact LF entering the colon is unlikely to originate from an exogenous, dietary source of LF. This LF probably originates from granules of activated neutrophils in the upper Gl tract. Therefore, if oral administration of LF is indicated to exert an effect in the colon, ileal-release encapsulation of LF should be considered to prevent $\mathrm{Gl}$ degradation of $\mathrm{LF}$ before it enters the colon. 


\section{References}

Akin, D.T., Lu, M.Q. Lu, 51. Kendall, S., Rundegren, I. \& Amold, R.R. (1994): Bactericidal activity of different forms of lactolerrin Adv Exp Med Biol 357: $51-70$.

Baker, E.N. Lindley, P.F. (1992): New perspectives on the structure and function of transferrins 1 Inorg biochem 47(3-4): 147-60.

Baldwin, D.A. lenny, E.R. \& Aisen, P. (1984): The effect of human serum transferrin and milk lactoterrin on hydroxyl radical formation from superoxide and hydrogen peroxide i Biol Chem 259(21): 13391.4

Bellamy, W. Takase, M., Yamauchi, K., Wakabayashi, H., Kawase, K. \& Tomita, M. (1992): Identifcation of the bactericielal domain of lactuerrin Biochim Biophys. Acta $1121(1-2)$ : 130-6.

Birgens, H.S. 1985): Lactolerin in plasma measured by an ELSA technicue: evidence that plasma lactolerin is an indicator of neutrophill lurnover and bone marrow activity in acute leukaemia Scand/Haematol 34(4): 326-31.

Brines, R.D. \& Brock, I.H. (1983): The effect of trypsin and chymotrypsin on the in witro antimicrobial and iron-binding propertes of lactoterrin in human millk and bovine colostrum. Unusual resistance of human apolactoferrin to proteolytic digestion Biochim Brophys Acta 759(3): 229 -35.

Brock. I.H., Arzabe, F., Lampreave, F. \& Pineiro, A. (1976): The effect of trypsin on bovine transierrin and lactoterrin Biochim Biophys Acla 446(1): 214-25.

Crouch, S.P., Slater, K.J. \& Fletcher, ). (1992): Regulation of cytokine release from mononuclear cells by the iron-binding protein lactoferin Blood 80(1): 235 -40.

Davidson, L.A. \& Lönnerdal, B. (1989): Fe-saturation and proteolysis of human lactoferrin: effect on brush-border receptor-mediated uptake of Fe and Mn Am / Physiol2576 Pt 1): C9304.

Furmanski, P. \& Li, Z.P. (1990): Multiple forms of lactoferrin in normal and leukemic human granulocyles Exp tenatol 18(8): $932-5$.

Gutteridge, I.M., Paterson, S.K., Segal, A.W. \& Halliwell, B. 1981): Inhibition of Lipid Peroxidation by the Iron-Binding Protein Lactorerin Bochem-1 199(1): 259-61

Harada, C, Itol, Y, Sitizyo, K., Takeuchi, T., Araki, Y. Kitagawa, H. (1999): Characteristic Iransport of lactolemin from the intestinal lumen into the bile via the blood in piglets Comp Blochem physiof A Mol hregr Physiol 1240); 32 i-7.

Ikeda, M. Nozaki, A. Suxgiyama, K., Tanaka, T. Naganuma, A, Tanaka, K, Sekihara, H., Shumotolmo, K. Saito, M. \& Kato, N. (2000): Characterization of antivial activify of lactoferrin against hepatitis C virus infection in human cultured cells Vrus Res 6611:51-63.

Kuwala, H., Yamauchi, K., Teraguchi, S., Ushida, Y., Shimokawa, Y., Toida, T. R Hayasawa, H. 2001 ): Functional iragnents of ingested lactofermin are resistant to proteolytic degradation in the gastrointestinal wact of adult rats / Nut $131(8): 2121-7$.

Murphy, M.E., Kariwa, H., Mizutani, T., Yoshimatsu, K., Arikawa, J. \& Takashima, 1. (2000) In vitro antiviral activity of lactoternan and ribavirin upon hantavirus. Arch Virol 145(8): 1571-82.

Nuijens, I.H., wan Berkel, P.H. \& Schanbacher, F.L. (1996): Structure and biological actions of llactoferrin Mammary Chand Brol Neoplasia 10 , 285-95.

Pereim, S.P. Rhodes, I.M. Campbell, B.J., Kumar, D., Bain, I.M. Murphy, G.M. \& Dowling. R.H. (1998a): Billary lactolem concentrations are increased in active inflammatory bowel disease: a fixctor in the pathogenesis of primary sclerosing cholangits? Clin Sci (Colch) 95:5): 637 44. 
Pereira, S.P., Rhodes, J.M. Campbell, B.J., Kumar, D., Bain, I.M., Murphy, G.M. \& Dowting, R.H. (1998b): Biliary lactoferin concentrations are increased in active infammatory bowel disease: at

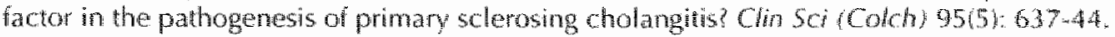

Sandhorn, W.). \& Hanauer, S.B. (1999): Antitumor necrosis factor therapy for inflammatory bowel disease: a review of agents, pharmacology, clinical results, and safely thlamm Bomel Dis $5(2)$ : $119-33$.

Steijns, I.M. \& van Hooijdonk, A.C. (2000): Occursence, structure, biochemical properties and technological characteristics of lactoferrin Br / Notr 84 Suppt 1 : $511-7$.

Sugi, K., Saitoh, O., Hirata, I. \& Katsu, K. (1996): Faecal lactoferrin as a marker for disease activily in inflammatory bowel disease: comparison with other neutrophil-derived proteins Am / Castroenterol 9 ) (5): $927-34$.

Sun, X.L., Baker, H.M., Shewry, S.C., Jameson, G.B. \& Baker, E.N. (1999): Structure of reconbinant thuman lactoferm expressed in Aspergillus awamori Acta Crystalogr D Bol Crystallogr 55(P) 2): $403-7$.

Swart, P., Kuipers, E.M., Smit, C., Van Der Strate, B.W., Harmsen, M.C. \& Meijer, D.K. (1998): LaCtoferrin. Antiviral activity of lactoferrin Adv Exp Med Bol 443: 205-13.

Troost, F. ., Steijns, 1., Saris, W.H. \& Brummer, R.1. 2001?: Gastric digestion of bovine lactolerm in wiwo in adults / Nuir $131(8): 2101-4$.

Wakabayashi, H., Abe, S., Okutomi, T., Tansho, S., Kawase, K. \& Yamaguchi, H. (1996): Cooperative anti-Candida effects of lactoferrin or its peptides in combination with azole antifungal agents $M$. crobiol immunol 40(11): 821-5.

Zagulski. T. larzabek, Z., Zagulska, A. \& Zimecki, M. 11998a): The main systemic, highly effective, and quickly acting antimicrobial mechanisms generated by tactoferin in manmals in viwo. Activ. ity in health and discase Adv Exp Med Biol 443:247-50.

Zagulski, T. Lipinski, P., Zaguiska, A. \& Jarzabek, Z. (1998b), Antibacterial system generated by lactoferrin in mice in viwo is primarily a killing system $\min$ / Exp Pathol 79(2): 117-23. 
104 
CHAPTER 8

\section{RECOMBINANT HUMAN LACTOFERRIN INGESTION ATTENUATES INDOMETHACIN- INDUCED ENTEROPATHY IN VIVO IN HEALTHY VOLUNTEERS}

Freddy J Troost, Wim HM Saris, Robert-Jan M Brummer European Journal of Clinical Nutrition, in press 


\begin{abstract}
Objective To determine whether recombinant human lactoterrin ingestion inhibits non-steroidal antinflammatory drugs (NSAID) -induced gastroenteropathy in vivo in healthy volunteers as a model for disorders associated with a rise in permeability of the stomach and the small intestine.

Design Fifteen healthy volunteers (age $23 \pm 1.4 y$ ) were tested. A sucrose and a lactulose/rhamnose (L/R) permeability test was performed to assess gastroduodenal and small intestine permeability as indicator of NSAID-induced gastiroenteropathy. All subjects consumed standardized meals for two days. On the second day at time =$24 \mathrm{~h}$ each subject ingested a drink containing $5 \mathrm{~g}$ recombinant human lactoferrin or placebo during breakfast. At $t=-9 \mathrm{~h}$, subjects ingested the same drink with $75 \mathrm{mg}$ of the NSAID indomethacin and after an overnight fast at $t=-1 \mathrm{~h}$ subjects consumed the drink and $50 \mathrm{mg}$ indomethacin. One hour later, at $t=0$, a permeability test was performed.
\end{abstract}

Results Small intestime permeability after indomethacin and placebo was significantly higher $(L / R$ ratio $=0.036 ; 0.014-0.092, P<0.05)$ compared to the permeability observed after ingestion of indomethacin and lactoferrin (0.028; 0.015-0.056), whereas gastroduodenal permeability did not differ between the two interventions $(P=0,3)$.

Conclusion Oral recombinant human lactotertin supplementation during a short-term indomethacin challenge reduced the NSAD-mediated increase in small intestinal permeability and hence may provide a nutritional tool in the treatment of hyperpermeability-associated disorders. 


\section{Introduction}

In normal conditions, only minute amounts of pathogens permeate the intestinal epto thelium that may cause a moderate local activation of the immune systen. However; if the intestinal permeability is increased, excessive penetration of luminal aggressive agents and antigens may attract local and circulating reutrophils which causes the release of reactive oxygen species (Bjarnason et al, 1993) and the initiation of gastro. intestinal inflammation (Söderholm \& Perdue, 2001; Wallace, 1993). This inflammation increases permeability to a greater extent, resulting in permeation of luminal aggressive agents through the mucosa and aggravation of local tissue inflammation which, in turm, leads to increased permeability (Ferry et al., 1989). An increase in intestinal permeability may finally result in a significant intrusion of pathogens, such as endotoxin, into the circulation and implies a serious health hazard. An increase in intestinal permeability or a decrease in intestinal barrier function is regarded as a pathophysiological factor in Crohn's disease (Meddings, 1997), celiac disease (Smecuol et al., 1997), viral gastroenteritis (Isolauri et al., 1989) and food allergy (Crowe \& Perdue, 1992). Shortly after the administration of indomethacin, a non-steroidal antiinflammatory drug (NSAID), small intestinal permeability is increased in the same order of magnitude as in these disorders (Bjarnason et al., 1986). In the present study we administered indomethacin to healthy volunteers as a model for the gastroenteropathy associated with a rise in small intestinall permeability. Controlling permeabillty with specific food ingredients such as lactoferrin (LF) may provide a tool in the treatment of these disonders.

In animal studies, several beneficial effects were attributed to LF. Bactericidal (Bellamy et al, 1992; Zagulski et al, 1998), anti-inflammatory (Nuijens, van Berkel \& Schanbacher, 1996), antiviral (lkeda et al., 2000; Murphy et al., 2000; Swart et al., 1998) and antioxidative activities (Baldwin, Jenny \& Aisen, 1984; Davidson \& Lönnerdal, 1989; Gutteridge et al., 1981) were discovered previously. Concomitant ingestion of lactoferrin together with indomethacin may protect against indomethacin-induced gastroenteropathy. I.F is a protein of the transterrin family. It is present in milk, saliva, tears, bille, blood plasma, mucosal and genital secretions (Britigan, Serody \& Cohen, 1994; Levay \& Viljoen, 1995) and released by neutrophil-specific granules (Davidson \& Lönnerdal, 1989). Since L..F is present in relatively high concentrations in human colostrum, it was thought to play an important role in the development of newborns. This hypothesis was strengthened by the discovery of specific LF receptors on the intestinal brush bordler (Kawakami \& Lönnerdal, 1991; Mazurier, Montreuil \& Spik, 1985), lymphocytes (Legrand et al., 1992) and possibly in hepafocyles (McAbee \& Esbensen, 1991). The physiological effects of LF have been reviewed by several investigators (Baker et al., 1991; Britigan el al, 1994; Brock, 1995; lyer \& Lönnerdal, 1993; Levay \& Viljoen, 1995) but the exact mechanisms of action are still unclear. Some of the observed and hypothesized effects of LF may be regulated through binding to a specific LF receptor in the small intestine. However, binding of LF to its receptor is a species-specific process. It was shown previously that bovine lfF does not recognize the human LF receptor, whereas rhesus monkey lactoferrin and human LF are structurally and functionally identical and have the same affinity for the intestimal brush- 
border membrame LF receptor (Davidson \& Lönnerdal, 1986; Daviclson \& Lönnerdal, 1988).

We investigated whether recombinant human LF was able to attenuate NSAIDinduced gastroenteropathy and may thus provide a nutritional intervention tool in the prevention or treatment of disorders associated with an increased intestinal permeability. 


\section{Methods}

\section{Subjects}

Fiffeen healthy non-smoking male volunteers (age $23.9 \pm 2.2$ y) were recruted for participation. All subjects were free of any medication and did not have a history of a gastrointestinal disorder. The study was carried out according to a double-blind randomized cross-over design. Each subject participated in two experiments with a washout period of two weeks in between. All subjects were informed orally and im writing about the aim and the protocol of the study and gave their written informed consent before participation. The study protocol was approved by the Ethics Committee of the University Hospital Maastricht, Maastricht, The Netherllands.

\section{Design}

To avoid high levels of dietary lactoferrin intake, subjects consumed a provided standardized diet and were not allowed to consume any dairy products on the wo days prior to the day of testing. For breakfast and lunch bread rolls of any kind and nondairy drinks were allowed ad libitum. Dinner consisted of a commercially available prepared pasta meal (Dinner 2 today, Bami Goreng, Honig, Koog a/d Zaan. The Netherlands). On each test day, a sucrose/lactulose/rhamnose test was carried out to as a measure of gastroduodenal and small intestinal permeability. Twenty-four hours prior to the permeability measurement, immediately after breaktast, subjects ingested a test drink. The flavoured test drink contained either $5 \mathrm{~g}$ recombinant human lactoferrin (rhLF, Agennix inc., Houston, TX, USA) dissolved in $100 \mathrm{~mL}$. water or flavoured placebo (100 $\mathrm{mL}$ water), present in a masked flask. In the evening, exactly nine hours prior to the permeability measurement, subjects ingested a test drink and $75 \mathrm{mg}$ indomethacin (Genfarma bv., Maarssen. The Netherlands) and after an overnight fast, one hour before permeability assessment, subjects ingested a test drink and $50 \mathrm{mg}$ of indomethacin. One hour later, after voiding, a hyperosmolar drink containing $20 \mathrm{~g}$ sucrose, $5 \mathrm{~g}$ lactulose (Genfarma bw., Maarssen, The Netherlands) and $0.5 \mathrm{~g} \mathrm{l.-}$ rhamnose (ICN Biomedicals Inc, Aurora, OH, USA) dissolved in $100 \mathrm{ml}$. water was ingested. Subsequently, urine was collected for five hours, Subjects stayed in the lab and were not allowed to eat during the time of urine collection. Consumption of water was allowed ad libitum during the last two hours of urine collection. The urine volume was determined. Urine aliquots were taken and stored at $-80^{\circ} \mathrm{C}$ until analysis.

Two weeks after the first experiment, subjects commenced the same protocol with the complementary test drink.

In an additional study to the effects of rhLF on small intestinal permeability, 5 of the above subjects ingested a lactulose/rhamnose/sucrose solution as described above after an overnight fast and after voiding. with concomitant ingestion of either $5 \mathrm{~g}$ rhlf, dissolved in $100 \mathrm{~mL}$ water, or $100 \mathrm{~mL}$ water in masked flasks on two separate days. After ingestion of the beverage, volunteers collected urine for $5 \mathrm{~h}$ as described above. The experiments were carried out to conform to a randomized cross over design. 


\section{Gastrointestinal permeability}

Urinary sucrose excretion provides an estimation of the permeability of the stomach and the proximal duodenum (Meddings et al., 1993). Urinary sucrose was determined with a Dionex ion chromatography system (Dionex Corporation, Sunnyvale, CA). All samples were spiked with sucrose to enable identification of sucrose in the complex urine matrix. Samples were put on a column (Dionex PA1 and guard column PA1) with a sodium hydroxide - sodium acetic acid gradient. Sucrose was detected using pulsed electrochemical detection.

Intestinal permeability was assessed using the lactulose/rhamnose gut permeability test. This test is based on the comparison of intestinal permeation of molecules of different sizes. The urinary lactulose / rhamnose excretion ratio is considered to be an accurate parameter for small intestinal permeability (van Nieuwenhoven et al., 1999). Lactulose and thamnose were determined by fluorescent detection high-pressure liquid chromatography (HPLC). All samples were spiked with lactose as an external standard that does not interfere with determination of lactulose and thamnose. Samples were incubated overnight with derivatization reagent (9-fluorenylmethyl chloroformate hydrazinel at $65^{\circ} \mathrm{C}$. After cooling to room temperature the reaction mixture was injected into a dedicated HPLC-system. The fluorescence was detected with a fluorescence detector (B\&L systems, Zoetermeer, The Netherlands). The protocol for lactulose and rhamnose analysis was well validated and described in detail previously (Rooyakkers, van Eijk \& Deutz, 1996).

\section{In vitro lactoferrin-indomethacin binding study}

An in vitro binding study to examine the ability of rhLF to bind indomethacin was performed. A water solution containing $25 \mathrm{mg} / \mathrm{L}$ indomethacin and $2.5 \mathrm{~g}$ rhLF was incubated for 7 and 22 minutes respectively. Subsequently, $0.5 \mathrm{~mL}$ of the rhLF/indomethacin solution was put over a $30 \mathrm{kDa}$ micropore filter and the amount of indomethacin present in the filltrate solution was determined by HPLC.

\section{Statistics}

Urinary sucrose excretion is presented as median excretion (mg). Five-hours urinary excretion of lactulose and rhamnose are presented as lactulose/rhamnose (L/R in $\mathrm{g} / \mathrm{g}$ ) ratios. Differences in urinary sucrose, L/R ratio"s and lactulose- and rhamnose recovery respectively between the lactoferrin- and the placebo intervention were assessed using non-parametric statistics (Willcoxon signed rank test, $\mathrm{P}<0.05$ was regarded as a statistical significant difference). Data are presented by Box-Whisker plots.

\section{Results}

None of the subjects suffered from gastrointestinall discomfort of any kind during the test days. No side effects of lactoferrin ingestion were observed.

The median urinary sucrose excretion was lower in the LF intervention $(8.86 ; 3.61$ 25.4) compared to placebo $(13.75 ; 2.89-24.62)$ but this difference did not reach statistical significance $(\mathrm{P}=0.31$; Figure 1$)$. 
Chapter $B$
Recombinant human lactoferrin ingestion attenuates indomethacin-induced enteropathy

Figure 1. Urinary sucrose and lactulosethamnose excretion
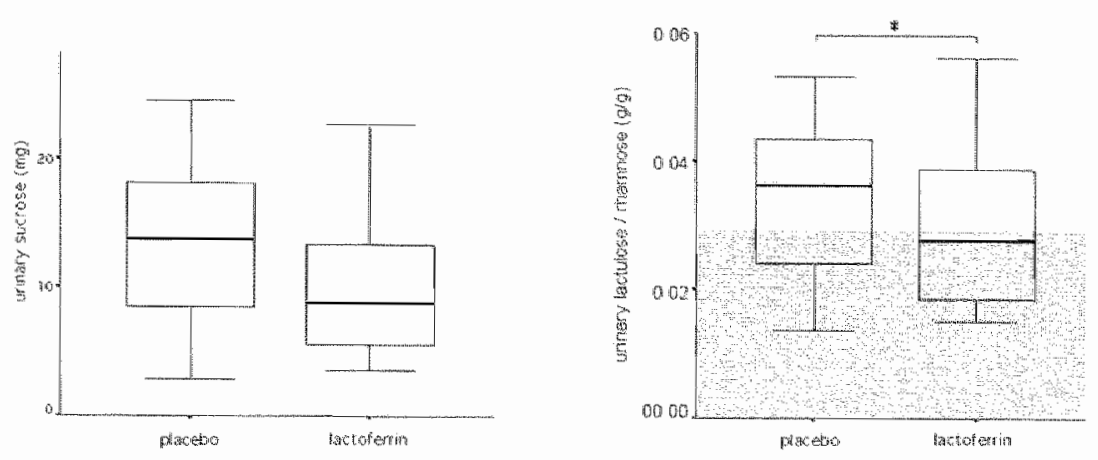

Five-h urinary sucrose and lacholose thamnose excetion after ingection of wo dosages of indonethacin $75 \mathrm{mg}$ at $9 \mathrm{~h}$ and $50 \mathrm{mg}$ indomethacin at $\mathrm{h}$, respectively, betore ingestion of a sucrose/lactulose/thamose solution) with or without ingestion of $5 \mathrm{~g}$ recombinant human factoferin at

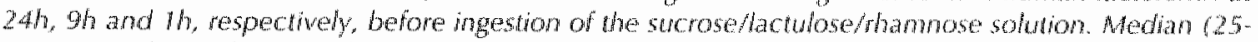
75 percentiles) values are displayed in boxes, 1090 percentiles are displaped in whiskers. (Sucrose; $P=0.31$, lactulose; $P<0.05, n=75$, Whocon signed rank test. The grey area indicates the average 2 sd urinary lactulose/rhamnose ratios obsened in control experiments in prevous investigations $(n-31)$ as the $95 \%$ reliabitity interwal for normal values in healthy subjects.

The $L / R$ ratio after ingestion of rhLF and indomethacin was significantly lower 0.028 $(0.015-0.056) ; P<0.05)$ than after the indomethacin challenge with placebo 10.036 $(0.014-0.092)$ ) (Figure 1). In Figure 2 the mean urinary lactulose / rhamnose ratio \pm 2 standard deviations as the $95 \%$ reliability interval in healthy controls is depicted $(0.014 \pm 0.016, n=31)$. These vallues were obtained from control experiments in previous studies with healthy volunteers using the same protocol and analysis equipment.

The observed difference in L/R ratio between the two interventions was due to a lower urinary lactulose recovery after lactoferrin administration compared to the placebo administration $(0.52 \%(0.40-0.99)$ and $0.74 \%(0.26-0.92)$ respectively: $P=0.054)$. Urinary thamnose recovery did not difer between the lactoferrin-and placebo administration $(21.08 \%(9.12-28.56)$ and $21.00 \%(12.31 .45 .53)$ respectively; $P=0.78)$.

The urinary lactulose/rhamnose ratio after ingestion of $5 \mathrm{~g}$ rhL $10.027 ; 0.02-0.03) \mathrm{did}$ not differ from the urinary lactulose/rhamnose ratio after ingestion of water $(0.03$; $0.02-0.03)$.

\section{In vitro lactoferrin-indomethacin binding study}

After 7 minutes of incubation, no indonethacin was bound to LF: indomethacin recovery in the filtrate was $100 \%$. After 22 minutes of incubation, $76 \%$ of the indomethacin appeared in the filtrate. 


\section{Discussion}

It is well established that the administration of indomethacin in dosages comparable to that used in the present study increases small intestinal permeability about $2-3$ fold (Bjarnason et al., 1993; Bjamason et al., 1989; Bjarnason et al., 1986), which is in line with our results. Intestinal permeability after taking indomethacin for seven days reverts back to normal within one week (Bjamason et al. 1991). Hence, in the present study the washout period of two weeks was sufficient to exclude any carry-over of the effects of indomethacin. Concomitant LF administration with indomethacin ingestion significantly attenuated the urinary lactulose/rhamnose ratio compared to placebo with indomethacin from 0.036 to 0.028 , indicating that LF attenuated indomethacininduced small intestinal permeability by a factor 1.4. Hence, LF administration does not completely prevent indomethacin-induced enteropathy. The observed lactulose/rhamnose ratio of 0.028 , however, is within the normal range as measured previously in control experiments in our lab, whereas 0.036 is above the normal range.

The difference in urinary lactulose/rhamnose ratios was caused by a lower urinary lactulose recovery atter LF ingestion compared to placebo. Lactulose permeates the intestinal epithelium paracellularly and hence, urinary excretion after ingestion of the sugar drink provides an estimation of the paracellular permeation route. Rhamnose excretion is predominantly a parameter of transcellular permeation. Since we did not observe a difference in rhamnose excretion, the abserved effect of LF on NSAIDinduced hyperpermeability can be solely attributed to its protective effect on the paracellular permeation route. In the second in wivo study we showed that LF did not affect small intestinal permeability in the unstressed small intestine. Hence, ingestion of LF does not inhibit normal small intestine permeability in humans, but provides an effective tool in the prevention of enteropathy in the small bowel.

Lactoferrin tended to exert a protective effect on gastroduodenal permeability as measured by urinary sucrose excretion. The observed difference between LF and placebo did not reach statistical significance due to a wide range in results. It has been shown previously applying the urinary sucrose excretion method that aspirin administration increased gastroduodenal permeation (Lambert et al., 2001), indicating that NSADS inflict damage to gastric and duodenal mucosa. The obserwed trend in the present study warrants further investigation with sufficient power in order to elucidate the extent and pathophysiology of LF-associated protection of NSAID-induced damage to the stomach and the proximal duodenum.

Colostrum contains relatively large amounts of lactoferrin. A protective effect of a bovine colostrum preparation on indomethacin-induced increase in small intestinal permeability was previously observed. Colostrum supplementation during 7 days inhibited the indomethacin-induced hyperpermeability of the small intestine seen after 5 days of indomethacin intake compared to placebo. The placebo solution was an isoproteinaceous whey solution free of a number of growth factors that are present in the colostrum (Playford et al., 2001). No information was awalable about lactofermin contents of the solutions used in this study. The results of the present study indicate that these effects could at least partly be attributed to LF present in the colostrum. 
As will be explained below, the observed effect of LF in attenuating paracellular epithelial damage may be due to a protective effect on the regulation of the paracellular permeation route. LF may also interfere with another direct or indirect pathophysiological process by which indomethacin administration leads to gastroenteropathy such as the uncoupling of mitochondrial respiration, mediation of cytokine production, inhibition of cyclooxygenase-mediated prostaglandin production or induction of intracellular transcription factors.

It is well established that NSAD administration causes gastroenteropathy, thereby damaging the tight junctions between enterocytes. This thas a detrimentat effect on the intestinal barrier function. NSAIDs may induce enteropathy by several distinctive mechanisms.

NSAIDs are able to uncouple oxidative phosphorylation, which results in reduction of intracellular ATP levels and, as a consequence, loss of control of the integrity of tight junctions. This is regarded as the first step in the development of gastrointestinal injury (Somasundaram et al, 1995; Somasundaram ef al., 1997). This uncoupling causes efflux of hydrogen and calcium ions from mitochondria and promotes oxygen radical damage (Bjarnason et al, 1993; Carafoli, 1987). Due to this oxidative stress, tight junctions are damaged and paracellular permeability increases. If is a wellrecognized antioxidative agent because of its strong iron chelating capacily. Iron ions bound to If are not able to participate in Fenton Chemistry in which the highly reactive hydroxyl radicals are produced. The chelation of iron by LF diminishes the production of hydroxyl radicals and consequently oxidative stress (Britigan et a/., 1994). This may contribute to the observed protective effect of oral LF ingestion since indomethacin-induced enteropathy is in part caused by oxidative stress in the epithelium. The ferrochelating properties of LF also result in antimicrobial activity of LF in human plasma serum as iron deprivation inhibits bacterial growth (Aguila et al, 2001). Addiw tionally, LF exerts bactericidal activity against antibiotic-resistant bacteria in vitro independent of its iron-binding capacity (Bellamy et al, 1992; Nibbering et al., 2001). These findings indicate that LF may protect against indomethacinuinduced snteropathy by preventing intrusion of bacteria in the epithellum of the small intesline, which occurs when the intestinal epithelium becomes more permeable and resulls in a rurther progression of the damage. Because the ferrochelating properties of If may explain its protective effect on indomethacin-induced enteropathy, iron free LF (apol.F) as used in the present study, may be more effective 10 protect against enteropathy than ironsaturated LF (hololf). Apolf has a maximal capacity to bind iron whereas holotf has a limited capacity to bind free iron, although some iron binding can still occur.

The observed protective effects of oral LF ingestion may partly be due to the regutatory function of LF in the immune system. Oral lactoferin ingestion decreases spontaneous and lipopolysaccharide-induced production of the pro-inflammatory cylokines $14-6$ and TNFa by peripheral blood cells (Zimecki et al, 1999; Zimecki et al. 1998). Moreover, LF and LF-derived peptides can stimulate the release of 11 - 8 from polymorphonuclear leukocytes, which activate neutrophils (Shinoda et al., 1996) and inhibit Iymphocyte production of TNFa, IL-1 and IL-2 in vitro (Crouch, Slater \& Fletcher, 1992). This mediating effect of $L F$ on the local and systemic immune response may 
inhibit the proceeding of free radical-induced damage caused by local activation of the immune system due to NSAID-induced enteropathy. Regulation of cytokine production may be an important mechanism of action of LF resulting in protection of the integrify of the epithelial barrier, although data are equivocal. It was previously shown that oral LF administration stimulates the production of the pro-inflammatory interleukin-18 (II-18) in the mucosa of the small intestine in rodents with experimental metastasis (Kuhara et al., 2000). No data are available regarding the effects of oral LF ingestion on IL-18 production in any other physiological conditions.

It may be that the effect of LF on cytokine production is a receptor-mediated process. In that case, the origin of the rhLF administered in the present study may be essential. LF administration of animal origin may not exert the same effects as those observed in the present study since LF binding to its receptor is a species-specific process.

It is generally recognized that NSAIDs inhibit cyclo-oxygenase (COX) activity. This results in a decrease of prostaglandin (PG) synthesis and consequently a further deterioration of the epithelial barrier (Bjarnason et al., 1989; Hawkey \& Rampton, 1985). It is unlikely that the protective effect of LF on the integrity of the epithelial wall involves PG production because existing knowledge does not provide any indications for a mediating effect of L.F on PG production.

Hypothetically, binding of indomethacin to LF would prevent indomethacin-induced gastroenteropathy because indomethacin bound to LF may lack biological activity. In the in vitro LF / indomethacin binding study we showed that indomethacin did only bind L.F in minute amounts at a slow rate. After 7 minutes of incubation, no indomethacin-LF binding was observed and after 22 minutes $76 \%$ of the indomethacin was recovered. This implies that at least $76 \%$ of the indomethacin was present as free indomethacin after 22 minutes. In previous studies we showed that after 7 minutes almost half of the test drink ingested is emptied from the stomach, while after $22 \mathrm{~min}$ utes most if not all of the test drink is emptied from the stomach into the small intestine (Iroost et al, 2001). Hence, in the present study indomethacin entered the small intestine predominantly unbound to LF. The observed protective effect of oral LF administration can probably not be explained by LF-indomethacin binding. We previously showed that the major part of orally ingested LF survives gastric passage in vivo in adults, leaving most of the LF intact until it enters the intestine (Troost et al., 2001). The observed effects cannot be attributed to the presence of a protein load in the test drink. In contrast to LF, oral administration of casein leads to aggravation of NSAIDinduced damage to the epithelial barrier, probably because transepithelial movement of casein induces enhanced mast cell activation and consequently mucosal injury (Miller et at., 1991).

Intestinal permeability is increased in numerous diseases. Approximately $50 \%$ of patients with active Crohn's disease have an increased small intestinal permeability (Bjarnason et al, 1983). Moreover, it has been shown that an increase in intestinal permeability precedes clinical manifestation of Crohn's disease (May, Sutherland \& Meddings, 1993). A compromised intestinal barrier function is regarded as an etiological factor in Crohn's disease (Meddings, 1997), celiac disease (Smecuol et al., 
1997), viral gastroenteritis (Isolauri et al., 1989) and food allergy (Crowe \& Perdue, 1992). This implies that controlling permeability is important in the control of these diseases. Ingestion of the two dosages of indomethacin as carried out in the present study increased small intestinal permeability approximately 2.5 -fold, comparable to the increase in permeability observed in Crohn's disease (Wyatt et al., 1993). Hence, the protocol as used in this study may serve as an appropriate model for a variety of disease states in which small intestinal permeability is increased.

We conclude that orally administered rhLF exerts biological activity in the small intestine, resulting in inhibition of indomethacin-induced enteropathy. The exact mechanism of action of LF in attenuating enteropathy remains to be elucidated. It seems plausible that the antioxidative capacity of LF is involved in the attenuation of the indomethacin-induced stress. Binding of LF to its receptor, which may play a role in the pathophysiology of the observed effect of LF in the small bowel, is a speciesspecific process. Therefore the results of the present study may be species-specific, depending on the origin of the LF. It seems less likely that LF interferes with the effects of indomethacin on PG synthesis or prevents the biological activity of indomethacin by binding it. Lactoferrin administration may be beneficial in the control of oxidative stress-induced damage of the small intestinal epithelium and especially in patients using NSAIDs by its attenuating effect on increased small bowell permeability. 


\section{References}

Aguila, A.. Herrera, A. G., Morrison, D., Cosgrove, B., Perojo, A., Montesinos, 1., Perez, J., Sierra, G. Gemmell, C.C. \& Brock, 1.H. (2001): Bacteriostatic activity of human lactoferrin against Staphylococcus aureus is a function of its ironbinding properties and is not influenced by antibiotic resisbance FEMS Immunol Med Microbiol 312\%: 145-52.

Baker, E.N., Anderson, B.F., Baker, H.M., Haridas, M., Jameson, G.B., Norris, G.E., Rumball, S.V. \& Smith, C... (1991): Situcture, function and flexibility of human lactoterrin int / Biol Macromol $1313 \%: 122-9$.

Badwin, D.A., lemw, E.R. \& Aisen, P. (1984): The effect of human serum transferrin and milk lactoferrin on hydroxyl radical formation from superoxide and hydrogen peroxide / Biol Chem 259(21): 13391.4

Bellamy. W., Takase, M., Yamauchi, K, Wakabayashi, H., Kawase, K. \& Tomita. M. (1992): Identii. cation of the bactericidal domain of lactoferrin Biochim Biophys Acta 1121(1-2): 130-6.

Bjarnarson, 1., Fehilly, B., Smethurst, P., Menzies, I.S. \& Levi, A.J. (1991): Importance of local versus systemic effects of non-steroidal anti-inflammatory drugs in increasing small intestinal permeabitity in man Gut $32(3): 275-7$.

Bijarnason, 1., Hayllar, J., Macpherson, A.J. \& Russell, A.S. (1993): Side effects of nonsteroidal antiinflammatory drugs on the small and large intestine in humans Gastroenterology 104(6): 1832-47.

Bijarnason, 1. O'Morain, C., Levi, A.J. \& Peters, T.1. (1983): Absorption of 51 chromium-labeled ethylesnediamineletraacetate in inflammatory bowel disease Castroenterology 85(2): 318-22,

Bijarnason, 1., Smethurs, P., Fenn, C.C., Lee, C.E., Menzies, I.S. \& Levi, A.J. (1989): Misoprostol reduces indomethacin-induced changes in human small intestinal permeability Digestive Diseases And Sciences 34(3): 407-11.

Bjamalson, L, Williams, P., Smethurst, P., Peters, T.J. \& Levi, A.J. (1986): Effect of non-steroidal antinflammatory drugs and prostaglandins on the permeability of the human small intestine Gut $27(11): 1292-7$.

Britigan, B.E, Serody, I.S. \& Cohen, M.S. (1994): The role of actolerrin as an anti-inflammatory molecule Ad Exp Mad Biol 357 : $143-56$.

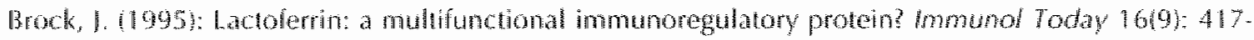
9.

Carafloli, E. (1987): Intracellular calcium homeostasis Annu Rev Biochem 56: 395-433.

Crouch, S.P., Sluler, KJ. \& Fletcher. 1. 1992: Regulation of cytokine release from mononuclear cells by the iron-binding protein lactoferin Blood $80011: 235-40$.

Crowe, S.E. \& Perdue, M.H. (1992): Gastrointestinal food hypersensitwity: basic mechanisms of pathophysiology Gastroenterology $103(3)$ : $1075-95$.

Davidson, L.A. \& Lonnerdal, B. (1986): Isolation and characterization of thesus monkey milk lactoterrin Pediatr Ress 20(2): 197-201.

Davidson, L.A. \& Lönerdal, B. 11988\%: Specific binding of lactoferrin to brushmborder membrane: ontogeny and effect of glycan chain Am / Physiol 254(4 Pt 1): G580-5.

Davidson, LA. \& Lömerdal, B. (1989): Fe-saturation and proteolysis of human lactoterin: effect on brush-border receptormediated uptake of Fe and Mn Am / Physiol 2576 Pt 1): G930.4. 
Ferry, D.M., Butt, T.I. Broom, M.F., Hunter, I. \& Chadwick. V.5. (1989): Bacterial chemotactic oligopeptides and the intestinal mucosal barrier Castroenterolog $67(1): 61-7$.

Gutteridge, J.M., Paterson, S.K., Segal, A.W. \& Halliwell, B. (19.81): Inhibition of Lipid Peroxidation by the Iron-Binding Protein Lactoterrin Biochem 1 199(1): $259-61$.

Hawkey, C.J. \& Rampon, D.5. (1985): Prostaglandins and the gastrointestinal mucosa: are they important in its function, disease, of treatment? Gastroenterology 89(5): $1162-88$.

lkeda, M., Nozaki, A., Sugiyama, K., Tanaka, T., Naganuma, A., Tanaka, K., Sekihara, H., Shimotohno, K. Sato, M. \& Karo, N. 2000): Characterization of antiviral activity of lactoferrin against hepatitis $C$ virus infection in human cultured cells virus Res $66(1): 51-63$.

Isolauri, E, Juntunen, M. Wiren, S., Vuorinen, P. \& Kowula, T. (1989): Intestinal permeability changes in acute gastroenteritis: effects of dinical factors and nutritional management / Pediatr Gastroenterol Nutr $8(4): 466-73$.

lyer, S. \& Lömnerdal, B. (1993): Lactoferrin, lactoferrin receptors and hon melabolism Eu / Clin Nut $47: 232-241$.

Kawakami, H. \& Lönnerdal, B. (1991): Isolation and function of a receptor for tuman lactoferin in human fetal intestinal brush-border membranes Am / Physiol 261 (5 Pt 1): C841-6.

Kuhara, T., ligo, M., lioh, T., Ushida, Y., Sekine, K., Terada, N., Okamura, H. \& Tuda, H. 2000): Orally administered lactoferrim exeris an antimetastatic effect and enhances procluction of $1 \mathrm{~L}-18$ in the intestinal epithelium Nutr Cancer 382): 192-9.

Lambert, G.P., Broussard, L.\#., Mason, B.L, Mauemann, W.J. \& Gisoli, C.V. (2001): Gastrointestinal permeability during exercise: effects of aspirin and energy-containing beverages / Appl P/ysiol 90(6): 2075-80.

Legrand, D., Mazurier, I. Elass, A., Rochard, E, Vergoten, G., Maes, P., Montreuil, I. \& Spik, G. (1992): Molecular interactions between human lactohansferrin and the phytohemagglutininactivated human lymphocyte lactotransferrin receptor lie in two loop-containing regions of the $\mathrm{N}$ terminal domain tof human lactotransferrin Biochemistry 31(38): $9243-5 \pi$.

Levay, P.F. \& Vilioen, M. (1995): Lactoferrin: a general review Haemotologica 80: 252-267.

May, G.R. Sutherland, L.R. \& Meddings, J.B. (1993) Is smatl intestinat permeability really increased in relatives of palients with Crohn's disease? Gastronferology 104(6): 1627-32.

Mazurier, J., Montreuil, J. \& Spik, G. (1985): Visualization of lactotransferin brusty-horder receptors by ligand-bloting Biochim Blophys Acta 821(3): 453-60.

MCAber, D.D. \& Ebensen, K. 1991): Binding and endocylosis of apo-and holo-betoferrin by isolated rat hepatocyles/ Biot Chem 266(35): 23624-31.

Meddings. H. B. (1997): Review anticle: Intestinal permeability in Crohn's disease Almen Phamacol Ther 1 i Suppl 3: 47-53; discussion 53-6.

Meddings, J.B., Sutherland, L.R., Byles, N.I. \& Wallace, 1.L. (1993): Sucrose: a novel permeability marker for gastroduodenal disease Castroenterology 104(6): 1619-26.

Miller, M.J., Zhang, X.I. Gu, X.A. \& Clark, D.A. (1991): Acute intestinal injury induced by acetic acid and casein: prevention by intraluminal misoprostol Castroenterology $101011: 22-30$.

Murphy, ME., Kariwa, H., Mizutani, T., Yoshimatsw. K., Arilkawa, 1. \& Takashima, 1. 12000): In vitro antiviral activily of lactoferrin and ribavirin upon hantawirus Arch Virol 145(B): 1571-82.

Nibbering, P.H. Rawensbergen, E., Welling, M.M. wan Berkel, L.A., van Berkel, P.I., Pauwels, E.K. \& Nuijens, 1.1. 2001): Human lactoferrin and peptides derived from its N lerminus are highly effective against infections with antibiotic-resistan bacteria bofect frmmun 6983): 146976 . 
Nuigens, I.H. van Berkel, P.H. \& Schanbacher, F.L. (1996): Structure and biological actions of lactoferrin / Mammary Gland Biol Neoplasia 13): 285.95.

Playlord, R.J., MacDonald, C.E. Calnan, D.P., Floyd, D.N., Podas, T, Johnson, W. Wicks, A.C., Bashir, O. \& Marchbank, T. 2001): Co-administration of the health food supplement, bovine colostrum, reduces the acute non-steroidal ant-infilamatory drug-induced increase in intestinal permeability Chin Sci (lond) $10066: 627-33$.

Rooyakkers, D.R. wan Eijk, H.M. \& Deutz, N.E. (1996): Simple and sensitive multi-sugar-probe gut permeability test by high performance liquid chromatography with fluorescence labelling / Chromatogr A.73011-23:99.105.

Shinoda, I., Takase, M. Fukuwatari, Y, Shimamuna, S, Koller, M. \&onig. W. (1996): Effects of lacIoferrin and lactolerricin on the release of interleukin 8 from human polymorphonuclear leukocytes Biosci Biotechnol Biachem $60(3)$ : 521-3.

Smecuol, E., Bai, 1.C., Vazquez, H.t., Kogan. Z., Cabanne, A., Niveloni, S., Pedreira, S., Boerr, L., Maurino, E. \& Meddings, J.B. (1997): Gastrointestinal permeability in cellac disease Castroenterology 11264$): 1129-36$.

Södlertolm, 1.D. \& Perdue, M.H. (2001), Stress and gastrointestinal tract. It. Stress and intestinal barnier function An I Physiol Castrointest Liver Physiol 28001 : G7-G13.

Somasundaram, S. Hayllar, H., Rafi, S., Wriggteswonth, I.M., Macpherson, A.J. \& Bjarnason, 1. (1995: The biochernical basis of non-steroidal anti-inllammatory drug-induced damage to the gastrontesthal tract: a review and a hypothesis Scand/ Gastroenterol 30(4): 289-99.

Somasundaram, S., Rafi, S., Hayllar, I., Sigthorsson, G., Jacob, M., Price, A.B., Macpherson, A., Mahmod. T., Scolt, D., Wrigglesworth, J.M. \& Bjamason, 1. (1997): Mitochondrial darnage: a possible mechanism of the "topical" phase of NSAID induced injury to the rat intestine Gut 41 (3): 344-53.

Swart, P.J., Kuipers, E.M., Smit, C., Van Der Strate, B.W., Harmsen, M.C. \& Meijer, D.K. (1998): Lactoferrin. Antiviral activity of lactoferm Adv Exp Med Biol 443: 205-13.

Troosit, F.J., Steijns I., Saris, W.H. \& Brummer, R.J. (2001): Gastric digestion of bovine lactofernin in wivo in adults / Notr 131(8): 2101-4.

van Nieuwenhoven, M.A., Geerling, B.J., Deutz, N.E., Brouns, F. \& Brummer, R.I. (1999): The sensitivily of the lactulosedhamnose gut permeability test Eur / Clin Invest 29(2): 160-5.

Wallace, I.L. (1993): Gastric ulceration: critical events at the neutrophit-endothelium interface Can ) Physiot phamacol 7 (1): $98-102$.

Wyat, 1., Vogelsang, H., Hubl, W., Waldhoet, T. \& Lochs, H. (1993): Intestinal permeability and the prediction of relapse in Crohn's disease Lancet $341(8859): 1437-9$.

Zagulski, T, larzabek, Z., Zagulska, A. \& Zimecki, M. (1998): The main systemic, highly effective, and quickly acting antimicrobial mechanisms generated by lactoferrin in mammals in vivo. Activity in health and disease Adv Exp Med Biol 443: 247-50.

Zimecki, M., Spiegel, K., Whaszczyk, A. Kubler, A. \& Kruzel, ML. (1999): Lactoferin increases the output of neutrophil precursors and attenuates the spontaneous production of TNF-alpha and $1 L-6$ by peripheral blowd cells Arch immunol Ther Exp 472): 113-8.

Zimecki, M., Whaszczyk, A., Cheneau, P., Brunel, A.S., Moizurier, J., Spik, G. \& Kubler, A. (1998): Inmunoregulatory effects of a nutritional preparation containing bowine lactoferrin taken orally by healthy individuals Arch Immunol Ther Exp 46,4y: $23 \|-40$. 
CHAPTER 9 


\section{Discussion}

An important function of the small intestine is its role in the defence network against pathogens, such as bacteria, viruses and (projoxidants. Although the role of the small intestine as an immunologically active organ is well recognized and its direct responses to pathogens are under extensive investigation, little is known about the role of dietary components in mucosal interactions or about the capacity of the small intestine to prevent damage to the intestinal mucosa. Detailed information about defence mechanisms of the human small intestine against oxidative stress and the effects of food ingredients on the integrity of the mucosal barrier is important, as this may result in the development of nutritional tools to prevent the initiation of intestinal and systemic inflammatory responses, initiated by luminal and mucosal challenges. The studies described in this thesis were designed to investigate nutrient-gut interactions and regulatory mechanisms in the small intestinal mucosa in vivo.

The studies described in chapters 3 and 4 were funded by the $5^{\text {th }}$ Framework of the European Union (EU). This project, entitled 'Evaluation of the safety and efficacy of iron supplementation in pregnant women', with EU reference 'FeMMES QLK1-1999$00337^{\prime}$, aimed to examine the effects of iron supplementation in humans, and to explore the mechanisms involved using cell culture and animal models. The participation in this project, in addition to the unique properties of iron in the intestine (participation in free radicals generating cascades, micronutrient interactions, and iron absorption), evolved in special emphasis of this thesis on the effects of iron administration in the human small intestine.

\section{Iron}

\section{Iron-induced damage}

Iron participates in many biological and biochemical processes. Among other effects, iron ions catalyze a cascade of reactions, generally referred to as Fenton chemistry, which results in the production of highly reactive hycroxyl radicals. This phenomenon was described in the introduction of this thesis. Hydroxyl radicals cause oxidative damage to virtually all biological molecules in their direct environment. Previous. studies show that iron supplements induce oxidative stress in the intestine Lund et al, 1999; Sriginthar \& Nair, 1998; Srigiridhar et al, 2001). The extent and location of iron-induced damage in vivo in humans has mot been investigated to date. It is important to study site-specific damage in the Gl tract, because the consequences of lipid peroxidation to compounds in the intestinal lumen or to enterocytes at the tip of the villi may ditfer from oxidative damage to enterocytes in the base of the villi, to tight junctions or to the structures undermeath the epithelial layer. Furthermore, the adverse effects induced by stress in one intestimal segment presumably differ from those observed in other segments.

The antioxidant defence nework in the small intestine may provide a system against intestinal oxidative stress, although data about endogenous antioxidant capacity in the intestine are scarce. In chapters 3 and 4 , we showed that iron administration in medi- 
cally prescribed dosages into the proximal small intestine induced lipid peroxidation in the lumen of the small intestime. This occurred in a dose dependent fashion. Ironinduced lipid peroxidation was accompanied by the release of, yet unidentified, antioxiclants into the small intestinal lumen. This observation was consistent thoughout all experiments. The antioxidant response occurred also in a dose-dependent way. It was evident that the antioxidant response to oxidative damage was instantaneous and very powerful, especially considering the dilution of the measured intestinal fluid samples with saline, as was discussed in the appropriate chapters. The rapid release of antioxidants indicated that it, most likelly, was not de novo synthesized, but released from a storage compartment. The question remained which compound was responsible for the observed rise in antioxidant capacity. Direct measurennent of several compounds with well-established antioxidant capacity in biological systems did not elucidate this problem. In an attempt to identify the unknown compound Nuclear Mag. netic Resonance (NMR) techniques were applied to investigate compositional differences between intestinal fluid samples with high and low antioxidant capacity (data not shown). Although consistent differences between the NMR spectra of these samples were observed, we are, at this stage, not able to attribute these observations to one specific molecule. The intestinal fluid samples will, in the near future be compared using two-dimensional NMR techniques. This might elucidate the compound(s) responsible for the differences in antioxidant capacity between the fluid samples.

The studies described in chapters 2,3 and 4 reveal the underlyng physiological response of the small intestine to iron supplementation. We showed that 4 weeks of high-dose iron therapy does not induce functional damage to the integrity of the small intestinal mucosa in iron deficient premenopausal women, nor was the mucosal integrity more susceptible to indomethacin-induced epithelial damage after one month of iron supplementation. The results of the study suggested that iron did not induce oxidative damage to the small intestinal mucosa. However, after developing a novel, accurate model to directly investigate processes in the lumen of the small intestine in vivo, we showed that iron induced lipid peroxidation in healthy wolunteers. The data showed that irom administration initially causes oxidative stress in the small intestine, which confirms previous data from animal experiments (Fodor \& Marx, 1988 ; Srigiridhar \& Nair, 1998; Srigiridhar \& Nair, 2000\%. However, it was shown for the first time that intestinal oxidative stress activated a powerful antioxidant network. The data from the studies described in chapters 2,3 and 4 suggested that, despite initial oxidative damage upon iron administration, the antioxidant response in the small intestine presumably prevents impaired mucosal integrity of the small intestine during pertods of iron therapy. However, the studies described in this thesis focused on intraluminal effects of iron administration and on the mucosal barrier function. The impact of in testinal iron administration on other properties of the small intestinal mucosa, such as enzyme activities in the brush border, or intraepithelial processes in vivo in humans remains to be investigated.

\section{Iron-mediated changes in gene expression patterns}

The study described in chapter 4 showed that iron or iron-induced oxidative stress mediated the expression of many genes in small intestimal mucosa. In an altempt to 
identify specific biological pathways, mediated at the transcriptomic level by the iron interventions, the study results were analyzed using public, shared databases. This approach revealed that iron or iron-induced oxidative stress strongly affected several distinct processes in the mucosa of the small intestine. Iron mediated several G protein coupled receptor (CPCR) associated processes. CPCRs comprise the largest supertamily of proteins in the body. They serve functions in a wide variety of biologicall pathways, which are generally related to intracellular signalling routes. The observation that three out of the six processes most strongly mediated by the iron interventions involved GPCRs suggests an important, previously unknown, stress response mechanism, which should be inwestigated in detail. The other three processes identified by the method used to allocate the observed changes in gene expression patterns to biologically pathways, namely cell cycle, calcium channels and complement activation, also warrant further investigation.

The genome-wide microarray scans contain a lot of data. They provide detailed information about baseline gene expression profiles in the healthy human small intestine, some mediated by iron or iron-induced oxidative stress, some involved in many specific biological pathways, and other genes with a yet unknown function. Many changes in gene expression profiles failed to reach significance, in part owing to the design of the microarray experiment. Mucosal tissue samples were obtained approximately 120 minutes after the start of iron perfusion. Recent literature shows that sig.. nificant changes in gene expression occur approximately 180 minutes after oral iron administration to rats (Frazer et al., 2003). Therefore, the timing of tissue sampling may not have been optimal for gene expression experiments. However in the original design a genome wide microarray was not included since the technology was still under development at that time. This aspect should be considered in the design of future gene expression experiments.

The variety of individual genes and biological pathways that were mediated by the iron perfusion experiments, confirms the importance of implementing genome-wide gene expression experiments in the investigation of poorly understood phenomena, such as intestinal oxidative stress, but also in many (intestinal) diseases. The microatray technology provides a sophisticated tool to obtain information about the complex dynamic equilibrium between a wide variety of processes. It can be applied to identify new signalling pathways in health and disease and, additionally, it has great potential to be implemented in scientific research as a "hypothesis generating" tool, because it provides information about virtually all dynamic processes in the body. Due to the huge amount of sometimes contradictory data, it may not provide definitive answers to specific hypotheses. For that purpose, implementation of dedicated complementary deoxyribonucleic acid (cDNA) microarrays, with a limited number of genes to be studied, may be indicated, in addition to other techniques such as proteomics and biochemical analyses of biological samples.

\section{Considerations of iron supplementation}

Iron supplementation affects the human small intestine in several ways. This thesis shows that iron given as single iron dosages of 80 or $400 \mathrm{mg}$ do not induce major oxi- 
dative damage to the small intestinal mucosa. The long-term effects of iron on mucosal gene expression and its consequences will need to be established. The question remains whether the initial iron-induced, oxidative damage observed in the intestinal perfusion experiments, affects other structures or processes in the small intestine. It may be suggested that free radicals pass the epithelium and induce damage to the structures underneath. This may affect the microvasculature or the lymph system in the mucosa, or damage the enteric nerwe system. Furthermore, free radicals, produced in the lumen of the small intestine, may cross enterocyte membranes and attack other compounds in these cells. Polyunsaturated fatty acids (PUFAs) are vulnerable to free radical-induced damage, due to the presence of multiple double bonds. Theretore, mitochondrial outer membranes with large concentrations of PUFAs appear to be especially vulnerable to oxidative damage. Moreover, the nucleus of epithelial cells may be attacked, which may induce DNA strand breaks of other molecular damage. These issues need to be addressed in future studies of the effects of iron and oxidative stress in the small intestine in vivo. Furthermore, the experiments described in this thesis were carried out in relatively healthy volunteers. In people at higher risk of intestinal oxidative stress, such as in the malnourished, newborns, the elderly, or patients suffering from Gl diseases, therapeutic amounts of iron may lead to more severe clamage.

Chapter 5 showed that iron supplements inhibit the absorption of zinc, when taken in a water solution. This phenomenon was already present with moderate amounts of supplemental iron, suggesting that long-term iron supplementation may impair body zinc status. If the cause of iron deficiency anaemia is malnutrition, as is observed regularly in developing countries, inhibition of zinc absorption is a severe health threat and, hence, deserves special attention in the medical treatment of those patients (Allen, 1994; Solomons \& Ruz, 1997). Copper absorption was not impaired by the presence of iron and hence, should not need special attention. The studies described in this thesis show that usual, medically used amounts of iron can safely be prescribed to iron-deficient but otherwise healthy patients, if care is taken regarding the patients zinc status. It should, however, be considered that high dosage of iron may induce damage to the intestinal submucosa, as described above. Hence, iron therapy should be limited to the replenishment of body iron stores.

\section{Lactoferrin}

\section{Gastrointestinal digestion of lactoferrin}

The studies described in chapters 6 and 7 aimed to investigate the metabolic fate of the glycoprotein lactoferrin in the gastrointestinal tract. Several effects have been attributed to this protein. Its capacity to bind iron with high affinity suggests a role in the defence against microbes, viruses, inflammation and oxidative challenges, whereas the presence of specific lactoferrin receptors in the apical membrane of the intestinal mucosa suggests functions in enterocyte-specific processes, such as iron absorption. The potential functional roles have resulted in the development of oral lactoferrin supplements, which claim to be beneficial to human health and are commercially available as over-the counter supplements. 
Detailed information about lactoferrin degradation, prior to studying its effects in various sites of the GI tract, was needed to design subsequent studies of the effects of lacloferrin supplementation. Chapter 6 describes lactoferrin survival during gastric transit. Up to $79 \%$ of intact lactoferrin, ingested in a sugar solution into the stomach of healky wolunters, entered the small intestine as intact lactoferrin. Hence, most lactoferrin, either as apo- or as hololactoferrin, enters the small intestine in its original, intact form. The study described in chapter 7 showed that recombinant human lactoferrin is fully degraded in the small intestime. In this study applying the ileostomy model, trace amounts of lactoferrin appeared in the ileostomy effluent. These minute amounts originated most likely from an endogenous source. We suggest that neutrophils, attracted by immune activation owing to pathogenic challenges in the lumen of the small intestine, degramulate upon infiltration into the mucasa or after release into the lumen of the smatl intestine, thereby releasing endogenously produced lactoferrin (Furmanski \& Li, 1990; Pereira et al, 1998). A low level of immune activation is part of normal intestinal physiology. The low lactoferrin concentrations in ileostomy effluent should, therefore, not be considered as indicators of gastrointestinal disease activity. High faecal lactoferrin levels can be found in subjects with an intact gastrointestinal tract. It was shown that faecal lactoferrin can be regarded as a marker of disease activity in Inflammatory Bowel Disease patients (Sugi et al, 1996). The data from chapter 7 suggest that faecail lactoferrin predominantly originates from the colon, and not from the small intestine.

The lactoferrin used in the studies described in chapters 6 and 7 was isolated from bovine and recombinant human sources, respectively. Lactoferrin binding to its specific receptors is a species specific process. Therefore, it is important to carefully consider the origin of the lactoferrim used in the design of studies of lactoferrin in the gastrointestinal tract. Despite the different origin of the lactoferrin used in chapters 6 and 7. the molecular structure of bovine and (recombinant) human lactoferrin are largely identical; bovine lactoferin consists of 689 amino acids, whereas human lactoferrin contains 691 amino acids. The three-dimensional structure of these lactoterrins is largely the same (Baker \& Lindley, 1992; Steijns wan Hooijdonk, 2000). Therefore, the assumption that the different isoforms of lactoferrin are digested at approximately the same rate seems to be justified.

The results from chapters 6 and 7 indicate that oral lactoferrin supplements deliver intact lactoterm to the small intestine without the need to protect against gastric degradation. Functional effects of lactoferrin supplementation may therefore be expected in the small intestine. If lactoferrin administration is indicated for application in the colon, the use of ileal release-encapsulation or enemas should be considered.

\section{Functional application of lactoferrin supplements}

In chapter 8, the non-steroidal anti-inflammatory drug indomethacin was administered to induce standardized mucosal damage in healthy volunteers. Synchronous supplementation with lactoferrin inhibited the indomethacinminduced rise in small intestinal pemeability. This was the first study to show a beneficial effect of lactoferrin administration on gut function in humans. The underlying mechanism of action is not clear. 
Although it seems plausible to attribute the protective effects of lactoferrin to its antioxidant capacity, this explanation is not supported by the outcome of the studies described in chapters 3 and 4 . In these studies, oxidative stress in the small intestine was provoked by local administration of acute dosages of ferrous iron. Iron initiated lipid peroxidation in the intestinal lumen. In all experiments, this rise in lipid peroxidation was accompanied by a synchronous rise in antioxidant capacity. From those studies we concluded that the detrimental effects of oxidative stress in the human small intestine were inhibited by the release of a powerful antioxidant into the lumen of the small intestine. Considering the large antioxidant capacity available to counteract the oxidant challenges, it is unlikely that administration of an exogenous antioxidant, such as lactoferrin, would provide an additional protection against acute intestinal oxidative damage. Hence, the observed beneficial effect of lactoferrin administration, described in chapter 8 , was probably not induced by the antioxidant capacity of lactoferrin, but by another mechanism of action.

This does not exclude a beneficial role of antioxidant supplementation in oher situations associated with impaired gut function. Chronic oxidative stress in the intestine may result in depletion of the endogenous antioxidant capacity of the intestinal secre. tions. Moreover, malnutrition may impair the endogenous antioxidant defence network, and, hence, antioxidant supplementation may be indicated to prevent intestinal oxidative damage. Furthemore, in patients with a so-called 'compromised gut', an additional, oxidative stress may induce enteropathy, whereas this may be prevented by dietary antioxidant supplementation or by dietary components that stimulate the generation of a capable antioxidant network.

\section{Considerations for future research}

The studies described in this thesis were designed to investigate responses of the human small intestine in vivo to dietary factors, such as iron and lactorerrin. Future studies should be designed to further investigate nutrient-mucosal interactions in the small intestine. Information about the causal relation between intestinal oxidative stress and inflammation, about the interaction between dietary components and the mucosal barrier, and about enviromment-gene interachions in intestinal mucosa will contribute to the understanding of gut function in health and disease, and maly provide nutritional tools to optimize gut health. Specific aims, which should be investigated, are to identify the antioxidant which was released upon oxidative damage in the small intestine, to investigate the possibilities of increasing the endogenous antioxidant depot in patients with low antioxidant levels, as was observed in several Gll disorders, to investigate the impact of iron administration in the small intestine on submucosal structures and to elucidate the consequences of the observed changes in gene expression patterns following iron administration in the small intestine. 


\section{References}

Alden, L.H. (1994): Nutritional influences on linear growh: a general review Eur 1 Cin Nutr 48 suppl $1: \$ 75-89$.

Daker, EN. \& Lindley, P.F. (1992): New perspecives on the structure and function of transtersins / Horg Biochem 47(3-4): $147-60$.

Fodor, 1. \& Marx, 1.) (1988): Lipid peroxidation of rabbit small intestinal microvillus membrane vesicles by iron complexes Biochim Brophys Acta 961(1): 96-102.

Frazer, D.M., Wilkins, S.I., Becker, EM., Murphy, T.L., Vulpe, C.D., McKie, A.T. \& Anderson, G.J. 2003): A rapid decrease in the expression of DMT1 and Dcyb but not ireg1 or thephaestin explains the mucosal block phenomenon of iron absomption Gut $52(3 ;: 340-6$.

Furmanski, P. \& L, Z, P. (1990): Multiple forms of lactoferrin in normal and leukemic human gram nulocytes Exp themato $1818: 932-5$.

Lund, E.K., Whanf, S.G., Faimeather Tait, S.J. \& Johnson, I.T. (1999): Oral ferrous sulfate supplements increase the free radical-generating capacity of feces from healthy volunteers Am i Chn Nut 6942): 250-5.

Pereira, S.P., Rhodes, I.M., Campbell, B.I, Kumar, D., Bain, I.M., Murphy, G.M. \& Dowling, R.H. (1998): Biliary lactoferrin concentrations are increased in active inflammatory bowel disease: a factor in the pathogenesis of primary sclerosing cholangitis? Chn Scl (Colch) 95(5): 637-44.

Solomons, N. \& Ruz, M. (1997): Zinc and iron interaction: concepts and perspectives in the deweloping world Nutrition Research 17(1): 177.185.

Srigiridhar, K. Nair, K.M. (1998): Iron deficient intestine is more susceptible to peroxidative damage during iron supplementation in rats Free Radic Biol aved 25(6): 660-5.

Srigiridhar, K. \& Nair, K.M. (2000): Supplementation with alphatocopherol or a combination of alphatocopherol and ascorbic acid protects the gastrointestinal inact of iron-deficient rats against ironinduced oxidative damage during iron repletion $\mathrm{Br} / \mathrm{Nutr}$ 84(2): $165-73$.

Srigiridhar, K., Nair, K.M. Subramanian, R. \& Singotamu, L. (2001): Oral repletion of iron induces free radical mediated alterations in the gastrointestinal tract of rat Mol Cell Bsochem 219(1-2): 90 -8.

Sicing, I.M. \& van Hoolidonk, A.C. 2000): Occurrence, structure, biochemical properties and technological characteristics of lactoferrin Br/ Nutr 84 Suppl 1: $\$ 11.7$.

Sugi, K., Sairoh, O., Hirata I. \& Katsu, K. (1996): Faecal lactorerrin as a marker for disease activily in inflammatory bowel disease: comparison with other neutrophil-derived proteins Am / Gastroen. (cho/ 9115$): 927-34$. 


\section{Summary}

The small intestinal mucosa forms a functional, tightly controlled barrier against intrusion of a wide variety of pathogenic components. Its integrity may be compromised by factors such as dietary pathogens and toxic food ingredients. In this thesis research is focussed on two food ingredients with positive but potentially also negative health aspects; iron and lactoferrin. Iron is an important micronutrient, due to its participation in many biochemical processes, however, free iron ions are known to catalyze the formation of highly reactive hydroxyl radicals. These radicals are extremely reactive, and may cause damage to all biological molecules in the body. Hence, iron ingestion may lead to undesirable side effects in the gastrointestinal tract and also, iron may compete for absorption with other micronutrients, especially divalent cations such as zinc and copper. The presence of high amounts of dietary iron may, therefore, impair the bioavailability of zinc and copper. In this thesis we investigated the deleterious effects of iron administration on the integrity and biochemistry of the small intestinal mucosa, and on the bioavailability of zinc and copper. The milk protein lactoferrin is a food ingredient with potential positive effects on the intestinal mucosa due to its biological activity, among others the antioxidant and iron binding capacity. We investigated effects of lactoferrin in the small intestine as a second food ingredient.

Chapter 2 describes a study of the effects of iron supplementation on the integrity of the small intestinal mucosa. In this placebo-controlled study, we showed that small intestinal permeability, a well-accepted indicator of the integrity of the small intestinal mucosa and a parameter of epithelial damage, was not affected by oral iron supplementation at daily dosages of $100 \mathrm{mg}$ iron for 28 days. These findings suggested that, in contrast with previous data from in vitro and animal studies, iron did not induce oxidative stress in the intestine. To investigate iron-mediated biochemical processes in the small intestine in vivo, we developed an intestinal perfusion technique. Chapter 3 describes the results of the first study applying this novel technique. We administered iron into the proximal small intestine, and sampled small intestinal fluid. We showed that iron administration induced lipid peroxidation, a parameter of oxidative damage, in the lumen of the small intestine. This was accompanied by a momentary rise in total antioxidant capacity of the samples, suggesting that oxidative stress triggered the release of a powerful but yet unidentified antioxidant in the small intestine. In this study, we were unable to investigate the effects of iron administration on the small intestinal mucosa. Therefore, in the study described in chapter 4 , the intestinal perfusion technique in humans was combined with gastroduodenoscopy to obtain tissue samples from the small intestinal mucosa. The effects of different dosages of iron on oxidative stress and antioxidant capacity in small intestinal secretions and on gene expression profiles in small intestinal mucosa were investigated. We showed that iron administration in the small intestine caused oxidative damage and the release of antioxidants in a dose-dependent manner. Also, the iron intervention resulted in changes in the expression of eighty-nine genes. Functional mapping of genome-wide microarray experiments, carried out to investigate changes in gene expression profiles, identified six biological processes that were significantly mediated by the iron intervention. Although it is clear that several of these processes were associated with cell signalling 
pathways, the biological implication of these results will have to be elucidated in future studies, specifically aiming to investigate these processes.

A study of the interaction between iron, zinc and copper was described in chapter 5 The investigation was designed to quantify zinc and copper absorption in the small intestine in the presence of different amounts of iron. We showed that a single dosage of iron significantly inhibited zinc absorption. The rate of inhibition of zinc absorption was not dependent on the dosage of iron. Copper absorption was not affected by the presence of iron.

The milk protein lactoferrin is suggested to exent many different biological activities in the intestine, in part due to its strong iron-binding capacity. Antioxidative, antiviral, anti-inflammatory and bactericidal properties were previously atributed to the molecule. Prior to studying its possible application as a functional food ingredient to de. crease or prevent gastrointestinal disorders, it is important to obtain detailed information about its gastrointestinal survival rate. Gastric digestion of bovine lacloferrin was investigated in the study described in chapter 6 . We showed that more than $60 \%$ of all lactoferin administered to the stomach survived gastric transit. It was previously suggested that iron-saturated lactoferrin (hololactoferrin) was less susceptible to gastrointestinal degradation than the iron-unsaturated form (apolactoferrin). However, this study showed that gastric digestion of holo- and apolactoferrin in wivo did not statistically differ. The metabolic fate of lactoferrin after oral administration, and after transit through the stomach and the small intestine, was investigated in the study described in chapter 7 . We demonstrated in this study applying the ileostomy model that orally administered recombinant human lactoferrin is completely digested before it is emptied from the small intestine. We observed small but relatively constant amounts of intact human lactoferrin appearing in the ileal effluent, and suggest that these trace amounts of lactoferrin originated, most likely, from an endogenous sounce, such as the granules of infiltrating neutrophils in the small intestine.

We investigated the capacity of lactoferrin to prevent or inhibit mucosal damage in the stomach and in the small intestine in vivo in the study described in chapter 8 . The non-steroidal anti-inflammatory drug indomethacin was administered to healthy volunteers to provoke damage to the intestinal epithelium. This caused standardized, well-investigated and reproducible gastrointestinal damage, which was quantified by measuring the permeability of the small intestine using the lactulose/mamnose gut permeability test. Oral lactoferrin supplementation reduced the indomethacin-induced damage to the mucosa of the small intestine. This is the first study to show a functional, beneficial effect of lactoferrin supplementation in humans, and justifies the design of further studies to investigate the application of lactoferrin supplements in patients suffering from gastrointestinal cisorders, as well as healthy people, in order to prevent gastrointestinal discomfort. 


\section{Samenvatting}

De binnenwand van de dunne darm, de darmmucosa, vormt een functionele verdediging tegen het binnendringen van ziekteverwekkers. De integriteit van de darmmucosa kan verminderen onder invloed van verschillende factoren, bijvoorbeeld ten gevolge van pathogene bacteriën of toxische componenten die via de voeding de darm binnen komen. In dit proefschrift worden twee voedingscomponenten bestudeerd. Enerzijds is het onderzoek gericht op het melkeiwit lactoferrine als voorbeeld van een voedingsingredient met mogelijke positieve eigenschappen ten aamzien van de integriteit van de darm. Anderzijds is speciale aandacht besteed aan het micronutrient ijzer, dat een belangrijke functie heeft in vele biochemische processen. Het is echter bekend dat de aanwezigheid van ijzer kan leiden tot een snelle vorming van schadelijke hydroxyl radicalen. Deze radicalen zijn zeer reactief, en kunnen schade berokkenen aan alle biologische molecule in het lichaam. Dien tengevolge kan de inname van ijzer leiden tot het optreden van ongewenste bijwerkingen in het spijsverteringskanaal. Bovendien kan ijzer de opname van andere micronutrienten, zoals zink en koper, remmen omdat deze metalen voor een deel via een identiek mechanisme worden opgenomen vanuit de darm. Hierdoor ontstaat een competitie voor opname. De aanwezigheid van grote hoeveelheden ijzer in de voeding kan dus wellicht de biologische beschikbaarheid van zink en koper remmen.

In dit proefschrift hebben wij enerzijds de schadelijke effecten van ijzertoediening op de integriteit van de darmmucosa en op biochemische processen in de dunne darm bestudeerd, alsmede de invloed van de aanwezigheid van ijzer op de opname van zink en koper. Anderzijds is onderzoek verricht naar het afbraak in en de effecten van lactoferrine in het spijswerteringskanaal.

In het onderzoek dat in hoofdstuk 2 beschreven staat is het effect van ijzersuppletie op de integriteit van de dunne darm onderzocht. We hebben aangetoond dat de doorlaatbaarheid, ofwel de permeabiliteit, van de dunne darm, hetgeen een maat is voor integriteit wan de darmwand en gebruikt kan worden als een parameter van darmschade, niet beinvloed wordt door ijzersuppletie. Deze bevinding duidt er op dat ijzer geen schade aan de darmwand veroorzaakt. Dit is in tegenspraak met de gegevens die uit eerder gepubliceerd reageerbuis- en proefdieronderzoek beschikbaar zijn. We hebben een darmperfusietechniek ontwikkeld om het mogelijk te maken de invloed van ijzer op biochemische processen in de darmholte te bestuderen. Hierbij wordı bij gezonde mensen een deel van de dunne darm doorgespoeld met een vloeistof en kunnen darmsapmonsters worden afgenomen. In hoofdstuk 3 wordt het eerste onderzoek beschreven waarin gebruik is gemaakt van deze nieuwe techniek. Hierbij hebben we het eerste deel van de dunne darm doorspoeld met een ijzerhoudende oplossing. Tijdens deze perfusie zijn darmsapmonsters afgenomen. De resultaten van dit onderzoek laten zien dat toediening van ijzer in de darm leidt tot een snelle vorming van vetzuurperoxides. Dit is een maat voor oxidatieve schade. We hebben bovendien aangetoond dat deze schade samenging met een zeer sterke stijging van de antioxidatieve capaciteit in de darmsapmonsters. Deze gegevens duiden op het feit dat oxidatieve schade in de dunne darm van mensen leidt tot een directe vrijmaking van antioxidanten. Onderzoek naar de identiteit van deze antioxidant heeft tot nu toe geen duidelijke identificatie opgeleverd. In dit onderzoek waren wij niet in staat om 
de effecten van ijzertoediening in de dunne darm op de darmmucosa zelf te onderzoeken, omdat slechts darmvloeistof en geen darmweefsel werd argenomen. Daarom hebben we in het onderzoek dat staat beschreven in hoofdstuk 4 de darmperfusietechniek gecombineerd met het afnemen van darmweefsel door middel van gastroduodenoscopieën. In dat onderzoek zijn de effecten van verschillende doseringen ijzer op oxidatieve schade, op antioxidatieve capaciteit en op de genetische aansturing, ofwel de genexpressie, van cellen in de darmmucosa onderzocht. Dit onderzoek bevestigde dat ijzertoediening in de dunne darm oxidatieve schade en de vrijmaking van antioxidanten veroorzaakt. Beiden waren afhankelijk van de hoeveelheid ijzer dat werd toegediend. De toediening van ijzer veroorzatkte een verandering in de expres. sie van 89 genen. Na functionele analyse van deze genexpressie resultaten bleek dat zes biologische processen significant waren beinvloed door de ijzertoedieningen. Enkele van deze processen waren betrokken bij de overdracht van signalen. Toekomstig onderzoek dat specifiek gericht dient te zijn op de bestudering van deze processen moet de biologische betekenis van deze resultaten ophelderen.

In hoofdstuk 5 wordt de invloed van verschillende hoeveetheden ijzer op de opname van zink en koper beschreven. De resultaten van dit onderzoek laten zien dat de aamwezigheid van ijzer de opname van zink in de dumne darm remt. Hierbij maakt het niet uit of er een kleine of grote hoeveelheid ijzer aanwezig is. De opname van koper werd niet beïnvloed door de aanwezigheid van ijzer.

Het melkeiwit lactoferme heeft, vooral door zijn sterk ijzerbindende capaciteit, verscheidene eigenschappen die de darmgezondheid kunnen verbeteren. Aan het molecuul worden onder andere antioxidatieve, antivirale, anti-inflammatoire en antibacteriële eigenschappen toebedeeld. Voordat kan worden onderzocht of er een rol voor lactoferrine in voedingssupplementen is weggelegd, dient eerst informatie verkregen te worden omtrent de afbraak van lactoferrine in het spijsverteringskamaal. In het onderzoek dat beschreven is in hoofdstuk 6 is de afbraak van lactoferrine, afkomstig uit koemelk, in de maag onderzocht. Meer dan $60 \%$ van hel lactoferrine dat in de maag werd gebracht bleek onveranderd vanuit de mag in de dunne dam te worden geledigd. Voorgaand onderzoek liet zien dat lactoferrine dal verzadigd is met ijzer beter bestand zou zijn tegen atbraak im thet spijsverteringskanaal dam onverzadigd lactoferine. Dit werd echter niet bevestigd in ons onderzoek. In het volgende onderzok, be schreven in hoofdstuk 7 , hebben we de afbraak van recombinant humaan lactoferrine ma passage van de maag en de dunne darm onderzocht met behulp van het ileostoma model. Het ingenomen lactoferrine werd volledig afgebroken tijdens de passage door de maag en dunne darm. De zeer kleine hoeveelheden lactolerrine die met een constante snetheid werden uitgescheiden uit de dunne darm waren zeer waarschijnlijk afkomstig uit endogene lactoferrine productie.

Naar aanleiding van de eerder gepubliceerde aanwijzingen dat lactoferrine de gezondheid op verschillende manieren kan bevorderen hebben we een onderzoek uitgevoerd naar het vermogen van lactoferrine om schade an de darmmucosa te voor komen. Voor dit onderzoek, dat beschreven stat in hootdstuk 8 , hebben we het medicijn indomethacine aan gezonde vrijwilligers gegeven. Indomethacine wordl in de medische praktijk voorgeschreven om pijn en ontstekingsreacties te bestrijden. Het heeft als bijwerking dat de darmmucosa wordt beschadigd, waardoor de darmdoor- 

Het is af, het proefschrift is klaar. In een dankwoord wordt een passende beschrijving van de argelopen promotieperiode verwacht, eventueel aangedikt met een aardige anckdote, geschreven vanuit de achtergrond wan de auteur. Verwachte clichés, zoals werhalen wanuil een wielerperspectief, zal ik u echter besparen. Hora est, nietwaar? U heeft immers net wol overgave het proefschrift gelezen. Ik zal dit dankwoord dan ook beknopt houden.

Tijdens mijn stage-verbliff in Pittsburg, USA, in 1997 bereikte mij per $\mathbb{E}_{\text {-mail reeds het }}$ bericht dat er bij de capaciteitsgroep Humane Biologie wan de Universiteit Maastricht een AiO positie aan zat te komen en dat ik er, eenmaal terug in de lage landen, goed aan zou doen daar op te solliciteren. lk ben niet lang daama aan de slag gegaan met het AiO project, waarvan bij aanvang slechts wast stond dat het onderzoek een brug zou moeten vormen tussen de gastroenterologie en her humane voedingsonderzoek. Het eindresultaat wan dat project is dit proetschrift.

Voor het tot stand komen van dit proefschrift ben ik met name mijn twee promotores veel dank verschuldigd. Wim, ik ben je buitengewoon erkentelijk voor de wijze war. op je mijn promotic-onderzoek als promotoir hebt begeleid. Met name jouw netwerk aan contacten binnen de universiteit en met industrie was essentieel voor verschillende studies, evenals je inzicht in de 'hot topics' in de levenswetenschappen. Daarmast heb je een grote bijdrage gehad in het opzetten van verschillende onderzoeken. Met name in de beginperiode van het promotieproject heb je, met je soms confronterende kritiek mijn artikelen in een leesbaar format gebogen. Ook je positie als tweedehands-auto verkoper, sponsor wan mijn fanclub tijdens de Ridderronde in Maastricht en van luttele meters bier tijdens weer eens een feestawond met de capgroep, evenals: je medewerking aan promotievideo's heb ik zeer gewaardeerd. Tot op de dag van vandaag blijf je me verbazen met je werklust (ik herinner me de E-mail die je me schreef toen je tijdens je vakantie in Canada op de boot stond te wachten, en dus toch niets te doen had ...).

Robert-Jan, als directe begeleider was jij het meest intensief bij mijn onderzoek betrokken. Je vakkennis op onder andere het gebied van de gastroenterologie en de klinische voeding, en je drang om voortdurend te zoeken naar nieuwe modellen om voeding darm interactie in vivo in mensen te bestuderen was onontbeerlijk voor het welslagen van verschillende onderzoeken. Naast je actieve rol in inhoudelijke discussies, hat uitvoeren van de experimenten en het corrigeren van de manuscripten zat de grote kracht van onze samenwerking waarschijnlijk in de koffiepauzes. De keren dat je even een kop koffie kwam halen zijn inmiddels ontelbaar. Kofie was uiterard bijzaak. Voor jou als goede manier on de ziekenhuishectiek voor enkele minuten te ontopen, voor mij als anti-RSt kwartiertje, waren deze korte bijeenkomsten steevast het platform voor veel, zelis af en toe wetenschaps-gerelateerde, hersenspinsels, of dit nu om veeziektes, politiek, opwoeding of met name sport ging. Ook de schaatsavonturen, met helm en pirouette, zal ik niet snel vergeten. Ik ben dan ook blij dat we in de toekomst binnen NUTRIM onze samenwerking zullen voorzetten.

Naast mijn direcle promotieteam' zijn er natuurlijk velen in de loop der jaren geweest. die een grote of kleinere bijdrage aan de totstandkoming van dit proefschrift hebben geleverd. Chris, mijn kamergenoot op de UNS50 gedurende enkele jaren, het zal 
nooit meer hetzelide worden zonder jou. Voorbij zijn de tijden van Jack Daniels, pannekoeken en YMCA. Joost, Patrick en Reinout, tsja, wat te zeggen en het toch fatsoenlijk houden? Wielrennen, al dan niet hypoglycaemisch, mountainbiken, schaatsen, en vooral promotiefeesten, De Orgied, $3 \times 3=9$ etc., steekwoorden die in meer of mindere mate bij jullie horen. Wat voor computer-analyse- of andere problemen ook voorbij kwamen, door ons gezamenlije vermogen om veel energie te steken in vol. strekt irrelevante zaken is de accu, ondanks/dankzij tysiek lijden tijdens het sponten. altijd weer opgeladen. Veel dank hiervoor. De LDVDM, capgroepsborrels, Charlemagnelestijnen, carnavalsuitspattingen en promotiefeesten waren, laten we zeggen, aangenaam vertoeven, mede door de subtiele inbreng van onder andere Luc, Jos, Enkhuizer Irritantje, Edgar, Michiel en Margriet. Daarnaast stonden veel collega's parat wanneer dat gewenst en ongewenst was. Marieke, Tanja, Lydia, Guy, Annemiek, Neeltje, Manuela, Ilse, Kristel, Marco, Matthijs, Lars, Gerard, Joan, Paul, Loek, Eefje, Marja, Gijs, Joris, Cyriel, Jogchum, Annemie, Petra, Arjen, Wouter, Gert, Claudia, Marielle, llona, Desiree en Truus, jullie, en uiteraard allen die hier niet bij name genoemd staan, hebben naast de nodige vakhulp (EHBO bij op hol- of juist vastgeslagen computers verlenen, lab-en statistische analyses, papierrompslomp) door het mede. organiseren van dan wel deelnemen aan de HBTOLRPOOLO, karten, schaatsen, fielsen, etc), er voor gezorgd dat het werk de afgelopen jaren vaak meer leek op een dag in Apenheul dan op jaren van wetenschappelijk onderzoek. A special word of appreciation for you, Dean. It was a shame that you had to leave Masitricht, but we will of course stay in touch. Thanks for your company during ouir ice-skating trips, and especirally for your excellent help with the English grammar in this thesis. Ik wil Ellen Oosterwijk van harte bedanken voor het maken van het ontwerp woor de omslag van dit proefschrift.

Veel collega"s hebben vanuit hun eigen vakgebied meegeholpen aan het tot stand komen van dit proefschrift. Hierbij wil ik met name de werknemers van de afdeling gastroenterologie van thet Academisch Zjekenhuis Maastricht bedanken voor de witstekende, professionele hulp bij het uitvoeren van de darmperfusie experimenten. voor deze en andere experimenten was ook de hulp van de vershillende slagiaires, Erica, Els, Els en Lourens, onontbeerlijk. Mede dankzij de vaak lange dagen dir jullie gemaakt hebben tijdens het uitvoeren van de experimenten en analyses waren we in staat het perfusiemodel verder te ontwikkelen. Voor het opzetten van verschillende onderzoeken heb ik waardevolle informatie en praktische en/of financièle steungekregen van Jan Steijns (DMV international), Karel Petrak (Agennix Inc.), en de collega's van het EU project FeMMES. Voor het opzetten en uitvoeren van verschillende biochemische analyses ben ik met name veel dank verschuldigd aan Joan, Gent, Geerda Tindemans (DMV international) en Zhi-Dong Jiang, Universily of Texas. Ook Jos ("hou maar op, ezel, er komt toch niels uit!") verdient een woord van dank voor zijn onophoudelijke en altijd opbeurende kritick.

De onderzoken hadden niet tot stand kunnen komen zonder de grote inzet van de proefpersonen. Allen die zich hebben onderworpen a an de vak tijdrovende en ingrijpende onderzoeksprotocollen, zoals bloedafnames, het inbrengen van maag- of darmsondes, gastroscopieën, het minutieus afwegen van de dagelijkse voeding het zelf dagenlang verzamelen van lichaamsmonsters, het gebruiken van ijzerpillen en het 
innemen van sukerdrankjes; van harte bedankt voor jullie inzet! Zonder jullie was geen wan de in dit proefschrift beschreven onderzoeken mogelijk geweest.

Het is al weer een flink aantal jaren geleden dat ik vanuit Terwolde naar Maastricht ben gekomen. De onvoorwaardelijke steun en het vertrouwen van mijn ouders was altijd vanzelfsprekend. "Blijf doen wat je leuk vindt, dan komt de rest vanzelf" "hebben jullie me meermalen meegegeven. Dat doe ik dan maar. Pa en ma, bedankt, voor alles.

Mery, ik weet dat het woor jou niet altijd een feest was als ik op onze spaarzame dagen samen weer eens vertrok voor het fietsen van wedstrijden in afgelegen oorden. Desondanks ben je er altijd voor me geweest en zul je er altijd woor me zijn. Ik zal je altijd dankbaar blijuen voor de fantastische prinses die je op de wereld hebt gezet. Iris, hoe klein je ook bent, ontzettend bedankt voor jouw onvoorstelbare levenslust en energie, waar ik zo af en toe stiekem iets van mee neem. Deze is voor jou. 


\section{Publications}

\section{Full papers}

Schrauwen P, Troost F, Xia 1, Ravussin E, Saris W. Skeletal muscle UCP2 and UCP3 expression in trained and untrained male subjects. Int / Obes Relat Metab Disord. 1999;23:966-72.

Kelley $\mathrm{D}_{v}$ Thate $\mathrm{F}$, Troost F, Huwe $\mathrm{T}$, Goodpaster B. Subdivisions of subcutaneous abdominal adipose tissue and insulin resistance. Am \& Physol Endocrinol Metab. 2000;278:E941-8.

Troost F, Steijns l, Saris W, Brummer R-J. Gastric digestion of bovine lactoferrin in wiwo in adults. / Nutr. 2001,131:2101\%4.

Konings E, Troost F, Castenmiller J, Roomans H, Van Den Brandt P. Saris W. Untestinal absorption of different types of folate in healthy subjects with an ileostomy. $\mathrm{Br}$ ) Nutr. 2002;88:235-42.

Troost F, Saris W, Brummer R-J. Orally ingested human lactoferrin is digested and secreted in the upper gastrointestinal tract in vivo in women with ileostomies. I Nutr. 2002;132:2597-2600.

Troost F, Saris W, Haenen $G$, Bast $A$, Brummer R-1. A new method to study oxidative damage and antioxidants in the human small bowel: effects of iron application. Am I Physiol Gastrointest Liver Physiol. 2003:285:C354-G359.

Troost F, Brummer R-J, Dainty J, Hoogewerff J. Bull V, Saris W. Iron supplements inhibit zinc but not copper absorption in wivo in ileostomy subjects. Am / Clin Nutr. $2003 ; 78$, in press.

Troost F, Saris W, Brummer R-f. Recombinant human lactoferrin ingestion attenuates indomethacin-induced enteropathy in wivo in healthy wolunteers. Eur / Clin Nutr. 2003; in press.

Troost F, Brummer R-I, Haenen G, Bast A, van Haaften R, Evelo C, Saris W. In wivo regulation of gene expression in the small intestinal mucosa by iron-induced oxidative stress. submitted.

Troost F, Sapis W, Brummer R-I. Mucosal integrity of the small intestine in women using iron supplements. submitted. 


\section{Published abstracts}

Troost F, Schrauwen P, Saris W. The impact of venous occlusion on the athletic health test cut-off value. Eur I Clin Invest. 2000;30.

Troost $F$, Kilkens $T$, Van Eijk H, Deutz N, Saris W, Van Nieuwenhoven $M$, Brummer $\mathbb{R}-1$. The effect of an oral dosage of ferrous fumarate on intestinal permeability. Eur J Clin Invest. 2000; 30 .

Troost F, Saris W, Brummer R-J. Recombinant human lactoferrin supplementation reduces the indomethacin-induced increase of intestinal permeability in healthy adults. Gastroenterology. 2001;120:A264.

Troost F, Rutten E, Seminck E, Saris W, Brummer R-J. The effect of chronic iron therapy and indomethacin challenge on intestinal permeability in iron deficient women. Gastroenterology. 2001;120:A265.

Troost F, Saris W, Haenen G, Bast A, Brummer R-J. The measurement of iron-induced oxidative stress in the intestine using a novel intestinal perfusion technique. Gastroenterology. 2001:120:A285.

Troost F, Saris W, Brummer R-j. Orally ingested recombinant human lactoferrin is digested in the stomach and small intestine in vivo in ileostomists. Proceedings of 10th UEGW Geneva 2002. Gut. 2002:51.

Troost F, Saris W, Brummer R.J. Iron-induced oxidative stress causes the release of a yet unidentified antioxidant in the small intestine in vivo in adults. Proceedings of 10th UEGW Geneva 2002. Gut. 2002;51.

Troost F, Saris W, Brummer R-y. Ferrous sulfate administration induces oxidative stress and the release of an antioxidant in the small intestine in vivo in humans. Abstracts from the spring and autumn meetings of the Netherlands Society of Gastroenterology. European lournal of Gastroenterology and Hepatology. 2002;14:A69.

Troost F, Saris W, Brummer R-J. Survival of orally ingested human lactoferrin and endogenous lactoferin secretion in the stomach and small intestine in wivo in women. A study using the ileostomy model. Abstracts from the spring and autumn meetings of the Netherlands Society of Gastroenterology. European fournal of Gastroenterology and Hepatology. 2002;14:A77.

Troost F, Saris W, Brummer R-1. Iron supplementation inhibits zinc absorption in vivo in ileostomists. Abstracts from the spring and autumn meetings of the Netherlands Society of Gastroenterology. Furopean Journal of Gastroenterology and Hepatology. 2002;14:A58.

Troost F, Saris W, Brummer R-J. Quantification of iron-induced lipid peroxidation and antioxidant defense mechanisms in the human small intestine using a newly developed perfusion model. Gastroenterology. 2003;124:P69.

Troost F, Saris W, Dainty I, Brummer R-J. Iron supplements inhibit zinc- but not copper absorption in vivo in ileostomists. Castroenterology. 2003:124:P126.

Troost F, Saris W, Haenen G. Bast A, Van Haaften R, Evelo C, Brummer R-I. Gene expression in the human small intestine in wivo. Effects of iron-induced lipid peroxidation. Gastroenterology. 2003;124:P183. 
142 


\section{Curriculum vitae}

Name: Troost, Frederik lan (Freddy)

Date of birth: June 20,1973

Place of birth: Twello, The Netherlands

Education: 1992: graduated from the Atheneum at 'Openbare Scholengemeenschap Alexander Hegius', Deventer, The Netherlands.

1997: Master of Health Sciences, speciallization Movement Sciences at the Faculty of Health Sciences, Maastricht University, Maastricht, The Netherlands. Periods of practical work were carried out at the department of Human Biology, Maastricht University, under supervision of dr. E. Blaak, and at the department of Endocrinology and Metabolism, University of Pittsburg, Pittsburgh, PA, USA, under supervision of prof. D. Kelley and dr. B. Goodpaster.

1997-2003: PhD student at the department of Human Biology, Nutrition and Toxicology Research Institute Maastricht (NUTRIM), Maastricht University under supervision of prof. R-J Brummer and prof. W Saris. The PhD project resulted in several scientific publications and in this thesis.

Awards: Troost F, Saris W, Brummer R-J. Recombinant human lactoferin supplementation reduces the indomethacin-induced increase of intestinal permeability in healthy adults. Castroenterology. $\angle U U 1 ; 1 \angle U: A 204$. joster or Lisunction, Ligesuve Lisease Week 2001 . Troost F, Saris W, Haenen $G$, Bast A, Brummer R-J. The measurement of iron-induced oxidative stress in the intestine using a novel intestinal perfusion technique. Gastroenterology. 2001;120:A285. Poster of Distinction, Digestive Disease Week $200 \%$.

Troost F, Saris W, Brummer R-l. Orally ingested recombinant human lactoferrin is digested in the stomach and small intestine in vivo in ileostomists. Proceedings of 10th UEGW Geneva 2002. Gut. 2002;51. Travel grant Best Abstract.

Future: May 2003-present: post-doctoral research fellow at NUTRIM Maastricht University. 